ORNL/CON-391

\title{
STATE REGULATION AND ITS EFFECTS ON ELECTRIC-UTILITY USE OF DSM RESOURCES
}

\author{
Energy Division \\ Martin Schweitzer \\ Timothy R. Young*
}

August 1994

Sponsored by

Office of Energy Efficiency and Renewable Energy

U.S. Department of Energy

Prepared by the

OAK RIDGE NATIONAL LABORATORY

Oak Ridge, Tennessee 37831

managed by

MARTIN MARIETTA ENERGY SYSTEMS, INC.

for the

U.S. DEPARTMENT OF ENERGY

under Contract DE-AC05-84OR21400

*Energy, Environment, and Resources Center; University of Tennessee, Knoxville 


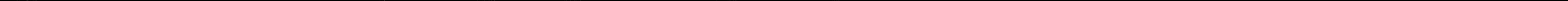




\section{DISCLAIMER}

This report was prepared as an account of work sponsored by an agency of the United States Government. Neither the United States Government nor any agency thereof, nor any of their employees, make any warranty, express or implied, or assumes any legal liability or responsibility for the accuracy, completeness, or usefulness of any information, apparatus, product, or process disclosed, or represents that its use would not infringe privately owned rights. Reference herein to any specific commercial product, process, or service by trade name, trademark, manufacturer, or otherwise does not necessarily constitute or imply its endorsement, recommendation, or favoring by the United States Government or any agency thereof. The views and opinions of authors expressed herein do not necessarily state or reflect those of the United States Government or any agency thereof. 


\section{DISCLAIMER}

Portions of this document may be illegible in electronic image products. Images are produced from the best available original document. 


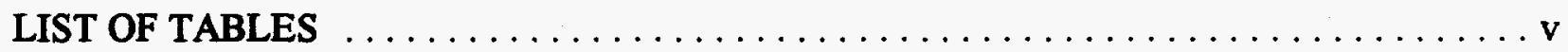

LIST OF FIGURES $\ldots \ldots \ldots \ldots \ldots \ldots \ldots \ldots \ldots \ldots \ldots \ldots \ldots \ldots \ldots$

ABBREVIATIONS $\ldots \ldots \ldots \ldots \ldots \ldots \ldots \ldots \ldots \ldots \ldots \ldots \ldots \ldots \ldots \ldots$ ix

EXECUTIVE SUMMARY $\ldots \ldots \ldots \ldots \ldots \ldots \ldots \ldots \ldots \ldots \ldots \ldots \ldots \ldots \ldots \ldots \ldots$

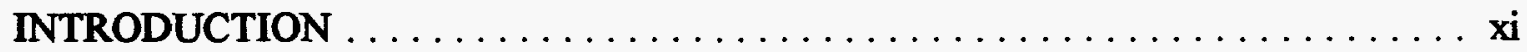

UTILITY DSM USAGE $\ldots \ldots \ldots \ldots \ldots \ldots \ldots \ldots \ldots \ldots \ldots \ldots \ldots \ldots \ldots \ldots \ldots \ldots$

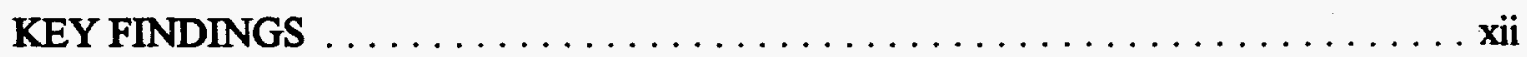

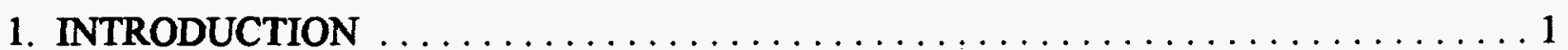

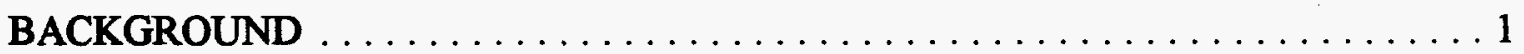

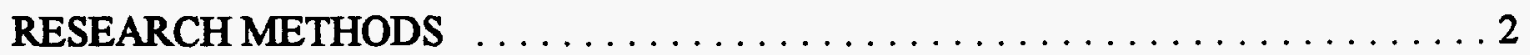

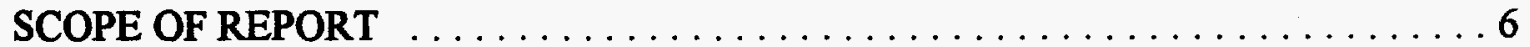

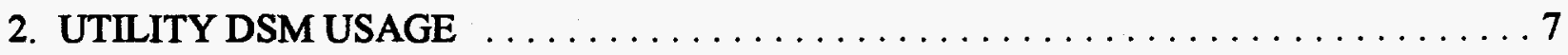

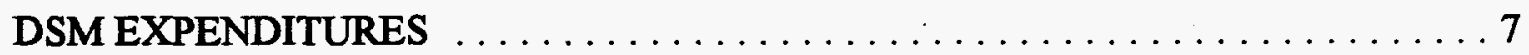

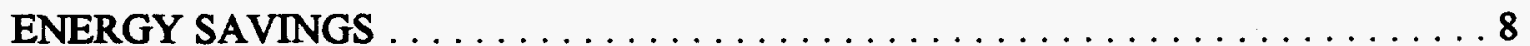

PEAK REDUCTION $\ldots \ldots \ldots \ldots \ldots \ldots \ldots \ldots \ldots \ldots \ldots \ldots \ldots \ldots \ldots \ldots \ldots$

COMPARISON OF OUTCOMES $\ldots \ldots \ldots \ldots \ldots \ldots \ldots \ldots \ldots \ldots \ldots$

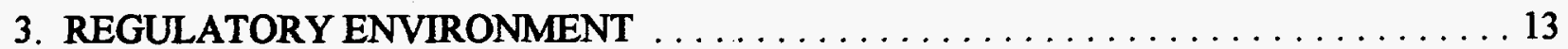

KEY CHARACTERISTICS OF SERVICE AREA $\ldots \ldots \ldots \ldots \ldots \ldots \ldots \ldots 13$

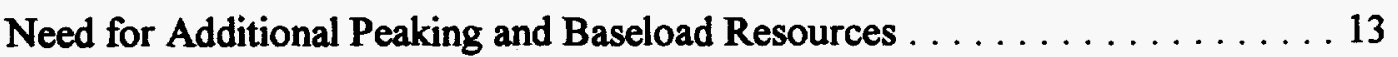

Economic Climate ............................. 15

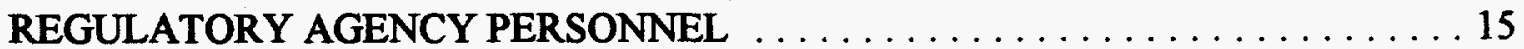

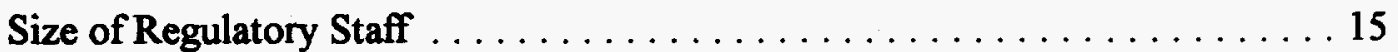

Background of Regulatory Commissioners $\ldots \ldots \ldots \ldots \ldots \ldots \ldots \ldots$

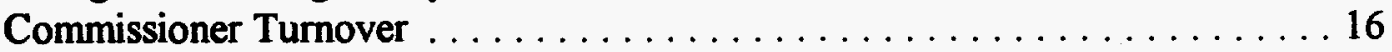

REGULATOR ATTITUDES AND ACTIONS $\ldots \ldots \ldots \ldots \ldots \ldots \ldots \ldots \ldots$

Load Building, Energy Efficiency, and Load Reduction $\ldots \ldots \ldots \ldots \ldots 17$

Public Involvement . . . . . . . . . . . . . . . . . . . . . . 17

Information Sources for Regulatory Decisions $\ldots \ldots \ldots \ldots \ldots \ldots \ldots 20$

Provision of Assistance Programs for Utilities and NUPs $\ldots \ldots \ldots \ldots \ldots 22$

ALL ENVIRONMENTAL FACTORS $\ldots \ldots \ldots \ldots \ldots \ldots \ldots \ldots \ldots \ldots \ldots \ldots \ldots \ldots$

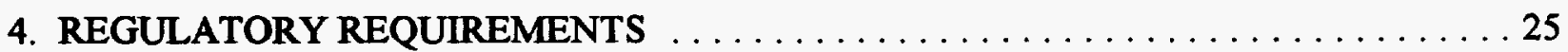

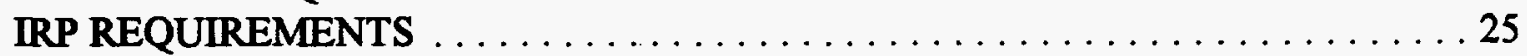

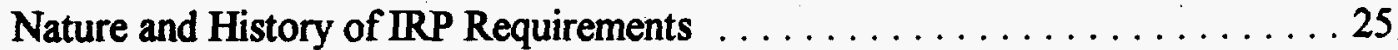

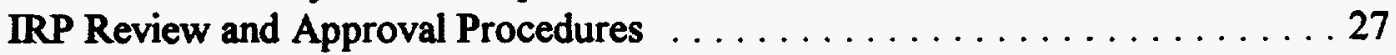

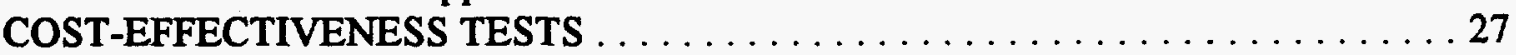


ENVIRONMENTAL EXTERNALITIES . . . . . . . . . . . . . . . . . . 29

TREATMENT OF DSM EXPENDITURES $\ldots \ldots \ldots \ldots \ldots \ldots \ldots \ldots \ldots \ldots \ldots$

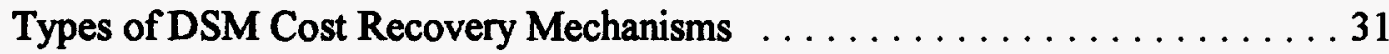

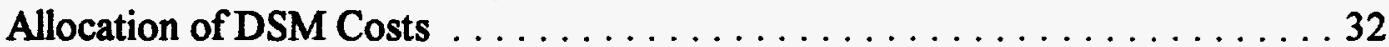

LOST REVENUE RECOVERY $\ldots \ldots \ldots \ldots \ldots \ldots \ldots \ldots \ldots \ldots \ldots \ldots \ldots$

FINANCIAL INCENTIVES FOR DSM USE $\ldots \ldots \ldots \ldots \ldots \ldots \ldots \ldots \ldots \ldots$

Types and Magnitude of Financial Incentives $\ldots \ldots \ldots \ldots \ldots \ldots \ldots \ldots \ldots \ldots \ldots \ldots$

Methods Used to Calculate Energy Savings and Load Reduction . . . . . . . 37

Incentive Thresholds, Caps, and Penalties . . . . . . . . . . . . . . 38

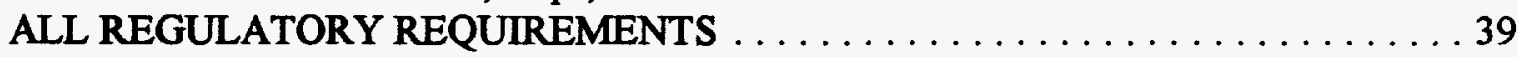

5. CONCLUSIONS $\ldots \ldots \ldots \ldots \ldots \ldots \ldots \ldots \ldots \ldots \ldots \ldots \ldots \ldots \ldots \ldots \ldots$

KEY ENVIRONMENTAL CHARACTERISTICS $\ldots \ldots \ldots \ldots \ldots \ldots \ldots \ldots \ldots 41$

KEY REGULATORY REQUIREMENTS $\ldots \ldots \ldots \ldots \ldots \ldots \ldots \ldots \ldots \ldots \ldots$

IMPLICATIONS FOR REGULATORS $\ldots \ldots \ldots \ldots \ldots \ldots \ldots \ldots \ldots$

ACKNOWLEDGMENTS $\ldots \ldots \ldots \ldots \ldots \ldots \ldots \ldots \ldots \ldots \ldots \ldots \ldots$

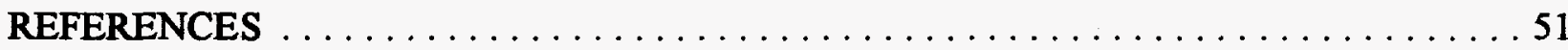

APPENDIX A. DESCRIPTION OF LARGEST CONSUMER-OWNED

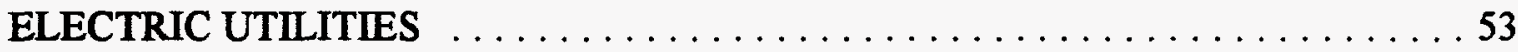

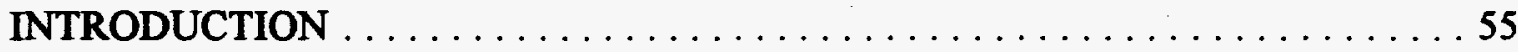

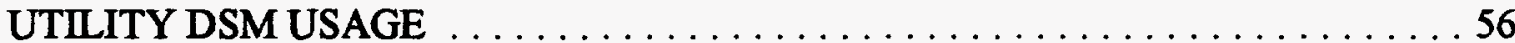

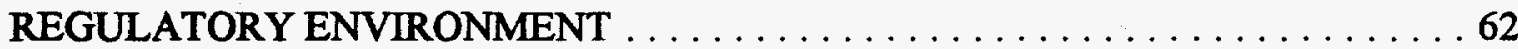

REGULATORY REQUIREMENTS $\ldots \ldots \ldots \ldots \ldots \ldots \ldots \ldots \ldots \ldots \ldots \ldots \ldots$

APPENDIX B. HYPOTHESIZED RELATIONSHIPS $\ldots \ldots \ldots \ldots \ldots \ldots \ldots \ldots \ldots \ldots$

APPENDIX C. INTERVIEW PROTOCOL $\ldots \ldots \ldots \ldots \ldots \ldots \ldots \ldots \ldots \ldots \ldots$ 


\section{LIST OF TABLES}

Table

ES.1 Amount of variance in DSM usage explained by key variables $\ldots \ldots \ldots \ldots \ldots$ xiv

3.1 Relationships between need for additional resources and outcome measures . . . . . . 14

3.2 Relationships between regulator support for load building and outcome measures . . . 18

3.3 Relationships between regulator support for key public involvement mechanisms

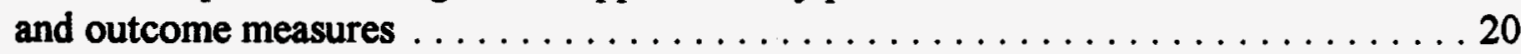

4.1 Relationships between nature and history of IRP requirements and outcome measures . 26

4.2 Relationships between cost-effectiveness test requirement and outcome measures . . . 28

4.3 Relationships between key externality cost approaches and outcome measures . . . . . 30

4.4 Relationships between use of DSM rider to recover program costs and outcome

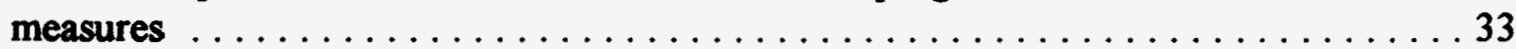

4.5 Relationships between use of key lost revenue recovery approaches and outcome

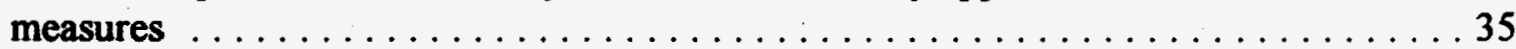

4.6 Relationships between use of key financial incentive mechanisms and outcome

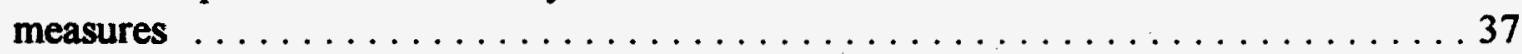

A. 1 Consumer-owned utilities included in study $\ldots \ldots \ldots \ldots \ldots \ldots \ldots$ 


\section{LIST OF FIGURES}

Figure

$\underline{\text { Page }}$

ES.1 State-aggregated DSM usage - measures of central tendency . . . . . . . . . . xii

2.1 State-aggregated DSM expenditures, 1992 and $1997 \ldots \ldots \ldots \ldots \ldots \ldots \ldots \ldots$

2.2 Breakdown of expenditures for those states spending less than $1 \%$ of retail revenues on DSM programs, 1992 and $1997 \ldots \ldots \ldots \ldots \ldots \ldots \ldots \ldots \ldots \ldots$

2.3 State-aggregated energy savings due to DSM programs, 1992 and $1997 \ldots \ldots \ldots$

2.4 Breakdown of energy savings for those states saving less than $1 \%$ of retail sales due to DSM programs, 1992 and $1997 \ldots \ldots \ldots \ldots \ldots \ldots \ldots \ldots \ldots$

2.5 State-aggregated peak reduction due to DSM programs, 1992 and $1997 \ldots \ldots \ldots$

2.6 Breakdown of peak reduction for those states reducing retail peak demand by less than $10 \%$ through the use of DSM programs, 1992 and $1997 \ldots \ldots \ldots \ldots \ldots \ldots 11$

2.7 Comparison of outcome measures for IOUs, 1992 and $1997 \ldots \ldots \ldots \ldots$. . . . . 12

3.1 Number of years until new peaking and baseload units will be needed by states . . . . 14

3.2 Principal work experience of state regulatory commissioners: mean percentages

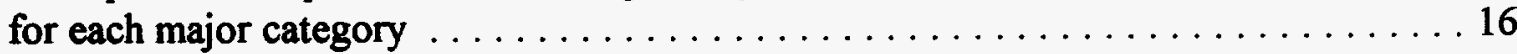

3.3 Distribution of support for load building, energy efficiency, and load reduction programs by state regulatory commissioners $\ldots \ldots \ldots \ldots \ldots \ldots \ldots \ldots \ldots \ldots \ldots \ldots$

3.4 Distribution of support for various forms of public involvement by state regulatory commissioners . . . . . . . . . . . . . . . . . . . . . . . . 19

3.5 Distribution of responses on importance of various types of information to state regulators when making regulatory decisions $\ldots \ldots \ldots \ldots \ldots \ldots \ldots \ldots \ldots \ldots \ldots \ldots \ldots$

4.1 Year in which IRP requirements were established by state regulatory bodies . . . . . 26

4.2 Number of states requiring utility use of various cost-effectiveness tests $\ldots \ldots \ldots . \ldots 28$

4.3 Number of states requiring utility use of various methods for treating environmental

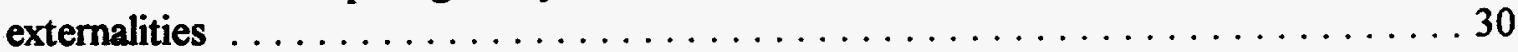

$4.4 \quad$ Number of states allowing selected types of DSM cost recovery mechanisms . . . . . . 32

4.5 Number of states using selected types of lost revenue recovery mechanisms . . . . . 34

4.6 Number of states using different types of DSM incentive mechanisms . . . . . . . . 36

4.7 Number of states using incentive thresholds, caps, and penalties for poor

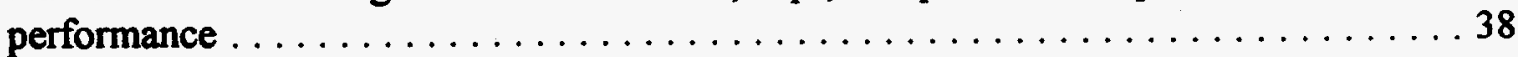

5.1 Amount of variance in DSM expenditures explained by key independent variables . . . 45

5.2 Amount of variance in energy savings explained by key independent variables . . . . . 46

A.1 DSM expenditures by consumer-owned utilities, 1992 and $1997 \ldots \ldots \ldots \ldots$

A.2 Breakdown of expenditures for consumer-owned utilities spending less than $1 \%$ of retail revenues on DSM programs, 1992 and $1997 \ldots \ldots \ldots \ldots \ldots \ldots \ldots$

A.3 DSM-induced energy savings by consumer-owned utilities, 1992 and $1997 \ldots$. . . . . 59

A.4 Breakdown of energy savings for consumer-owned utilities saving less than $1 \%$ of retail sales due to DSM programs, 1992 and $1997 \ldots \ldots \ldots \ldots \ldots \ldots \ldots$

A.5 DSM-induced peak demand reduction by consumer-owned utilities, 1992 and $1997 \ldots 61$

A.6 Breakdown of peak reduction for consumer-owned utilities reducing retail peak demand by less than $10 \%$ through the use of DSM programs, 1992 and $1997 \ldots \ldots \ldots 6$

A.7 Comparison of outcome measures for consumer-owned utilities, 1992 and $1997 \ldots 62$ 
A.8 Number of years until new peaking and baseload units will be needed by consumer-owned utilities

A.9 Principal work experience of board members for consumer-owned utilities: mean percentages for each major category

A.10 Distribution of support for load building, energy efficiency, and load reduction programs by board members of consumer-owned utilities

A.11 Distribution of support for various forms of public involvement by board members of consumer-owned utilities

A.12 Distribution of responses on importance of various types of information to board members of consumer-owned utilities when making policy decisions

A.13 Year in which IRP requirements were established by consumer-owned utilities . . . . . 68

A. 14 Number of consumer-owned utilities using various cost-effectiveness tests . . . . . 68

A.15 Number of consumer-owned utilities using various methods for treating environmental externalities

A.16 Number of consumer-owned utilities using selected types of DSM cost recovery mechanisms 
cous

DSM

EEI

EIA

ERAM

IOUs

IRP

IRPs

kWh

NUPs

ORNL

PUCs

RIM

ROE

RPC

TRC consumer-owned utilities

demand-side management

Edison Electric Institute

Energy Information Administration

Electric Revenue Adjustment Mechanism

investor-owned utilities

integrated resource planning

integrated resource plans

kilowatt hour

non-utility parties

Oak Ridge National Laboratory

Public Utility Commissions

Ratepayer Impact Measure

return on equity

revenue per customer

Total Resource Cost 


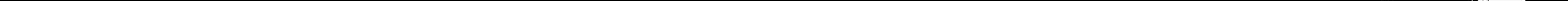




\section{EXECUTIVE SUMMARY}

\section{INTRODUCTION}

State Public Utility Commissions (PUCs) and similar regulatory agencies are commonly believed to exert a powerful influence over the electric utilities within their jurisdiction. Specifically, it is often assumed that utility use of demand-side management (DSM) resources will be greater in states that provide inducements, such as financial incentives and lost-revenue recovery mechanisms, to enhance the profitability of DSM usage. These commonly-assumed relationships between regulatory actions and utility use of DSM resources were tested by researchers at Oak Ridge National Laboratory (ORNL) in a study sponsored by the U.S. Department of Energy's Office of Energy Efficiency and Renewable Energy.

Information was collected from both primary and secondary sources on the regulatory environment in which investor-owned utilities (IOUs) operate and on the specific regulatory requirements established by the presiding state agencies. The regulatory environment consists of important features of the service area, characteristics of regulatory agency personnel, and regulator attitudes and actions. The regulatory requirements of interest pertain to integrated resource planning (IRP), cost-effectiveness tests, environmental externalities, cost treatment of DSM programs, lost revenue recovery, and financial incentives. In addition, information was collected on DSM usage by the IOUs - aggregated by state. This information was sought for all 49 states that regulate IOUs and for the District of Columbia; all but one provided us with primary data, and we obtained secondary data on DSM usage and other selected factors for all 50 regulatory agencies.

Twenty-three hypotheses, describing possible relationships between DSM usage and important environmental and regulatory factors, were developed by the authors and tested using regression analysis. Each hypothesis was tested for six different measures of utility DSM usage: (1) 1992 DSM expenditures as a percentage of retail revenues; (2) projected 1997 DSM expenditures as a percentage of retail revenues; (3) 1992 DSM-induced energy savings as a percentage of retail electricity sales; (4) projected 1997 energy savings as a percentage of retail sales; (5) 1992 DSM-induced peak reduction as a percentage of retail peak demand; and (6) 1997 peak reduction as a percentage of retail peak. Because the first measure-1992 DSM expenditures-does not involve estimates of performance or future projections, we consider it the most reliable of the six.

\section{UTILITY DSM USAGE}

Information on DSM expenditures and associated energy savings and peak reduction was provided by electric utilities throughout the country in response to the U.S. Energy Information Administration's (EIA) 1992 census of electric utilities. Virtually all IOUs with DSM programs reported detailed information on their 1992 and projected 1997 DSM activities. The information submitted by the individual utilities was aggregated according to the state(s) in which each utility 
operated to yield 1992 and 1997 DSM expenditures, energy savings, and peak reduction for each state. Figure ES.1 presents the means and medians calculated from this state-aggregated data set. The numbers given here for DSM expenditures describe the amount spent in a single year-1992 or 1997. In contrast, the figures for energy savings and peak reduction are cumulative, describing the effects of all DSM programs undertaken as of the date in question. Accordingly, it could be misleading to directly compare the percentages shown here for expenditures with those for energy savings and peak reduction. However, it is legitimate to note that cumulative peak reduction dwarfed cumulative energy savings in 1992, and that peak reduction is still projected to exceed energy savings in 1997, but by a substantially smaller margin. This means that energy savings will increase at a much more rapid rate than will peak reduction. It also is legitimate to observe that annual DSM expenditures are expected to double from 1992 to 1997.
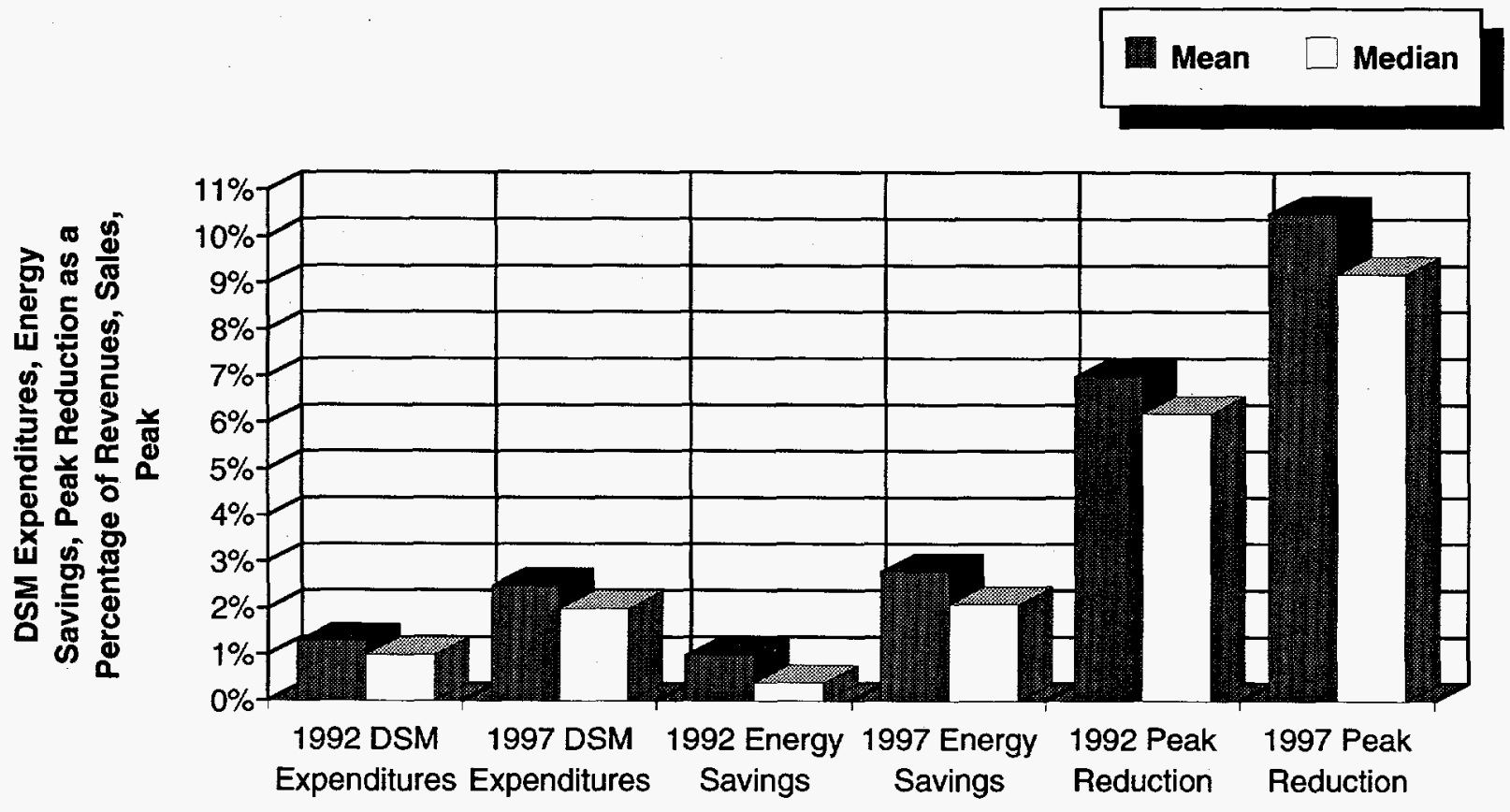

Fig. ES.1. State-aggregated DSM usage-measures of central tendency.

\section{KEY FINDINGS}

The extent to which PUCs supported the use of collaboratives and workshops as mechanisms to obtain public involvement on important policy and program issues was more strongly related to utility DSM usage than was any other environmental factor. Greater regulator support for collaboratives tended to be associated with more aggressive use of DSM resources, while the opposite was true concerning support for workshops-a public involvement approach that is considerably less interactive than collaboratives. The next most powerful environmental factor influencing utility use of DSM was regulator support for utility load building. Not surprisingly, the relationship between these variables was negative, meaning that greater regulator 
support for load building was associated with lower DSM usage. In addition, states with less immediate need for new peaking and baseload resources had lower DSM expenditures.

Of all the regulatory requirements studied, the approaches used to treat environmental externalities and grant financial incentives to IOUs had the strongest relationships with utility DSM usage. Both lost revenue recovery and IRP requirements had moderately strong associations with utility use of DSM resources. And DSM cost recovery approaches and costeffectiveness tests, while not unimportant, were least strongly linked with DSM usage.

Table ES.1 shows how much of the difference in DSM usage by the various states was explained by key environmental and regulatory factors. These variables are arranged in descending order according to the strength of their relationship to 1992 utility DSM expenditures. Our findings leave little doubt that regulators have played a vital role in encouraging more aggressive use of DSM resources through their regulations concerning environmental externalities, financial incentives, and other subjects as well as by their support for highly interactive approaches to obtaining public involvement on important policy and program issues. A basic factor that appears to underlie many of the important environmental and regulatory variables is a desire by state regulators to put DSM on an equal footing with supply-side resources and a support for aggressive utility use of beneficial demand-side resources. And it appears that, without continued strong PUC policies, the DSM efforts undertaken by IOUs could suffer.

The regulatory policies that have encouraged IOUs to increase their use of DSM resources have done so by stimulating utilities to examine potential DSM resources, by ensuring that a broad range of interests are actively represented in the process, by increasing the costeffectiveness of DSM relative to the alternatives, and by ensuring that the vigorous pursuit of demand-side resources will enhance - or at the very least will not diminish - utility revenues and profits. The specific mechanisms by which this has been accomplished are shown in Table ES.1. It should be noted that these findings reflect the situation that existed in 1992, before the issues of competition and deregulation assumed the greater importance for utilities and their regulators that they currently have. We believe that a number of the relationships identified in this study will continue to hold in many states, at least in the near-term future. Still, the challenge facing regulators with an interest in promoting the use of cost-effective DSM resources is to understand the key changes that are taking place and to adopt policies that will continue to make DSM a desirable option. Regulatory agencies can take a first step toward this by examining the factors identified in this study as being strongly related to utility DSM usage to see whether these relationships are likely to hold in their jurisdiction in the years ahead. It also would be worthwhile for regulators to consider new policies and regulations-as needed - to encourage the continued beneficial use of DSM resources. 
Table ES.1. Amount of variance in DSM usage explained by key variables ${ }^{a}$

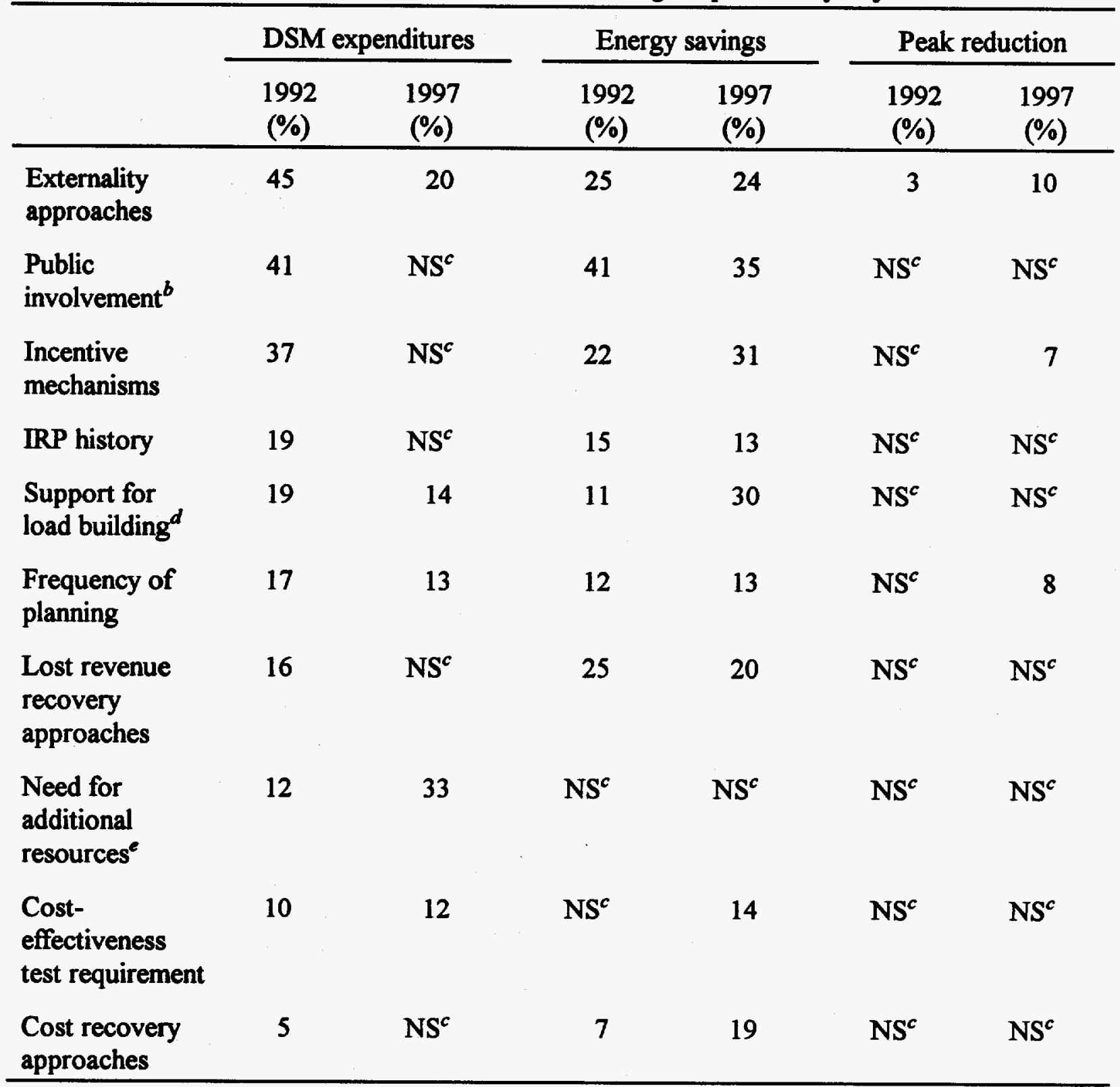

The percentages given in this table represent the amount of variance explained by those factors found to be significant at least at the .05 level. These findings come from individual tests of each related set of variables and not from a combined analysis of all significant variables. Because of multicollinearity, the percentages in each column cannot be summed to get total variance explained by all factors combined.

${ }^{6}$ Regulator support for collaboratives was positively related to DSM usage while support for workshops was negatively related to the same measures.

Not significant.

Regulator support for load building programs was negatively related to DSM usage.

The number of years until new baseload resources will be needed was negatively related to 1992 DSM expenditures; the number of years until both new baseload and new peaking resources will be needed was negatively related to projected 1997 expenditures. 


\section{INTRODUCTION}

\section{BACKGROUND}

It is commonly accepted that state Public Utility Commissions (PUCs) and similar regulatory agencies exert a powerful influence over the electric utilities within their jurisdiction. The attitudes and values of the commissioners and the specific regulatory requirements that they establish are expected to affect utility actions, including the mix of supply- and demand-side resources selected. Specifically, it is often assumed that utilities will tend to more aggressively pursue the use of demand-side management (DSM) in states that provide financial incentives, lostrevenue recovery mechanisms, and other inducements to enhance the profitability of this course of action. Under the sponsorship of the U.S. Department of Energy's Office of Energy Efficiency and Renewable Energy, researchers at Oak Ridge National Laboratory (ORNL) performed a study designed to test these commonly-assumed relationships between regulatory actions and utility DSM usage. ${ }^{1}$

In the course of this study, the authors collected information from both primary and secondary sources on the regulatory environment in which investor-owned utilities (IOUs) operate, on the specific regulatory requirements that the presiding state agencies have established, and on DSM usage by the IOUs-aggregated by state. This information was sought for all 49 states that regulate IOUs ${ }^{2}$ and for the District of Columbia. ${ }^{3}$ Of these 50 regulatory agencies, 49 provided us with primary data, and we obtained secondary data on DSM usage and other selected factors for all of them. The body of this report describes the states in terms of their DSM usage, environmental characteristics, and regulatory requirements and presents findings from tests of hypothesized relationships between DSM usage and important environmental and regulatory factors.

In addition to examining PUCs and their regulated utilities, we attempted to collect similar information for the 20 largest state- and locally-owned utilities in the U.S. and the three largest federal power systems. Descriptive data on the responding consumer-owned utilities (COUs) are presented in Appendix A.

\footnotetext{
${ }^{1}$ DSM, as used in this report, includes utility programs designed to save energy and reduce peak demand but does not include load-building programs.

${ }^{2}$ Nebraska does not perform such a regulatory function.

${ }^{3}$ Throughout this report, these 50 regulatory bodies will be referred to as states, even though the District of Columbia is included, and as PUCs, even though various states have other names for their primary regulatory bodies, such as Public Service Commissions and Public Service Boards.
} 


\section{RESEARCH METHODS}

Twenty-three hypotheses were developed, describing possible relationships between a state's environment and regulatory requirements and its DSM usage (Appendix B). These hypotheses were tested by using statistical analyses designed to determine how six different measures of utility DSM usage (our dependent variables) were related to specific environmental and regulatory factors (the independent variables). The six measures of DSM usage used were: (1) 1992 DSM expenditures as a percentage of retail revenues; (2) projected 1997 DSM expenditures as a percentage of retail revenues; (3) 1992 DSM-induced energy savings as a percentage of retail electricity sales; (4) projected 1997 energy savings as a percentage of retail sales; (5) 1992 DSM-induced peak reduction as a percentage of retail peak demand; and (6) 1997 peak reduction as a percentage of retail peak. Of the six, we consider 1992 DSM expenditures the most reliable because this measure does not involve estimates of performance or future projections.

The information on DSM expenditures, savings, and peak reduction came from utilities' 1992 responses to the U.S. Energy Information Administration's (EIA) annual census of electric utilities, known as Form EIA-861 ${ }^{4}$ (EIA 1992). Virtually all IOUs reporting the use of DSM resources filled out detailed information on their 1992 and projected 1997 demand-side activities.

Normalized 1992 DSM expenditures for each state were calculated by dividing total annual expenditures made by IOUs in each state ${ }^{5}$ - taken from EIA-861 - by the annual retail revenues for all IOUs in that state-from the Edison Electric Institute's (EEI) statistical yearbook for the same time period (1993a). ${ }^{6}$ We counted all utility outlays for conservation and load management programs but did not include expenditures for load building programs. In those instances where a single utility sells electricity in more than one state, we assumed that the distribution of DSM expenditures by state was the same as the distribution of retail electricity sales reported by the utility on Form EIA-861. Projections of DSM expenditures for each state were normalized using 1997 revenue projections. $^{7}$

\footnotetext{
${ }^{4}$ This survey is performed every year. Data from the 1992 version were the most recent that were available at the time of our study.

${ }^{5}$ We created state totals for expenditures and DSM effects using IOUs only, because consumer-owned utilities are not regulated by PUCs in most states (and, even where they are, such regulation usually is partial).

${ }^{6}$ The EEI yearbook also was our source for data on 1992 retail electric sales.

${ }^{7}$ The 1997 DSM expenditures provided by the utilities on ELA-861 were adjusted to 1992 dollars using a $4 \%$ per year inflation rate. We projected 1997 retail revenues using projected "Reference" growth rates for electricity sales and average electricity price given in EIA's Supplement to the Annual Energy Outlook 1993 (1993b).
} 
We calculated normalized 1992 energy savings for each state by dividing total gross annual savings ${ }^{8}$ by the annual retail electric sales for all IOUs in that state. Once again, we assumed that, for multi-state utilities, energy savings were distributed by state in the same way that retail sales were distributed. Statewide projected savings were normalized using 1997 retail electric sales. ${ }^{9}$

For each state, 1992 peak demand reduction was calculated by dividing total gross annual potential peak reduction ${ }^{10}$ by the annual retail peak demand for all IOUs in that state. ${ }^{11} \mathrm{We}$ assumed that both peak demand and peak reduction for multi-state utilities were distributed by state in the same way that retail sales were distributed. Statewide projected peak reductions were normalized using 1997 retail peak demand.

We developed an interview protocol designed to elicit most of the information needed from the 50 state regulatory agencies regarding the environment in which their IOUs operate and the specific regulatory requirements that they have established (see Appendix $C$ ). The section on environment covered important characteristics of the service area (e.g., the need for additional peaking and baseload resources), regulatory agency personnel (e.g., size of the regulatory staff and the background of commissioners), and regulator attitudes and actions (e.g., support for various public involvement mechanisms and the types of assistance programs provided). The section on regulatory requirements addressed regulations pertaining to integrated resource planning (IRP), cost-effectiveness tests, environmental externalities, cost treatment of DSM programs, lost revenue recovery, and financial incentives. Some of this information was gathered from secondary sources (National Association of Regulatory Utility Commissioners 1992; Reid, Brown, and Deem 1993), although we attempted to verify this information during our telephone interviews. Information on the state economic climate, which is not addressed in the protocol, was always obtained from secondary sources (EEI 1993a; EIA 1993a; U.S. Department of Commerce 1993). Staff members associated with each regulatory commission ${ }^{12}$ were interviewed by telephone or-if such interviews were inconvenient for the individual contacted-were sent a

\footnotetext{
${ }^{8}$ Gross savings are the summation of effects from all energy efficiency and load management programs without subtracting any additional energy use engendered by utility load building programs. For both energy savings and peak reduction, we took from EIA-861 the data describing "Annual" (meaning cumulative) rather than "Incremental" (meaning single-year-only) effects, because the former more accurately reflects the full range of utility DSM activities.

9Retail electric sales for 1997 were projected by adjusting 1992 figures with projected "Reference" case growth rates for electricity sales given in ELA's Supplement to the Annual Energy Outlook 1993. For each state, we used the growth rate for the multi-state region in which it is located, and we interpolated from the 10 year growth rate provided by EIA, assuming a constant rate of growth. The same method was used to project annual retail peak demand.

${ }^{10}$ Potential peak reduction was used rather than actual peak reduction because it provides a more accurate picture of the total magnitude of the programs implemented.

${ }^{11}$ Retail peak demand was derived by multiplying total noncoincident peak for each state-aggregated from EIA-861 data - by the proportion of each state's total sales that are retail-also from EIA-861.
}

${ }^{12}$ Key staff members with a good understanding of the workings of the PUC were our respondents in all cases. Individual public utility commissioners were not interviewed. 
copy of the protocol to fill out on their own. All of the information collected is current as of 1992 , in order to be consistent with the period covered by the EIA-861 data on utility DSM usage.

All research hypotheses were tested for the 50 state regulatory agencies as a group, using regression analysis. ${ }^{13}$ After the individual hypotheses were tested, combined analyses were performed-one examining all significant environmental factors, one focusing on all significant regulatory requirements, and one including all significant variables from both the environmental and regulatory arenas. While the results of both the hypothesis tests and the combined analyses are presented in this report, we emphasize the former and only touch briefly on the latter. The reason for this is that the hypothesis tests represent a sequential examination of the individual factors (or related sets of factors) that might influence utility DSM usage. Accordingly, our findings can provide useful information to state regulators and other interested parties with a need to know how specific environmental characteristics and regulatory requirements affect the use of DSM resources by utilities. Information of this kind is well-suited to the incremental decisions that often face regulators and stakeholder groups. In contrast, interpreting the results of the combined analyses can be difficult because many variables (both within the environmental and regulatory categories and across them) are correlated with each other, so the importance of a given factor can be masked due to the presence of its covariates.

In a small number of cases, we performed linear regression analysis, which uses only one independent variable in conjunction with a single dependent variable. In the vast majority of cases, however, we used multiple regression, which examines the relationship (or lack thereof) between a single dependent variable and more than one independent variable. For each hypothesis test, these independent variables were associated with each other in some way (e.g., various approaches to recovering lost revenues; different types of financial incentives). For each such set of variables, we ran a correlation analysis to identify any variables that might be highly correlated and whose presence together might mask each other's relationship to the dependent variable being studied. Where two or more variables were found to be strongly related, we dropped one of them from the regression equation and ran the analysis without it. Then, that variable was put back in the equation and one of the related variables was dropped. If the significance of the remaining variables increased or if new variables became significant as a result of these adjustments, we substituted reduced models for the larger equation. ${ }^{14}$ When reading the findings of our multiple regression analyses, presented in subsequent chapters, it is important to note that the relationship identified between a given independent variable and a specified dependent variable exists in the presence of all other independent variables used in the equation. It also should be noted that the

\footnotetext{
${ }^{13}$ The subject of one of the hypotheses-the effect of $\mathrm{SO}_{2}$ bonus allowances on DSM usage-is not discussed in this report because only three states reported approving such allowances in 1992 and no relationship was found between the number of bonus credits allowed and the use of DSM resources.

${ }^{14}$ In three cases, our correlation analyses indicated that the use of reduced models was appropriate. When testing the effects of the need for new resources, we found stronger relationships when running separate analyses for the need for new peaking and new baseload resources. Similarly, separate analyses for the length of time that IRP has been required and for the frequency with which plans must be prepared were found to yield results that were superior to those of the combined analysis. Finally, two separate analyses were used to explore the effects of incentive thresholds, caps, and penalties for poor performance-alternately dropping thresholds and penalties, which were highly correlated with each other.
} 
fact that a specific environmental or regulatory characteristic is related to increased DSM usage does not prove that the factor in question caused that increase, although that may be the case.

In discussing the findings of our statistical analyses, we report both p- and R-Square values. The $R$-Square value represents the proportion of the variance in the dependent variable that is explained by the independent variable(s). In other words, it tells us how much of the difference in the states' DSM usage is accounted for by a particular factor or related set of factors. The p-value represents the probability that a relationship found for our sample is a chance occurrence, and would not be duplicated in the larger population of which our sample is a part. The $p$-value is less important for our purposes because we have data on at least 45 state regulatory agencies (out of a total population of 50 ) for about two-thirds of our independent variables. Still, we will report only those relationships where the p-value is .05 or less, ${ }^{15}$ even where we have data on all 50 PUCs, because the amount of variance explained when $p$ is greater then .05 generally is too minor to be of interest. In interpreting the findings presented in subsequent chapters, it is important to note that the amount of variance in DSM usage explained by different sets of independent variables is not strictly cumulative due to the previouslymentioned correlations among many of the variables studied. ${ }^{16}$

In those cases where an equation containing binomial variables ${ }^{17}$ explains one-third or more of the variance in a given measure of DSM usage, we will list the coefficients given by our regression analysis for each significant independent variable. The coefficient tells us how much more (or less) DSM is used when a particular approach or mechanism is employed, in the presence of all the other approaches examined in that particular analysis. Suppose, for example, that the coefficient associated with a state requirement that utilities use quantitative methods to address environmental externalities is 0.0150 for 1992 DSM expenditures. This means that our regression model estimates that 1992 DSM expenditures as a percent of retail revenues are 1.5 percentage points greater in states with such a requirement than in states without such a requirement, provided their use (or non-use) of all other available approaches to address externalities is the same. ${ }^{18}$

\footnotetext{
${ }^{15}$ The .05 level frequently is used as a threshold for determining statistical significance.

${ }^{16}$ For example, if one set of independent variables explains $30 \%$ of the variance in a particular measure of DSM usage and another set explains $25 \%$ of the variance, it does not follow that $55 \%$ of the variance is explained by the two sets combined.
}

\footnotetext{
${ }^{17} \mathrm{~A}$ binomial variable is one with only two possible answers (e.g., "yes" or "no"). In this study, most of our binomial variables describe an approach or mechanism (such as the consideration of environmental externalities) that either is or is not used by a state or self-regulated utility.

${ }^{18}$ Taking this same example further, we can suppose that the intercept given by our regression analysis is 0.0100 . Then, if one state requires the use of quantitative methods as its sole approach to treating environmental externalities and another state has no requirements at all concerning this subject, our regression model predicts that 1992 DSM expenditures will be $2.7 \%$ of retail revenues in the former state and only $1.0 \%$ of retail revenues in the latter one.
} 


\section{SCOPE OF REPORT}

The remainder of this report presents detailed information on utility DSM usage and on the factors that potentially influence it. Chapter 2 describes 1992 and projected 1997 DSM expenditures, energy savings, and peak demand reduction for the IOUs-aggregated by state. Chapter 3 discusses key characteristics of the environment in which the IOUs operate and identifies significant relationships between these characteristics and utility DSM usage. Chapter 4 presents in-depth information on a broad array of state regulatory requirements; once again, significant relationships between these factors and utility use of DSM resources are presented. Finally, Chapter 5 summarizes and interprets the key findings presented in the preceding chapters and concludes with a discussion of their implications for regulators. 


\section{UTILITY DSM USAGE}

In this chapter, we discuss the use of DSM resources by IOUs. The information on DSM usage reported by the individual IOUs was aggregated according to the state(s) in which they operated to yield DSM expenditures, energy savings, and peak reduction for each state. Therefore, when we discuss mean or median DSM usage, we are referring to the mean or median of a 50 state data set and not of a data set consisting of separate observations for each individual utility. A recent ORNL report (Hirst 1994) contains more information from the EIA's 1992 census of electric utilities. 19

\section{DSM EXPENDITURES}

In 1992, expenditures for DSM programs as a percentage of retail revenues ranged from $0 \%$ in Mississippi to $4.8 \%$ in Washington. The mean expenditure on DSM was $1.3 \%$ of revenues, and the median was just over $1 \%{ }^{20}$ Figure 2.1 shows the frequency distribution for the 50 states, by $1 \%$ increments, for 1992 and 1997 . In 1992, only 10 states had total DSM expenditures amounting to $2 \%$ or more of revenues. By 1997 , the range of expenditures is projected to nearly double, and approximately half the states will have DSM expenditures amounting to $2 \%$ or more of retail revenues. During the same time period, the number of states spending less than $1 \%$ of retail electric revenues on DSM will be halved, with just over a fourth of the states expected to fall into that category in 1997. Both mean and median expenditures on DSM programs are expected to double by 1997 , to $2.5 \%$ and $2 \%$ of retail revenues, respectively. The DSM expenditures made by the various states in 1992 are highly correlated $(r=0.69)$ with the expenditures projected for the same states in 1997. This means that states whose expenditures are high relative to the other states in 1992 will tend to have relatively high expenditures in 1997 , while states whose DSM expenditures are relatively low in 1992 will tend to continue that pattern.

Figure 2.2 shows the breakdown of expenditures by those states spending less than $1 \%$ of retail revenues on DSM programs. In 1992, nearly half of those states had DSM expenditures that were less than $0.3 \%$ of retail electric revenues, and this number is expected to remain essentially unchanged in 1997 . However, the number of these states exceeding the $0.5 \%$ mark in 1997 will be about one and a half times as large as it was in 1992.

\footnotetext{
${ }^{19}$ The overall 1992 and 1997 DSM expenditures, energy savings, and peak reductions given in the Hirst report are slightly different than the findings presented in this document because the Hirst numbers are totals derived from all reporting utilities (IOUs and COUs) while the numbers in this document are means and medians calculated from the state-aggregated IOUs.

${ }^{20}$ The mean is the same as the simple average, and was calculated by summing the expenditures for each state and dividing by the total number of states. The median is that point at which exactly half the states spent less and half the states spent more. Where a distribution is highly skewed, the median generally provides a more useful measure of central tendency.
} 


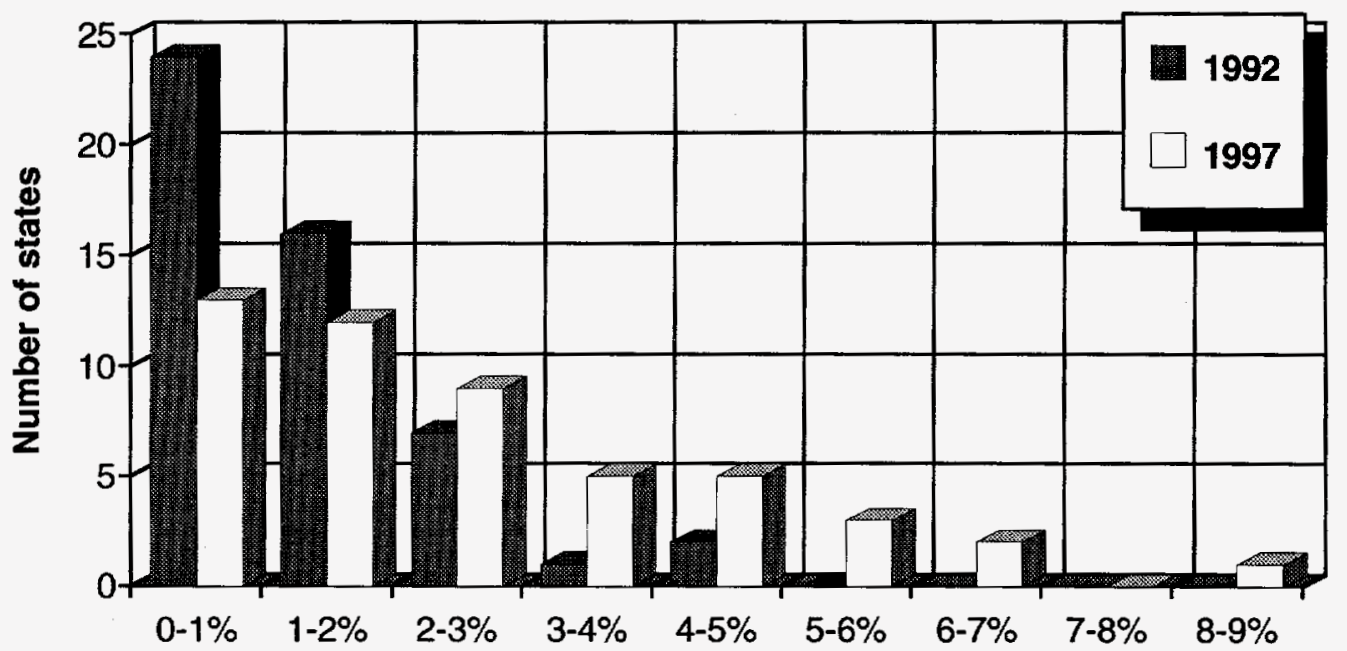

DSM expenditures as a percentage of retail revenues

Fig. 2.1. State-aggregated DSM expenditures, 1992 and 1997.

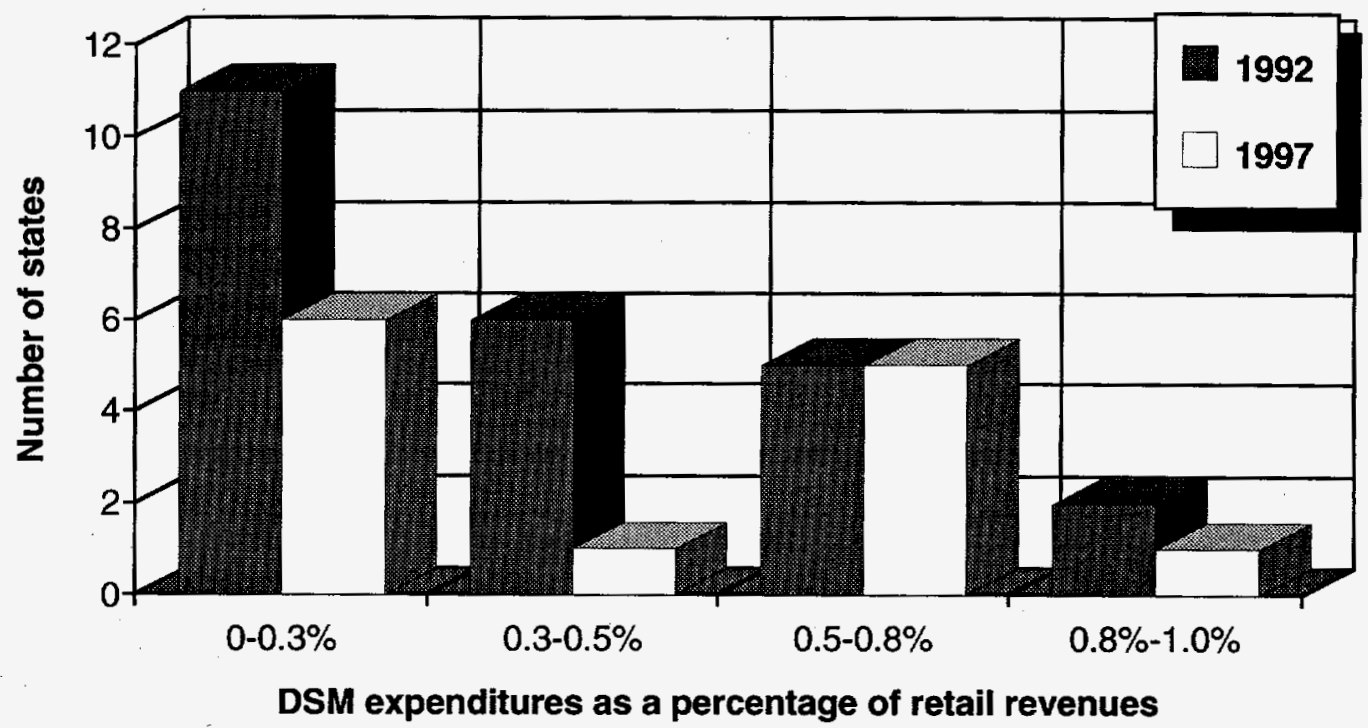

Fig. 2.2. Breakdown of expenditures for those states spending less than $1 \%$ of retail revenues on DSM programs, 1992 and 1997.

\section{ENERGY SA VINGS}

Figure 2.3 shows the distribution of energy savings as a percentage of retail electric sales for the IOUs aggregated by state. For 1992, energy savings ranged from no savings for 


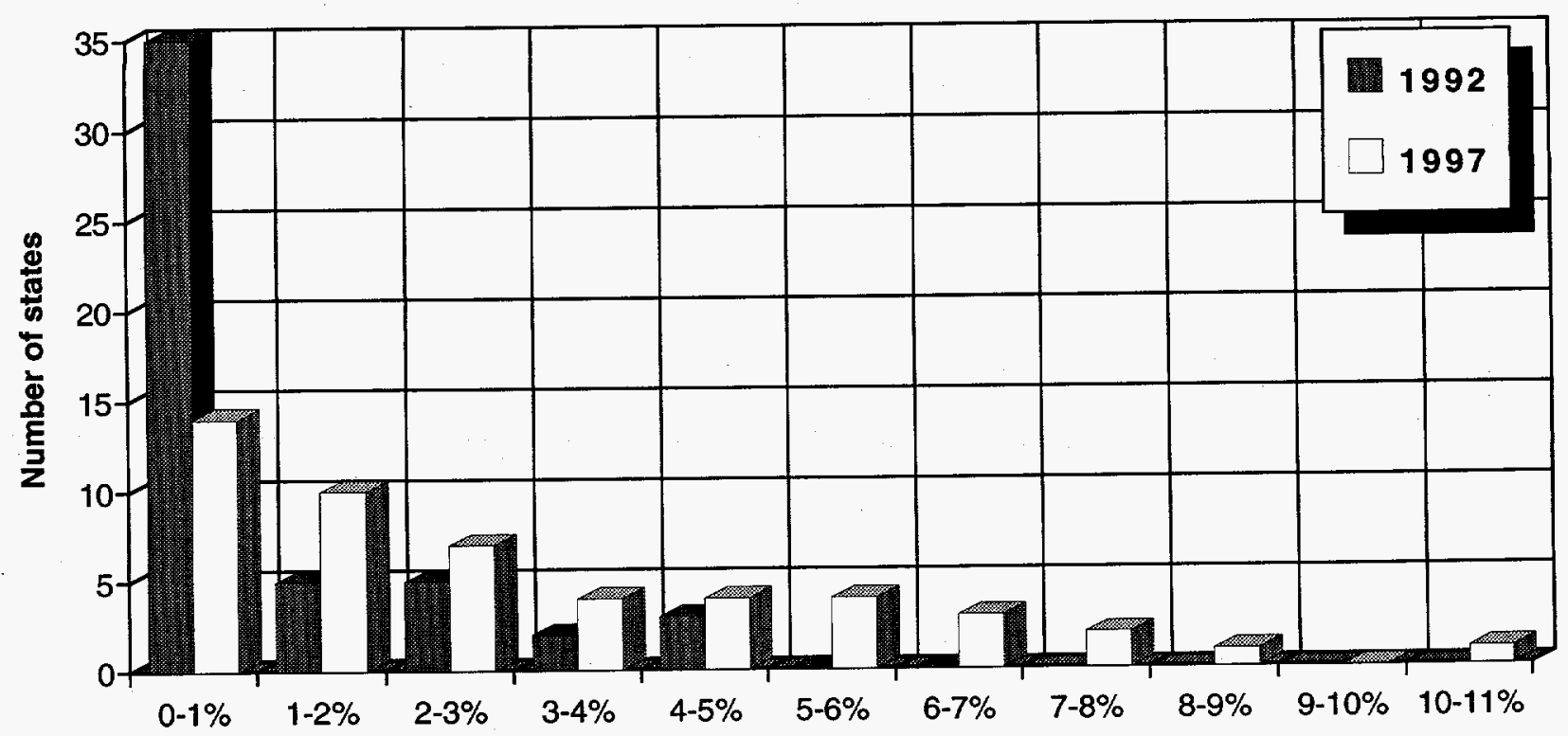

Energy savings as a percentage of retail electric sales

Fig. 2.3. State-aggregated energy savings due to DSM programs, 1992 and 1997.

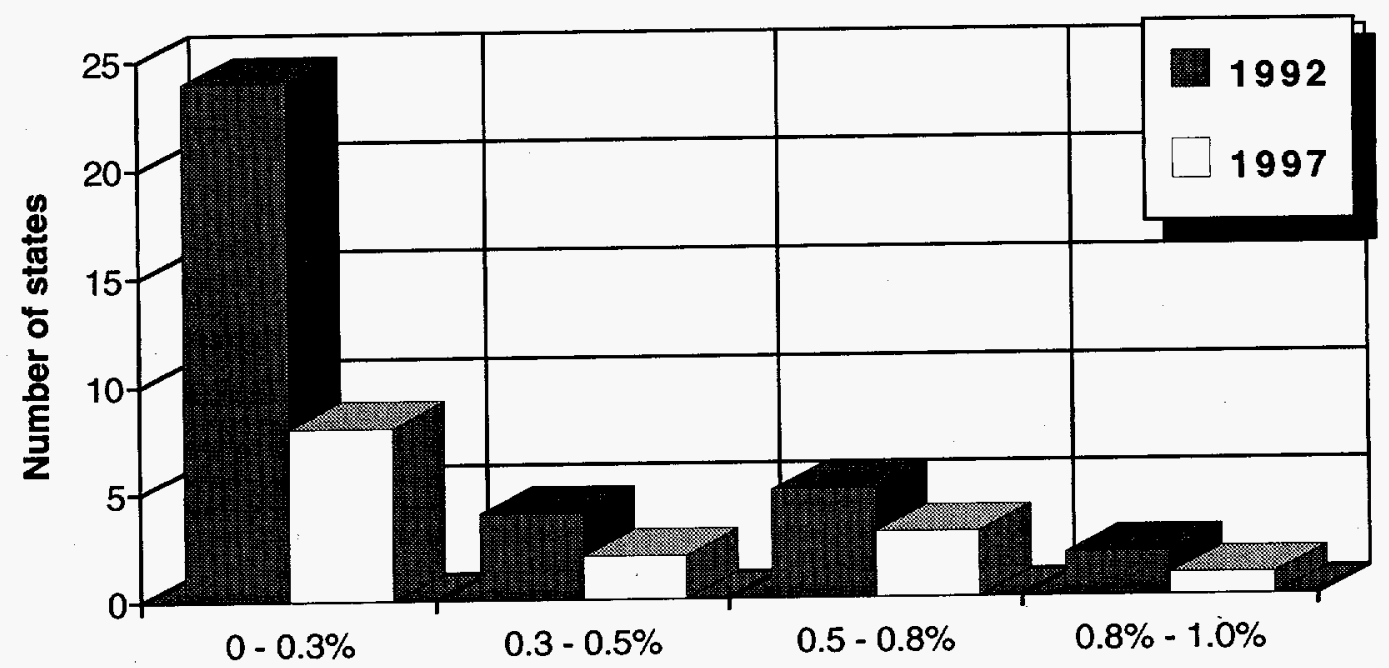

Energy savings as a percentage of retail electric sales

Fig. 2.4. Breakdown of energy savings for those states saving less than $1 \%$ of retail sales due to DSM programs, 1992 and 1997. 
Mississippi and Arkansas to the 4.7\% figure reported for the state of Washington. Once more, the distribution is highly skewed, with nearly three-quarters of the states having DSM-induced energy savings of less than $1 \%$ of retail electric sales. Mean energy savings for the states was just under $1 \%$ with a median of about $0.4 \%$. For 1997 , the number of states saving less than $1 \%$ is expected to decrease by two-thirds, and the projected range will extend from no savings all the way up to Washington's projected sales reduction of $10.7 \%$. The mean savings is expected to almost triple, to $2.8 \%$, while median energy savings will jump to $2.1 \%$, a nearly sixfold increase from 1992 . The energy savings achieved by the various states in 1992 are strongly correlated $(r=0.79)$ with the savings projected for the same states in 1997.

Of the 35 states saving less than $1 \%$ of retail electric sales in 1992, Figure 2.4 shows that over two-thirds experienced savings of less than $0.3 \%$. In 1997, far fewer states are expected to have savings of less than $1 \%$, and a slightly greater proportion of those that do will save $0.5 \%$ or more.

\section{PEAK REDUCTION}

The distribution of DSM-induced potential peak reduction for the state-aggregated IOUs is shown in Figure 2.5. 1992 reductions ranged from zero in Mississippi to almost $25 \%$ of retail peak demand in Vermont. The mean peak reduction was $7.1 \%$ and the median was $6.2 \%$. For 1997 , the peak reduction range is expected to increase. Mississippi expects no DSM-induced peak reduction while Vermont once again leads the field, this time with a projected reduction equal to $36.2 \%$ of its retail peak. Both mean and median peak reduction numbers are expected to increase by nearly half in 1997 - to $10.5 \%$ and $9.2 \%$, respectively. The reductions in retail peak achieved by the various states in 1992 are very highly correlated $(r=0.93)$ with the peak reductions projected for the same states in 1997.

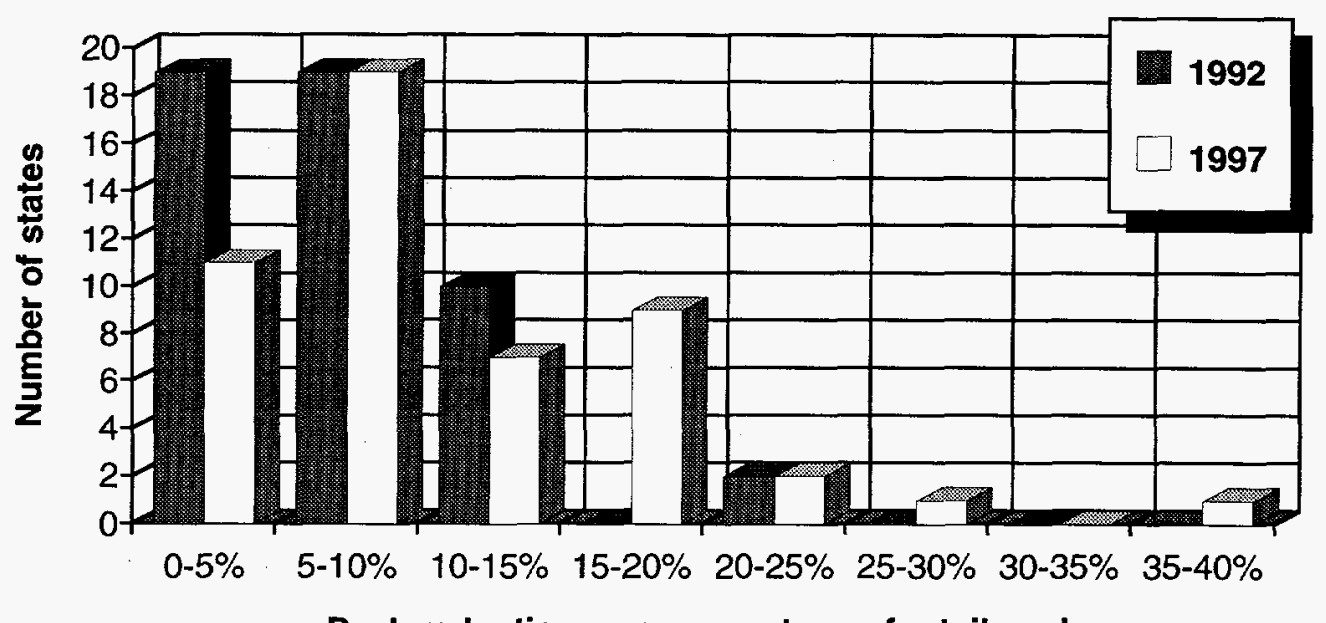

Peak reduction as a percentage of retail peak

Fig. 2.5. State-aggregated peak reduction due to DSM programs, 1992 and 1997. 
For those states achieving a retail peak reduction of less than $10 \%$, the 1992 distribution was fairly even across categories, with the same number of states achieving savings less than $5 \%$ as experienced savings between 5 and $10 \%$ (Fig. 2.10). For 1997, there will be approximately a one-fifth reduction in the number of states expecting a peak reduction of less than $10 \%$. As shown in Fig. 2.6, fewer states are expected to experience peak reductions of less than $5 \%$ and more will fall into the 7 to $10 \%$ category.

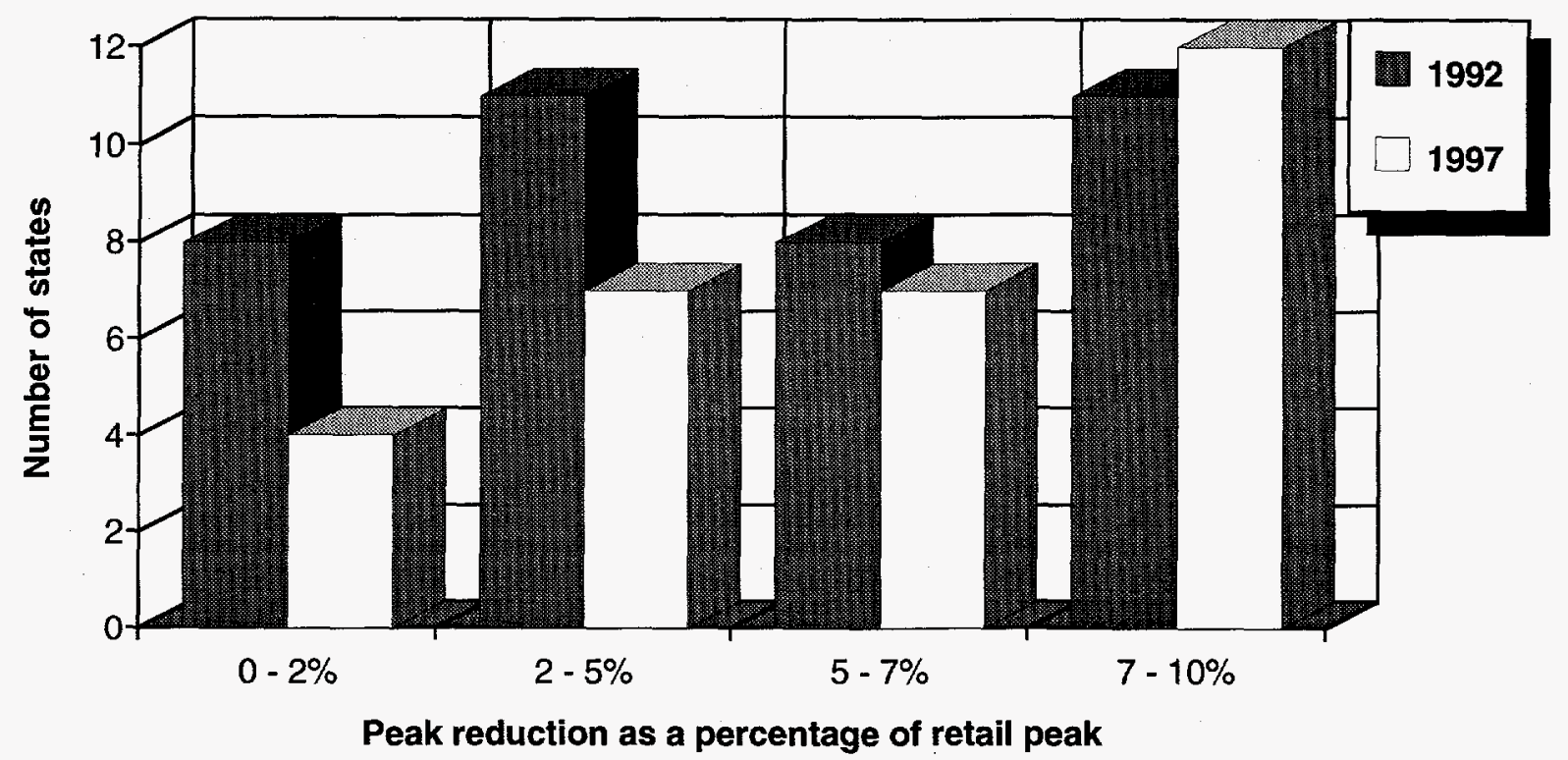

Fig. 2.6. Breakdown of peak reduction for those states reducing retail peak demand by less than 10\% through the use of DSM programs, 1992 and 1997.

\section{COMPARISON OF OUTCOMES}

Figure 2.7 graphically illustrates the accomplishments of the state-aggregated IOUs in terms of the various measures of DSM usage discussed above. While this figure shows both median and mean outcomes, the discussion will focus on the median as a better measure of central tendency in light of the skewed distributions treated here. As shown, the median DSM expenditure in 1992 was $1 \%$ of retail revenues, while the median energy saving (as a percent of retail sales) was about one-third of this. In contrast, the median peak reduction achieved through utility DSM programs was just over $6 \%$ of retail peak. In 1997, the projected median expenditure will equal $2 \%$ of retail revenues. The median energy saving will be very slightly larger than this, while the median peak is projected at just over $9 \%$. The reader should note that the numbers given here for DSM expenditures describe the amount spent in a single year (1992 or 1997), while the figures for energy savings and peak reduction are cumulative, describing the effects of all DSM programs undertaken as of the date in question. Accordingly, it could be misleading to directly compare the percentages reported here for expenditures with those for energy savings and peak reduction. 


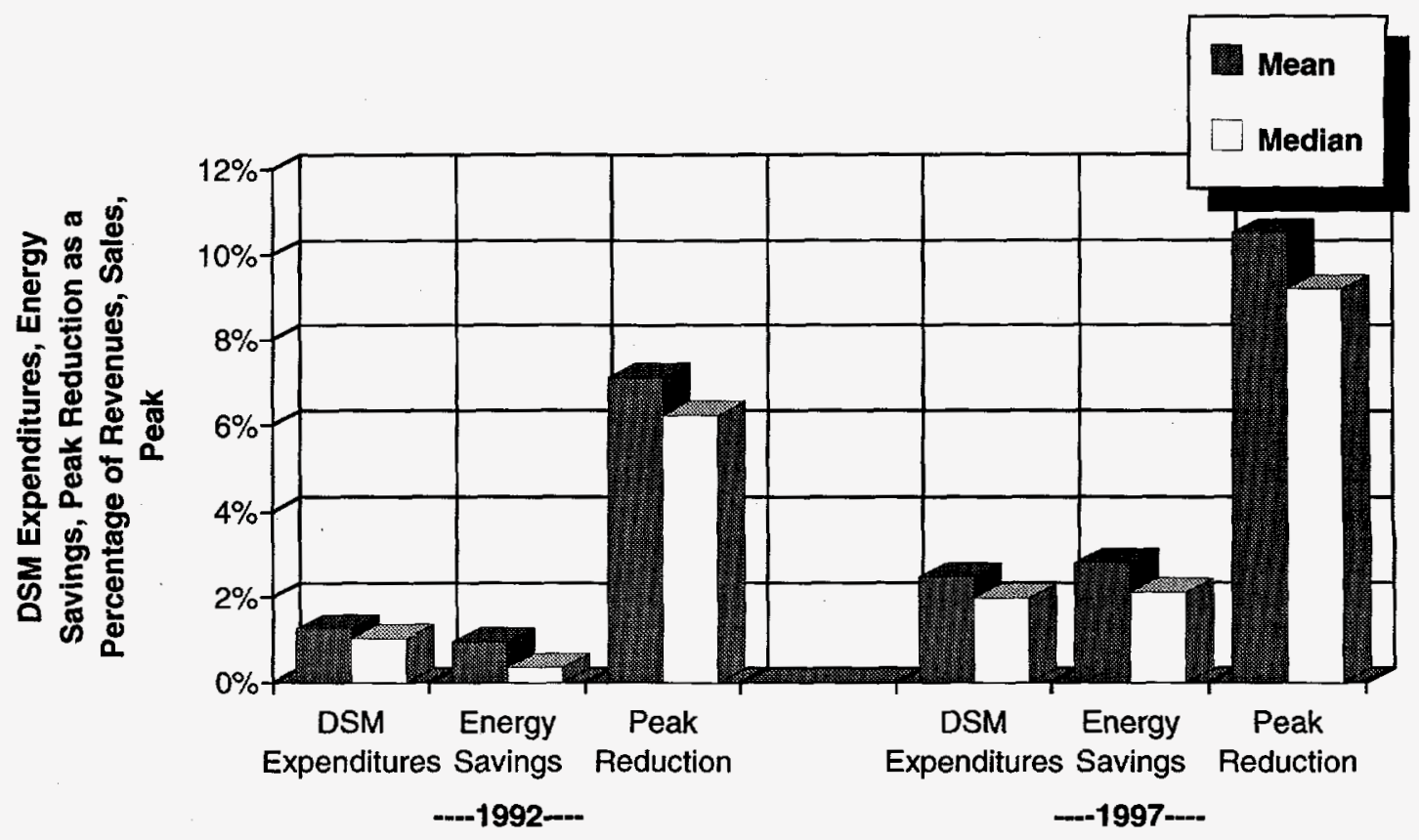

Fig. 2.7. Comparison of outcome measures for IOUs, 1992 and 1997.

For 1992, DSM expenditures and energy savings were highly correlated with each other $(r=0.73)$, meaning that states that were relatively high on one of these measures also tended to be relatively high on the other. However, neither of these measures was significantly correlated with peak reduction. For 1997, projected energy savings were highly correlated with DSM expenditures $(r=0.64)$ and somewhat correlated with peak reduction $(r=0.40)$, but DSM expenditures and peak reduction were not significantly correlated with each other.

Between 1992 and 1997, the median annual DSM expenditure is expected to grow by a little more than $90 \%$ (in 1992 dollars). During that same period, the median cumulative energy saving will grow by over $480 \%$. In contrast, the median cumulative peak reduction is expected to increase by just under 50\% between 1992 and 1997, meaning that it will grow at only about onetenth the rate that energy savings will. Clearly, IOUs intend - at least in the near-term future-to expand their energy-saving programs much more rapidly than their peak reduction efforts. This does not represent an abandonment of peak reduction programs, which have been the primary focus of past utility efforts, but it does indicate a strong interest in energy saving activities. 


\section{REGULATORY ENVIRONMENT}

This chapter focuses on the regulatory environment in which utilities operate.$^{21}$ First, we address the key characteristics of the utilities' service areas. Next, we examine the internal makeup of the regulating authorities. Finally, we present attitudinal responses from the regulators on various important issues related to IRP and DSM. This chapter describes the central tendency and distribution of the responses, and also presents the findings from our statistical tests of hypothesized relationships between the key factors listed above and utility DSM usage. In interpreting the findings of these tests, it is important to remember that many of the variables studied are correlated with each other. For example, the extent of regulator support for load building programs is positively correlated with another environmental factor-support for workshops as a public involvement mechanism $(\mathrm{r}=0.36)$-and is negatively correlated with a number of regulatory requirements, such as the requirement for preparation of integrated resource plans $(r=0.37)$, the frequency with which such plans must be prepared $(r=0.36)$, and the granting of financial incentives for utility use of DSM resources ( $r=0.37$ ). Practically speaking, such covariance can make it difficult to attribute causality to an individual variable, even though we have confidence in the identified relationship. As mentioned previously, the fact that many factors are highly correlated means that the amount of variance in DSM usage explained by different independent variables is not strictly cumulative.

\section{KEY CHARACTERISTICS OF SERVICE AREA}

\section{Need for Additional Peaking and Baseload Resources}

Forty-four state regulatory agencies reported when they anticipate that additional peak period resources would be needed in their states. Of those providing information on this, nearly two-thirds expected that they would need new peak period resources in five years or less and another one-fifth anticipated such a need in the next six to ten years (Fig. 3.1). Less than onetenth of the responding states will go more than 10 years before the need for new peak period resources arises. The length of time until new peaking resources will be required ranges from one to 18 years, with a mean of five and a half years and a median of only four years.

Table 3.1 shows the significant relationships between the need for additional resources and DSM usage revealed by our statistical analysis. A significant negative relationship was found between the number of years until a state will need new peaking resources and the DSM expenditures projected for $1997(p=.006)$. This means that projected DSM expenditures tended to be greater in those states that anticipated needing peak resources in fewer years. By itself, this independent variable explained about $14 \%$ of the variance in 1997 DSM expenditures $(\mathrm{R}-\mathrm{Square}=0.1426)$.

\footnotetext{
${ }^{21}$ To be consistent with the data on DSM usage presented in Chapter 2, this information is current as of the end of 1992.
} 


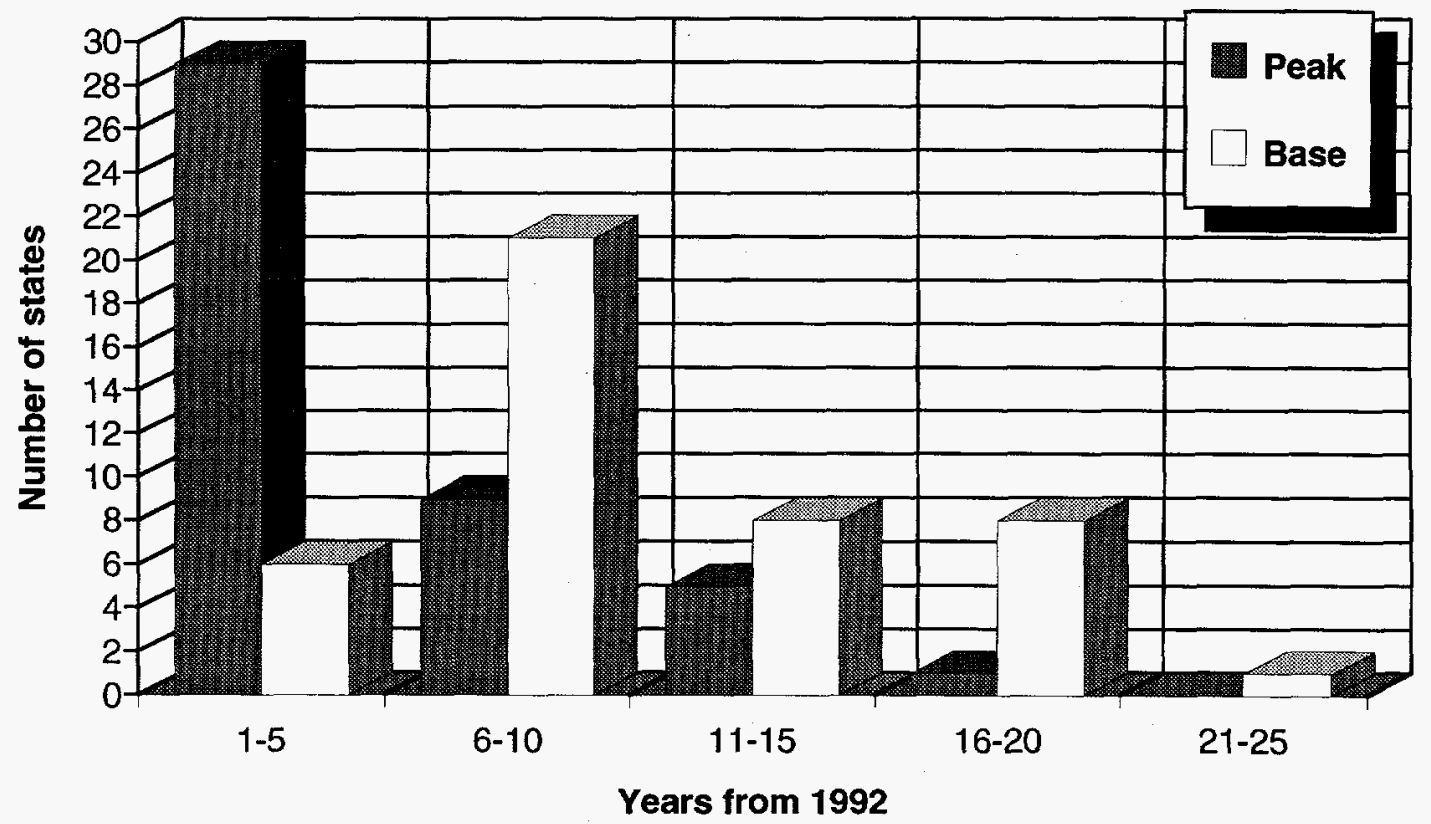

Fig. 3.1. Number of years until new peaking and baseload units will be needed by states.

Table 3.1. Relationships between need for additional resources and outcome measures ${ }^{a}$

\begin{tabular}{|c|c|c|}
\hline & \multicolumn{2}{|c|}{ Outcome measures } \\
\hline & $\begin{array}{c}1992 \text { DSM } \\
\text { expenditures }\end{array}$ & $\begin{array}{r}1997 \text { DSM } \\
\text { expenditures }\end{array}$ \\
\hline $\begin{array}{l}\text { Number of years until new peaking } \\
\text { resources will be needed }\end{array}$ & & $\underset{\text { (negative) }}{\mathrm{X}}$ \\
\hline $\begin{array}{l}\text { Number of years until new baseload } \\
\text { resources will be needed }\end{array}$ & $\underset{\text { (negative) }}{\mathrm{X}}$ & $\begin{array}{c}\mathrm{X} \\
\text { (negative) }\end{array}$ \\
\hline R-Square ${ }^{b}$ & 0.1178 & 0.3302 \\
\hline
\end{tabular}

aSignificant relationships (i.e., p-value $=.05$ or less) are indicated with an X. Negative relationships are indicated in parentheses.

${ }^{b}$ The R-Square value describes the proportion of the variance in the designated outcome measure explained by the significant independent variable(s).

Forty-three regulatory agencies reported when they anticipate that their state would need additional baseload resources. Only about one-seventh of those responding said that they would require new baseload resources within five years, but almost half anticipated the need for such resources in another six to ten years (Fig. 3.1). Less than one-twentieth of the responding states expected to go 20 years or longer before they need new baseload resources. The reported length 
of time until new baseload resources would be required ranged from one to 23 years, with a mean of almost 11 years and a median of 10 years.

We found a significant negative relationship between the number of years until a state will need baseload resources and DSM expenditures, both for $1992(p=.01)$ and $1997(p=.0002)$. In other words, as the immediacy of the need for baseload resources increases, DSM expenditures tended to rise. This is consistent with the finding, presented in an earlier report by the U.S. General Accounting Office (1991), that DSM programs tended to be unpopular in states where capacity margins were greater than $30 \%$. By itself, the number of years until baseload resources are needed explained about $12 \%$ of the variance in 1992 DSM expenditures (R-Square=0.1178) and $27 \%$ of the variance in projected 1997 expenditures (R-Square $=0.2700$ ). The fact that the need for baseload resources was a much better predictor of 1997 DSM expenditures than of 1992 expenditures indicates that the need for power is likely to have an increasing effect on utility DSM investments as this need becomes more immediate. It is also important to note that the need for baseload resources was a much better predictor of utility DSM expenditures than the need for peak resources, perhaps because the ability to forestall the need to build more expensive baseload units provides utilities with a better incentive to develop DSM programs and also because programs designed to reduce energy use generally cost much more than peak reduction programs. When the number of years until baseload resources will be needed was put into a multiple regression equation with the number of years until peak resources will be needed, they explained $33 \%$ of the variance in 1997 DSM expenditures (R-Square=0.3302).

\section{Economic Climate}

For 1992, the average electricity price in each state ranged from 3.5 to 10.3 cents per kilowatt hour ( $\mathrm{kWh}$ ) with a mean of $6.75 \mathrm{cents} / \mathrm{kWh}$ and a median of $6.3 \mathrm{cents} / \mathrm{kWh}$. The average price of natural gas in each state ranged from $\$ 3.80$ to $\$ 18.00$ per cubic foot with a mean of $\$ 6.22 /$ cubic foot and a median of $\$ 5.69 /$ cubic foot. As a final measure of state economic performance, we gathered data on the change in personal income from the fourth quarter of 1991 to the fourth quarter of 1992 . The percentage increase ranged from $2.7 \%$ to $8.2 \%$, with a $5.8 \%$ mean and median increase. Our statistical analysis revealed no significant relationship between the above-mentioned economic factors and any measure of DSM usage.

\section{REGULATORY AGENCY PERSONNEL}

\section{Size of Regulatory Staff}

Of the 46 states providing data on this item, the number of staff members responsible for administering electric utility regulation ranged from 0 to 150 , with a mean of 24 and a median of 10. Over three-fourths of the reporting PUCs had 30 staff members or less, and only about onetenth had a staff of 75 or more. The number of regulatory staff was found to be unrelated to our measures of DSM usage. 


\section{Background of Regulatory Commissioners}

Information was obtained for 46 state regulatory commissions on the percentage of their members whose principal past work experience fell into each of eight major job categories. The mean percentage for each of these categories was then calculated to give a picture of commissioners' backgrounds for the average state regulatory body. As shown in Fig. 3.2, almost one third of regulatory commissioners, on average, had a background as elected officials, and nearly the same percentage worked previously as staff members at government agencies.

Substantial numbers of commissioners also worked in business or had a private law practice. Environmental groups were the least represented on state commissions, but commissioners whose principal past work experience was in the utility industry were almost as scarce. No statistically significant relationship was found between the background of regulatory commissioners and utilities' DSM use.

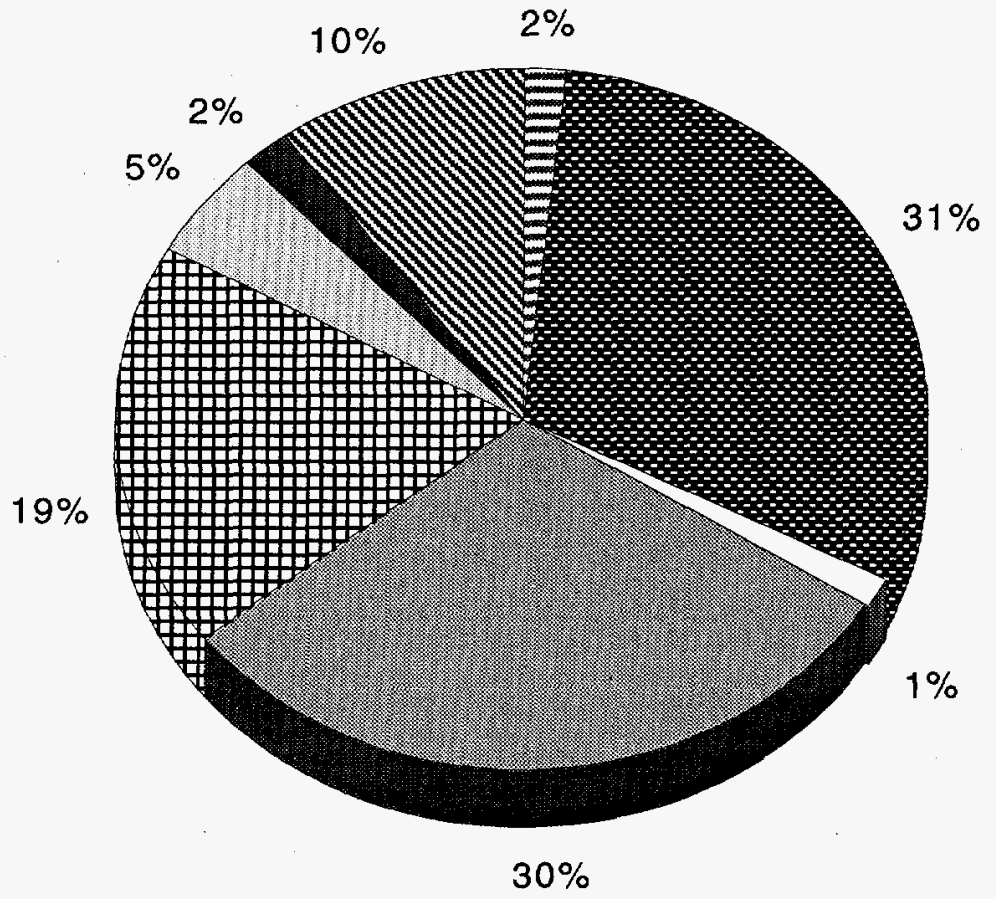

$=$ Utility

Elected Official

Environmental/Pub. Interest

Government Staff

囲 Commercial/Business Firm

Education

Farmer/Agribusiness

Private Law Practice

Fig. 3.2. Principal work experience of state regulatory commissioners: mean percentages for each major category.

\section{Commissioner Turnover}

Turnover in 1992 was minimal for the most part for PUCs and self-regulated power boards. Thirty-five of the state regulatory agencies experienced no turnover at all and only nine states replaced one-third or more of their members. Common reasons for turnover were an election defeat, expired term, or retirement. 


\section{REGULATOR ATTITUDES AND ACTIONS}

\section{Load Building, Energy Efficiency, and Load Reduction}

Respondents were asked to characterize the extent to which their commission or board, as a whole, supported load building, energy efficiency programs, and load reduction programs for their state or utility. Their answers were expressed in terms of a five-point scale ranging from one (strongly oppose) to five (strongly support); the mid-point (three) denoted neutrality on an issue.

On average, the PUCs tended to be neutral to very slightly opposed to load building programs. As shown in Fig. 3.3, the mean response on this question was 2.8 with a median of 3 . However, the range of responses spanned the entire scale, with some states expressing strong opposition to load building and others expressing strong support for this. In contrast, the state regulatory commissions were considerably more supportive of energy efficiency and load reduction programs. The range of attitudes toward energy efficiency efforts was very small, extending only from neutral to strongly supportive. The mean and median responses of 4.3 and 4, respectively, and the fact that no commissions were characterized as being opposed to energy efficiency show the strength of PUC support for programs that are designed to reduce energy consumption. Support for load reduction programs by the state regulators was slightly less than for energy efficiency but still substantial. There was a larger range of responses, extending from opposition to strong support, but the mean of 4.1 and median of 4 clearly indicate the positive attitude of state regulators toward utility initiatives to reduce peak power needs.

When a multiple regression analysis was performed using the three attitudinal measures described above, commission support for load building programs was found to be negatively related to 1992 DSM expenditures $(p=.02), 1997$ DSM expenditures $(p=.02), 1992$ energy savings $(p=.04)$ and 1997 energy savings $(p=.0006)$. This means that states that more strongly supported utility load building programs tended to have lower DSM usage. The amount of variance in the dependent variable that was explained by these models ranged from over $33 \%$ for 1997 energy savings to less than 15\% for 1997 expenditures and 1992 energy savings. As shown in Table 3.2, nearly all of this variance was explained by commission support for load building. No significant relationship was found between utility DSM usage and commission support for energy efficiency and load reduction programs.

\section{Public Involvement}

Respondents were asked to characterize the extent to which their commission or board, as a whole, supported the use of various mechanisms to obtain public involvement on important policy and program issues. Their answers were expressed in terms of the same five-point scale described above, with one denoting strong opposition and five indicating strong support.

The extent of overall PUC support was very similar for four of the five public involvement approaches about which the respondents were queried (Fig. 3.4). For each of these mechanismspublic meetings, collaboratives, task forces/advisory groups, and workshops - the median response was 4 (support) and the mean varied only slightly, from 4.3 for public meetings to 4.0 


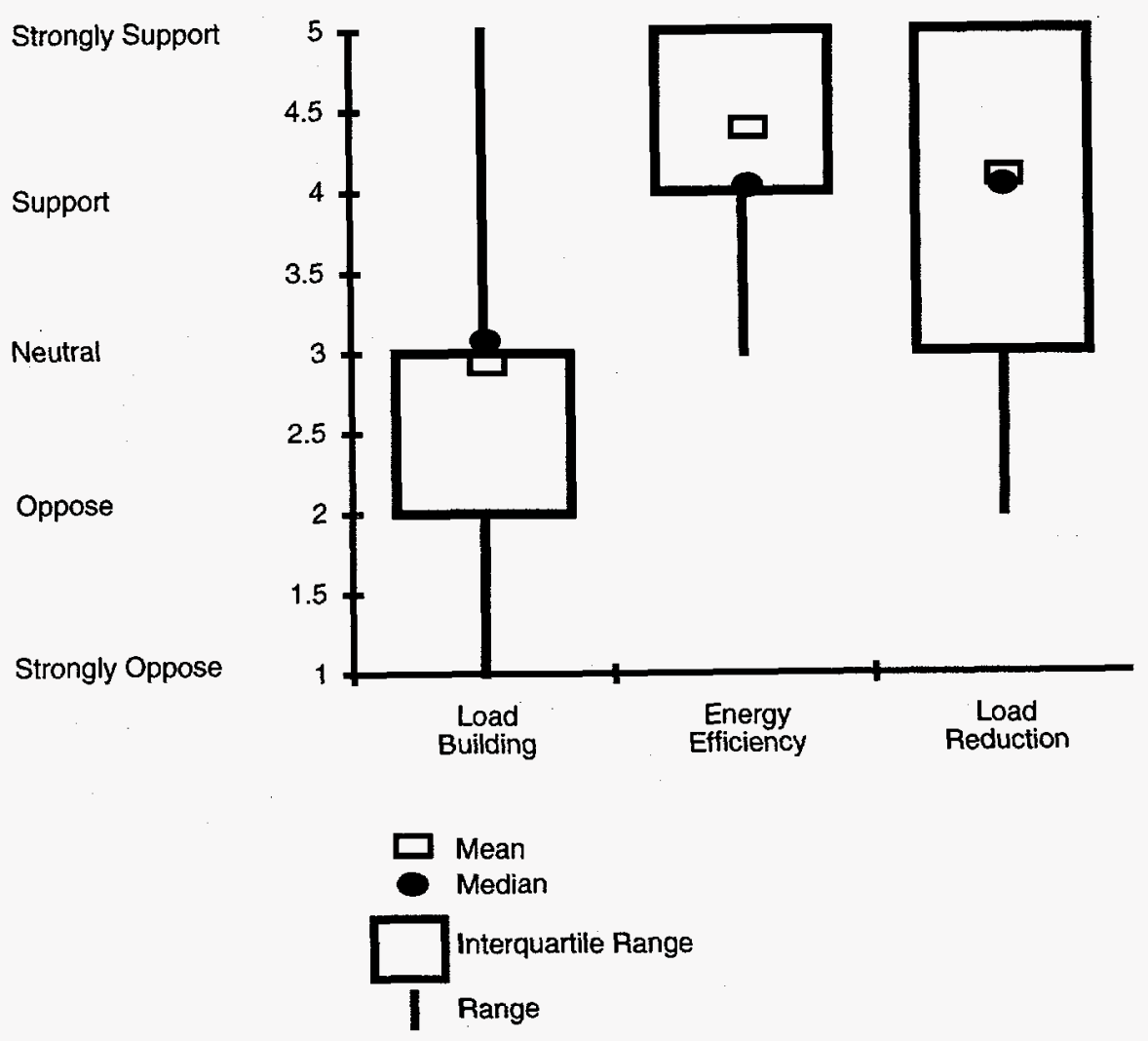

Fig. 3.3. Distribution of support for load building, energy efficiency, and load reduction programs by state regulatory commissioners.

Table 3.2. Relationships between regulator support for load building and outcome measures ${ }^{a}$

\begin{tabular}{lcccc}
\hline & \multicolumn{4}{c}{ Outcome measures } \\
\cline { 2 - 5 } & $\begin{array}{c}\text { 1992 DSM } \\
\text { expenditures }\end{array}$ & $\begin{array}{c}\text { 1997 DSM } \\
\text { expenditures }\end{array}$ & $\begin{array}{c}\text { 1992 energy } \\
\text { savings }\end{array}$ & $\begin{array}{c}\text { 1997 energy } \\
\text { savings }\end{array}$ \\
\hline $\begin{array}{l}\text { Support for load } \\
\text { building } \\
\text { programs }\end{array}$ & $\begin{array}{c}\mathrm{X} \\
\text { (negative) }\end{array}$ & $\begin{array}{c}\mathrm{X} \\
\text { (negative) }\end{array}$ & $\begin{array}{c}\mathrm{X} \\
\text { (negative) }\end{array}$ & $\begin{array}{c}\mathrm{X} \\
\text { (negative) }\end{array}$ \\
R-Square $^{b}$ & 0.1861 & 0.1400 & 0.1134 & 0.3028 \\
\hline
\end{tabular}

${ }^{a}$ Significant relationships (i.e., $\mathrm{p}$-value $=.05$ or less) are indicated with an $\mathrm{X}$. Negative relationships are indicated in parentheses.

${ }^{b}$ The R-Square value describes the proportion of the variance in the designated outcome measure explained by the significant independent variable. 


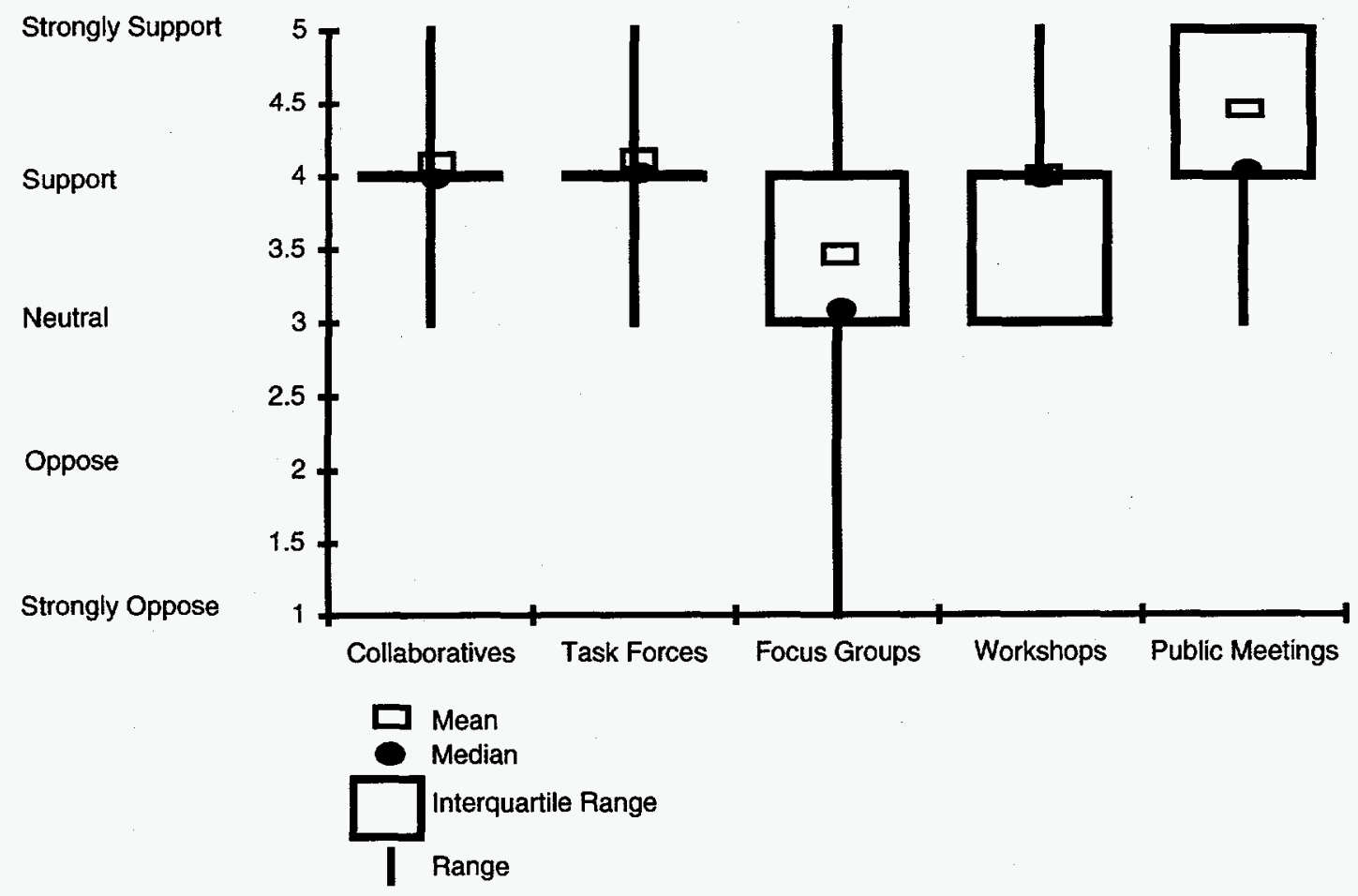

Fig. 3.4. Distribution of support for various forms of public involvement by state regulatory commissioners.

for workshops. The range of responses also was identical for each of these items. The method of obtaining public involvement that was clearly least favored was the use of focus groups, with a mean of 3.4 and a median of only 3 (neutral). In contrast to the response to the other public involvement mechanisms, some regulatory agencies expressed opposition to the use of focus groups.

As shown in Table 3.3, multiple regression analysis performed with all of the abovementioned public involvement mechanisms revealed a significant positive relationship between regulatory support for collaboratives and 1992 DSM expenditures $(p=.04), 1992$ energy savings $(p=.01)$, and 1997 energy savings $(p=.02)$. This means that DSM usage generally was greater in those states whose regulatory commissions were more favorably inclined toward the use of collaboratives. At the same time, the use of workshops - a public involvement approach that is considerably less interactive than collaboratives - was significantly negatively related to the same three variables ( $p=.01$ for 1992 expenditures, .04 for 1992 energy savings, and .04 for 1997 energy savings). In other words, utility DSM usage tended to be greater in states where the PUCs strongly supported intense interactions between utilities and non-utility parties (NUPs) and lower in states where PUCs had the strongest positive attitudes toward less interactive approaches. This is consistent with the findings from an earlier ORNL study (Schweitzer, Hirst, and Hill 1991), which found that utility support for these same methods of obtaining input into the planning process had an identical effect on DSM usage. 
Table 3.3. Relationships between regulator support for key public involvement mechanisms and outcome measures ${ }^{a}$

\begin{tabular}{lccc}
\hline & \multicolumn{3}{c}{ Outcome measures } \\
\cline { 2 - 4 } & $\begin{array}{c}\text { 1992 DSM } \\
\text { expenditures }\end{array}$ & $\begin{array}{c}1992 \text { energy } \\
\text { savings }\end{array}$ & $\begin{array}{c}\text { 1997 energy } \\
\text { savings }\end{array}$ \\
\hline $\begin{array}{l}\text { Support for } \\
\text { collaboratives }\end{array}$ & $\mathrm{X}$ & $\mathrm{X}$ & $\mathrm{X}$ \\
Support for workshops & $\mathrm{X}$ & $\mathrm{X}$ & $\mathrm{X}$ \\
(negative) & 0.4061 & (negative) & (negative) \\
R-Square & & 0.4089 & 0.3542 \\
\hline
\end{tabular}

${ }^{a}$ Significant relationships (i.e., $\mathrm{p}$-value $=.05$ or less) are indicated with an $\mathrm{X}$. Negative relationships are indicated in parentheses.

${ }^{b}$ The R-Square value describes the proportion of the variance in the designated outcome measure explained by the significant independent variables.

In our current study, the amount of variance in DSM usage that the public involvement variables explained was remarkably high. Over $42 \%$ of the variance in 1992 expenditures was explained by our regression model, nearly all of this $(R-S q u a r e=0.4061)$ by the extent of regulator support for collaboratives and workshops. Almost 58\% of the variance in 1992 energy savings was explained by our model, nearly three-fourths of this $(\mathrm{R}-\mathrm{Square}=0.4089)$ by these same two variables. And our model explained over 46\% of the variance in 1997 energy savings, with over three-fourths of this $(R-S q u a r e=0.3542)$ attributable to our two key variables. These findings indicate that the use of more highly interactive public involvement mechanisms-especially collaboratives-probably influenced utilities to use more DSM than they might have otherwise, and this conclusion is supported by earlier studies of collaborative outcomes (Schweitzer, English, and Altman 1994). However, it is likely that independent factors that tended to accompany commission support for collaboratives, such as support for DSM incentives and the use of lost revenue allowances, also influenced utilities' resource acquisition decisions to a great extent. In other words, the reader is reminded that there was significant covariance among the factors studied and is cautioned against assuming that a relationship among variables is necessarily a causal one.

\section{Information Sources for Regulatory Decisions}

Respondents were asked to characterize the importance that their commission or board, as a whole, attached to various types of information when making regulatory decisions on policy and program issues. Their answers were expressed in terms of a five-point scale with one indicating very slight importance, three indicating moderate importance, and five indicating very great importance. If a commission or board did not use a particular type of information, its answer was zero for that item. 
State regulatory agencies tended to place the highest value on filings and proposals from utilities and testimony at rate hearings, both of which had mean scores of 4.6 and medians of 5 (Fig. 3.5). Advice from regulatory staff, with a mean of 4.4 and a median of 4 , also was considered quite important. All of the respondents reported using these sources of information and the range of responses was very limited, extending no lower than three (moderate importance). The importance given by state regulatory agencies to other forms of information showed considerably more variability. The mean importance attributed to filings of materials by NUPs was 3.8, while the mean response to all the remaining items was less than 3 (moderate). However, when those respondents who did not use a particular source of information were excluded, the mean scores increased considerably. For example, among those states considering consensus filings by utility-NUP collaboratives, the mean score for this item was 4.1. Our statistical analysis revealed no significant relationship between the importance attributed to any of these information sources and the extent of utility DSM usage.

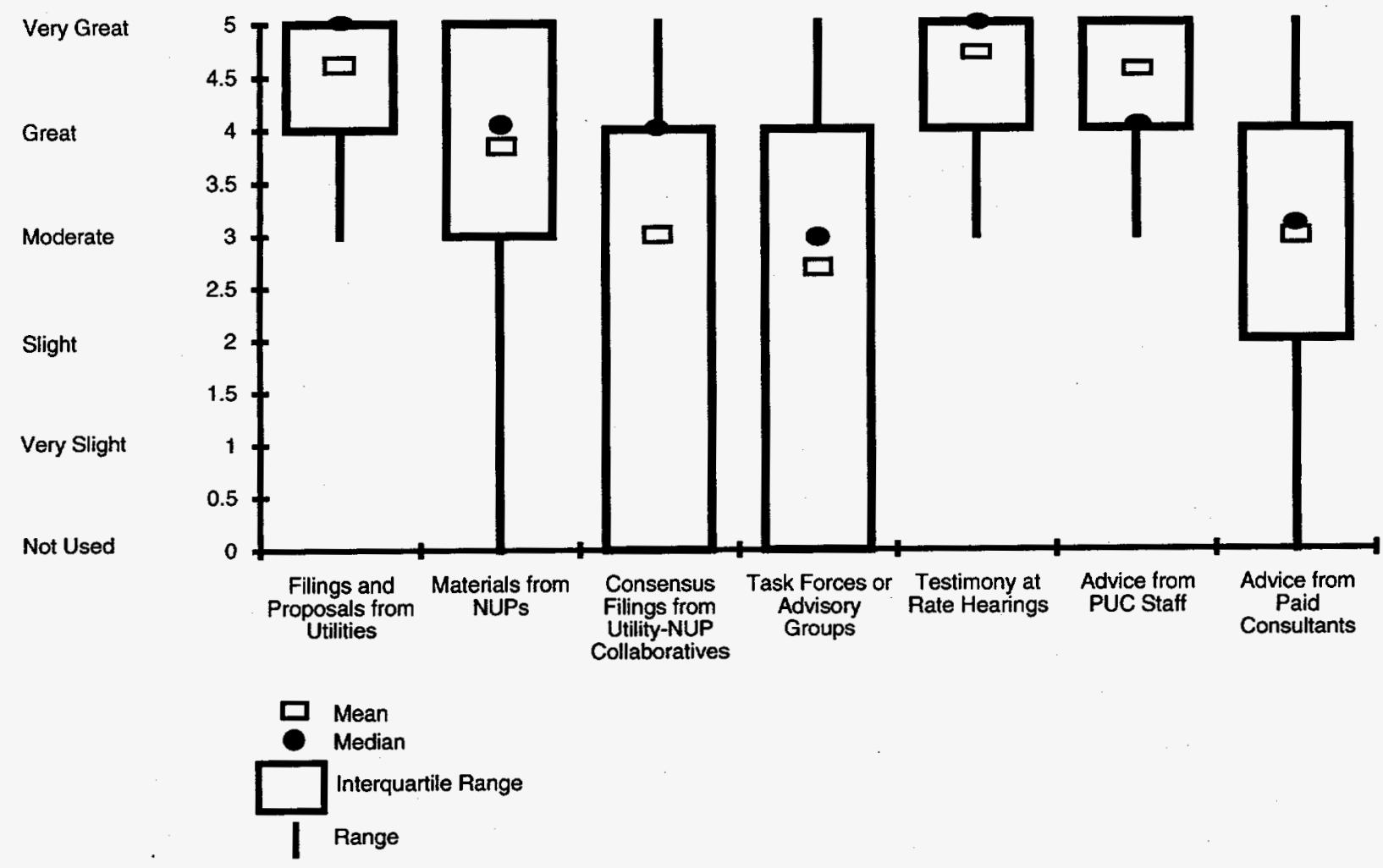

Fig. 3.5. Distribution of responses on importance of various types of information to state regulators when making regulatory decisions. 


\section{Provision of Assistance Programs for Utilities and NUPs}

During 1992, approximately half of the state regulatory agencies provided assistance of some sort to utility staff and/or NUPs on IRP and DSM-related issues. Of the 44 states responding to this question, 18 reported holding seminars or workshops for outside parties. Of these, two-thirds held three or less, with the remaining states providing between four and ten workshops during 1992. Eight state regulatory commissions held conferences for interested parties in 1992, with over half of these doing this only once or twice over the course of the year. Finally, only three states reported providing outside parties with educational materials regarding DSM or IRP. No relationship between DSM usage and the above-mentioned assistance programs was found.

\section{ALL ENVIRONMENTAL FACTORS}

In order to see how much of the variance in our dependent variables could be explained by all important environmental factors combined, we performed a stepwise regression analysis on the state data set using the five environmental variables (discussed above) that we found to be significant through our hypothesis tests. The stepwise regression technique begins by identifying the independent variable that has the highest explanatory power and continues to identify all significant variables in declining order of importance. ${ }^{22}$ Through this procedure, we found that three environmental factors - support for workshops as a public involvement mechanism $(p=.03)$, support for collaboratives $(\mathrm{p}=.05$ ), and the number of years until new baseload resources will be needed $(p=.04)$ - accounted for nearly $55 \%$ of the variance in 1992 DSM expenditures $(\mathrm{R}-\mathrm{Square}=0.5452)$ among the states.

Our independent variables also explained substantial amounts of variance in most of the other measures of DSM usage. Specifically, we were able to explain almost $48 \%$ of the variance in projected 1997 energy savings (R-Square $=0.4755), 44 \%$ of the variance in 1997 DSM expenditures ( $\mathrm{R}-\mathrm{Square}=0.4398$ ), and $38 \%$ of the variance in 1992 energy savings $(\mathrm{R}-\mathrm{Square}=0.3814) .{ }^{23}$ Only $10 \%$ of the variance in 1997 peak reduction $(\mathrm{R}-\mathrm{Square}=0.1045)$ and none of the variance in 1992 peak reduction was explained by the stepwise analysis. Support for workshops and collaboratives were significantly related to 1992 and 1997 energy savings, just as they were for 1992 DSM expenditures, and the number of years until baseload power is needed was significantly related to projected 1997 expenditures. In addition, support for load building programs had a significant negative relationship to 1997 expenditures, 1997 energy savings, and

\footnotetext{
${ }^{22}$ Because many of our independent variables are highly correlated, the set of significant environmental factors identified through our stepwise regression is not the only such set possible. If one key variable were eliminated from the analysis, another could emerge as being important.

${ }^{23}$ The fact that slightly less of the variance in 1992 energy savings was explained by the stepwise regression than by an earlier hypothesis test of public involvement mechanisms is explained by the fact that the number of observations used in the earlier test was slightly smaller (due to missing values on some of the variables not included in the stepwise analysis), and that the stepwise analysis probably included some data points that ran counter to the identified relationship.
} 
1997 peak reduction. Finally, the number of years until peak resources are needed was found to be negatively related to 1997 expenditures. 



\section{REGULATORY REQUIREMENTS}

This chapter discusses key regulations related to IRP and DSM that have been established by the PUCs. ${ }^{24}$ First, we cover IRP requirements for the states, including a look at the different types of cost-effectiveness tests used in making resource planning decisions and the various mechanisms by which the issue of environmental externalities is treated. Then, we address the different ways in which the states allow for DSM cost recovery, lost revenue recovery, and financial incentives. As in the previous chapter, we present descriptive statistics as well as key findings from our tests of hypothesized relationships between regulatory requirements and utility DSM usage. Once more, the reader is reminded that many of the variables studied are highly correlated with each other. For instance, requiring utilities to consider environmental externalities is positively correlated with requiring integrated resource planning $(r=0.48)$ and the use of specific cost-effectiveness tests $(r=0.48)$, as well as with allowing lost revenue recovery $(r=0.33)$ and granting financial incentives for DSM use $(r=0.31)$.

\section{IRP REQUIREMENTS}

\section{Nature and History of IRP Requirements}

Nearly three-quarters of the states required their IOUs to develop integrated resource plans (IRPs). Of these 37 states, about one-third established their IRP requirement in 1992, and nearly three-fourths established such a requirement between 1989 and 1992 (Fig. 4.1). Another 6 states established an IRP requirement in 1987 or 1988. Only four states required their IOUs to prepare IRPs before 1987, illustrating the relative newness of IRP and the serious consideration of DSM as a potential resource for meeting future energy needs. Over half of the states that required IRP had the utilities file their plans on a biennial basis, while nearly a third required filings every third year. Only four required annual filings.

Our statistical analysis revealed a positive relationship between the requirement for preparation of IRPs and four separate measures of DSM usage: 1992 DSM expenditures $(p=.007)$; projected 1997 DSM expenditures $(p=.03) ; 1992$ energy savings $(p=.04) ;$ and 1997 savings $(p=.007)$. In other words, DSM usage tended to be greater in states that required IRP than in states without such a requirement. However, the amount of variance explained by this factor alone is fairly small (R-Square $=0.1217,0.0768,0.0629$, and 0.1182 , respectively).

As shown in Table 4.1, we found a significant relationship between the frequency with which plans must be submitted and DSM expenditures (both 1992 and 1997), energy savings (1992 and 1997), and peak reduction (1997). Again, this relationship was positive, meaning that utility DSM usage tended to be greater in states that required more frequent plan submittal. The amount of variance in the dependent variables that was explained by the frequency of plan

\footnotetext{
${ }^{24}$ As with the data on regulatory environment presented in Chapter 3 , this information is current as of the end of 1992.
} 
preparation ranged from approximately $17 \%$ for 1992 expenditures $(R-S q u a r e=0.1654)$ to $8 \%$ for 1997 peak reduction $(\mathrm{R}-\mathrm{Square}=0.0756$ ).

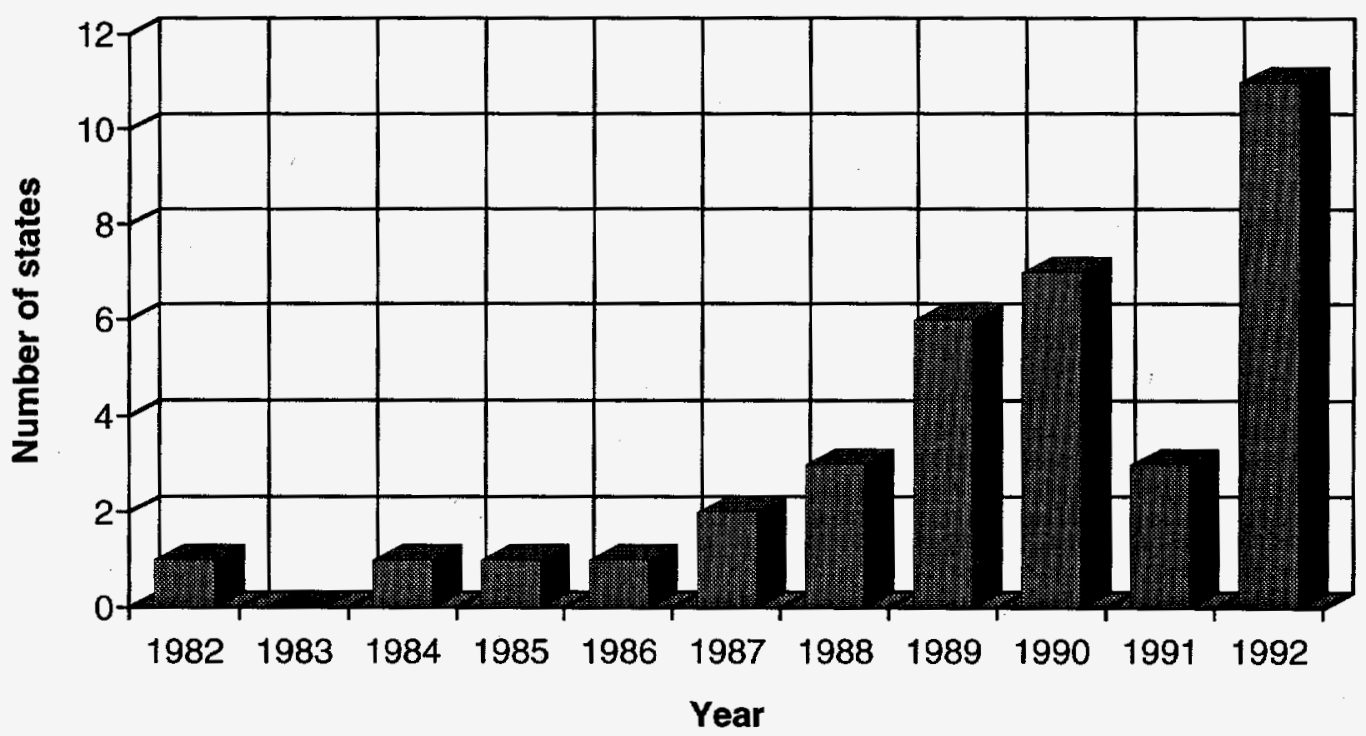

Fig. 4.1. Year in which IRP requirements were established by state regulatory bodies.

Table 4.1. Relationships between nature and history of IRP requirements and outcome measures ${ }^{a}$

\begin{tabular}{lccccc}
\hline & \multicolumn{5}{c}{ Outcome measures } \\
\cline { 2 - 6 } & $\begin{array}{l}\text { 1992 DSM } \\
\text { expenditures }\end{array}$ & $\begin{array}{c}\text { 1997 DSM } \\
\text { expenditures }\end{array}$ & $\begin{array}{c}1992 \text { energy } \\
\text { savings }\end{array}$ & $\begin{array}{c}1997 \text { energy } \\
\text { savings }\end{array}$ & $\begin{array}{c}1997 \text { peak } \\
\text { reduction }\end{array}$ \\
\hline $\begin{array}{l}\text { Frequency with } \\
\text { which plans must } \\
\text { be prepared }\end{array}$ & $\mathrm{X}$ & $\mathrm{X}$ & $\mathrm{X}$ & $\mathrm{X}$ & $\mathrm{X}$ \\
$\begin{array}{l}\text { R-Square } \\
\text { R-S }\end{array}$ & 0.1654 & 0.1254 & 0.1190 & 0.1333 & 0.0756 \\
$\begin{array}{l}\text { Length of time that } \\
\begin{array}{l}\text { IRP has been } \\
\text { required }\end{array}\end{array}$ & $\mathrm{X}$ & & $\mathrm{X}$ & $\mathrm{X}$ & \\
$\begin{array}{l}\text { R-Square } \\
\text { b }\end{array}$ & 0.1886 & & & & \\
\hline
\end{tabular}

aSignificant relationships (i.e., p-value $=.05$ or less) are indicated with an $\mathrm{X}$.

bThe R-Square value describes the proportion of the variance in the designated outcome measure explained by the significant independent variable listed immediately above it. 
There also was a significant positive relationship between the length of time that IRP has been required and DSM expenditures (1992) and energy savings (both 1992 and 1997), meaning that DSM usage tended to be greater in states that had an IRP requirement in effect for a longer period of time. The associated R-Square values ranged from 0.1886 for 1992 expenditures to 0.1285 for 1997 energy savings. Interestingly, a correlation analysis shows that the states that had IRP requirements in effect for longer periods had a strong tendency to require utility plans to be prepared more frequently $(r=0.68)$.

\section{IRP Review and Approval Procedures}

Over four-fifths of those states with an IRP requirement required a public review of the plan, and over half required formal approval of the utility integrated resource plan by the state regulatory body. Nearly all of the states that required formal plan approval established this procedure between 1989 and 1992 . Only about two-fifths of the states requiring the preparation of IRPs reported that approval of subsequent utility actions depended on their inclusion in the plan. And only one-tenth of the states with an IRP requirement said that approval of a plan guaranteed subsequent approval of specific actions that it contained. None of these review and approval procedures was found to be significantly related to utility DSM usage.

\section{COST-EFFECTIVENESS TESTS}

In the development of an integrated resource plan, a utility typically uses some sort of cost-effectiveness test to evaluate the different options for meeting the power needs of its customers. One commonly-used test is the Ratepayer Impact Measure (RIM) test. This measures different supply and demand options on the basis of their rate impact on a utility's customers. The Total Resource Cost (TRC) Test attempts to evaluate all direct costs and benefits that could effect the utility, participants, and nonparticipants, and the Societal Test is similar to the TRC Test except for the additional consideration of environmental externalities. The Utility Cost Test measures the costs and benefits to the utility itself, while the Participant Test determines the effect of various resource options on the actual customers using these programs.

Half of all the states-and over two-thirds of those that mandated IRP-required their regulated utilities to use one or more specific cost-effectiveness tests in the development of an integrated plan. Of the different types of tests, the TRC Test was most favored, with over a third of the states requiring its use. The Participant test was required least, with less than a tenth formally requiring this test (although most utilities use it anyway). The RIM and Utility Cost tests were each mandated by about one-fourth of the states. Figure 4.2 shows the distribution for all the major types of cost-effectiveness tests. There were 13 state PUCs that required multiple costeffectiveness tests, accounting for over one-third of all states that required IRP. Additionally, nearly two-thirds of the states that required IRP allowed their regulated utilities to file results from tests other than those required. 


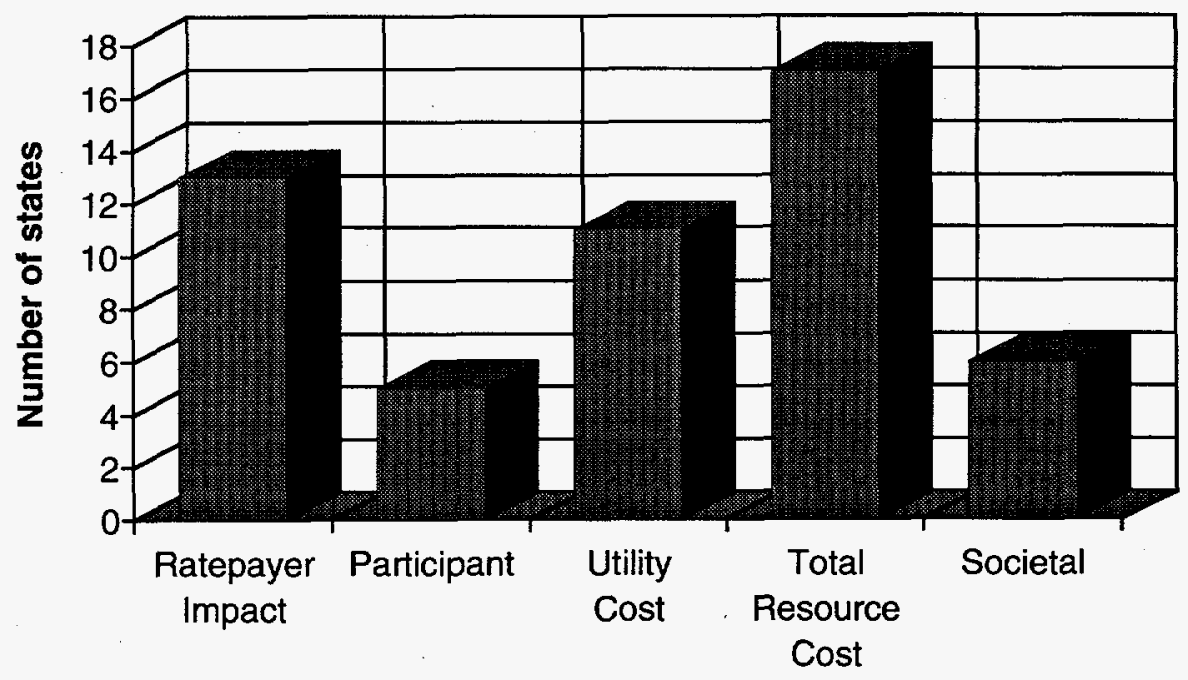

Type of cost-effectiveness test

Fig. 4.2. Number of states requiring utility use of various cost-effectiveness tests.

We found a significant positive relationship between a state requirement that utilities perform some specified cost-effectiveness test and 1992 DSM expenditures $(p=.03)$, projected 1997 expenditures $(p=.02)$, and 1997 energy savings $(p=.009)$. Table 4.2 shows that the amount of variance explained by the requirement for a cost-effectiveness test ranged from about $14 \%$ for 1997 expenditures (R-Square $=0.1408$ ) to $10 \%$ for 1992 DSM expenditures (R-Square=0.1019). No significant relationships were found between the requirement for any specific test and utility DSM usage.

Table 4.2. Relationships between cost-effectiveness test requirement and outcome measures ${ }^{a}$

\begin{tabular}{lccc}
\hline & \multicolumn{3}{c}{ Outcome measures } \\
\cline { 2 - 4 } & $\begin{array}{c}\text { 1992 DSM } \\
\text { expenditures }\end{array}$ & $\begin{array}{c}1997 \text { DSM } \\
\text { expenditures }\end{array}$ & $\begin{array}{c}1997 \text { energy } \\
\text { savings }\end{array}$ \\
\hline $\begin{array}{l}\text { Requirement for some specified } \\
\text { cost-effectiveness test(s) }\end{array}$ & $\mathrm{X}$ & $\mathrm{X}$ & $\mathrm{X}$ \\
R-Square $^{b}$ & 0.1019 & 0.1182 & 0.1408 \\
\hline
\end{tabular}

aSignificant relationships (i.e., $\mathrm{p}$-value $=.05$ or less) are indicated with an $\mathrm{X}$.

${ }^{b}$ The R-Square value describes the proportion of the variance in the designated outcome measure explained by the significant independent variable. 


\section{ENVIRONMENTAL EXTERNALITIES}

Environmental externalities as defined in the electric utility industry are societal costs of electricity production that are not directly quantified in rates charged to utility customers (National Association of Regulatory Utility Commissioners 1993). Impacts of electricity production include air pollution, water pollution, and health and safety concerns (EEI 1992a). Consideration of externalities can take two general approaches. Qualitative methods use expert judgement to rank various demand and supply-side options relative to their environmental effects. In contrast, quantitative methods attempt to assign specific values to externalities. The most commonly used quantitative approaches are: weighting and ranking, percentage adders, and monetization. Weighting and ranking involves generating and assigning values or weights to the environmental effects of various supply and demand-side resources. Percentage adders assign an additional percentage cost to resources that produce pollutants. Monetization methods-a subset of the broader category of quantitative methods-assign a price per unit of pollution. Monetized values can be assigned through direct costing, which tries to take into account the costs of all environmental impacts, and through a cost of control methodology, which uses the cost of using the best available control technology to mitigate environmental impacts (EEI 1992b; Hohmeyer and Ottinger 1990).

As of 1992, 19 states required their utilities to consider environmental externalities. This number represents almost two-fifths of all states and over half of the states that required their utilities to submit IRPs. Twelve states, or nearly two-thirds of those requiring consideration of environmental externalities, required the use of quantitative methods. Three of the 12 states required the use of two separate quantitative approaches. Of the various quantitative methods, cost of control and percentage adder methods were the most popular, followed by direct costing and weighting and ranking (Fig. 4.3). Nine states were required to consider qualitative measures in selecting resource options, and three of these also had to use a specific quantitative approach.

A state requirement that its regulated utilities consider environmental externalities was found to be positively related to 1992 DSM expenditures $(p=.0007)$, projected 1997 expenditures $(p=.002), 1992$ energy savings $(p=.02)$, and 1997 expenditures $(p=.007)$. The amount of variance explained by the presence of such a requirement ranged from about $20 \%$ for 1992 expenditures (R-Square $=0.1970$ ) to $9 \%$ for 1992 energy savings (R-Square $=0.0922$ ).

When we went beyond the simple question of whether or not externalities were considered and looked at the specific approaches to addressing externalities mandated by the states, we were able to explain substantially more of the variance in our dependent variables (Table 4.3). Over $48 \%$ of the variance in 1992 expenditures was explained by our regression model, nearly all of this (R-Square $=0.4494)$ by the use of three quantitative methods: percentage adders $(p=.0003)$; weighting and ranking ${ }^{25}(p=.01)$; and cost of control $(p=.03)$. This is a surprisingly large effect to be associated with a single category of regulatory requirement. The regression coefficients for these three variables were positive $0.0169,0.0233$, and 0.0079 , respectively. In other words, our

\footnotetext{
${ }^{25}$ Only a single state (Washington) reported using the weighting and ranking approach, so the coefficient associated with this variable should be accepted with some caution.
} 


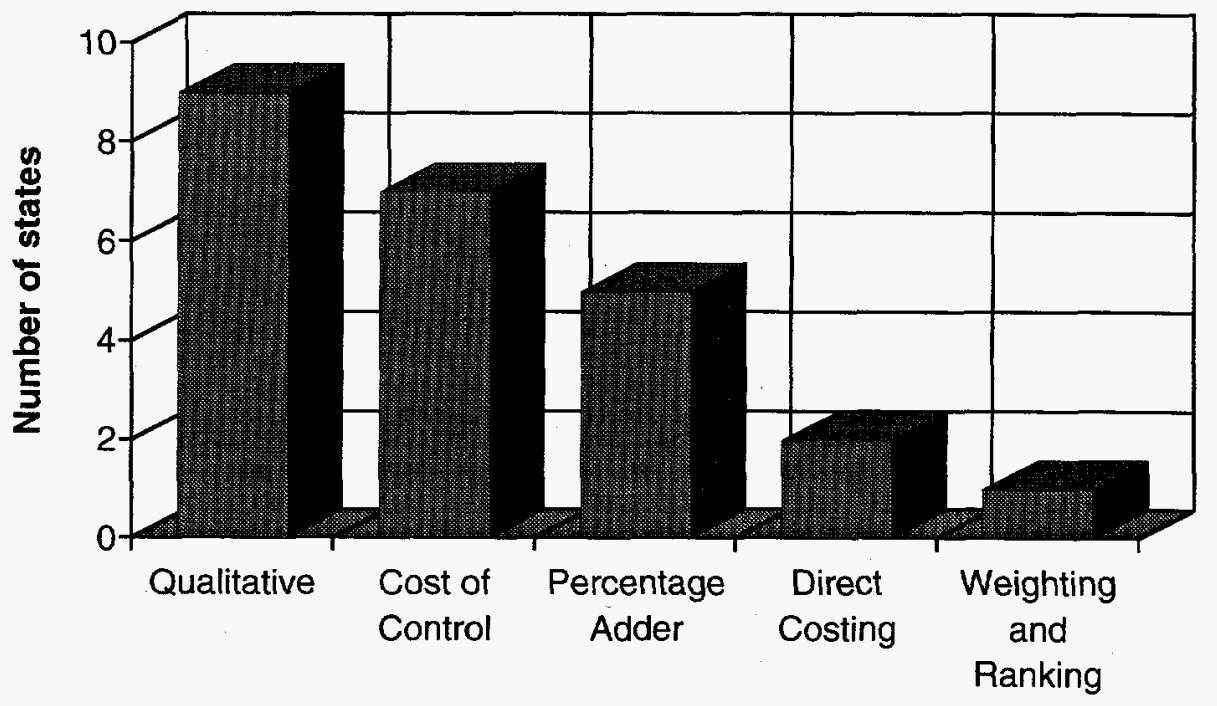

Type of externality cost method

Fig. 4.3. Number of states requiring utility use of various methods for treating environmental externalities.

Table 4.3. Relationships between key externality cost approaches and outcome measures ${ }^{a}$

\begin{tabular}{lcccccc}
\hline & \multicolumn{5}{c}{ Outcome measures } \\
\cline { 2 - 7 } & $\begin{array}{c}1992 \\
\text { DSM } \\
\text { expenditures }\end{array}$ & $\begin{array}{c}1997 \\
\text { DSM } \\
\text { expenditures }\end{array}$ & $\begin{array}{c}1992 \\
\text { energy } \\
\text { savings }\end{array}$ & $\begin{array}{c}1997 \\
\text { energy } \\
\text { savings }\end{array}$ & $\begin{array}{c}1992 \\
\text { peak } \\
\text { reduction }\end{array}$ & $\begin{array}{c}1997 \\
\text { peak } \\
\text { reduction }\end{array}$ \\
\hline $\begin{array}{l}\text { Use of } \\
\text { percentage } \\
\text { adders }\end{array}$ & $\mathrm{X}$ & $\mathrm{X}$ & & $\mathrm{X}$ & $\mathrm{X}$ & $\mathrm{X}$ \\
$\begin{array}{l}\text { Use of } \\
\text { weighting } \\
\text { and ranking }\end{array}$ & $\mathrm{X}$ & $\mathrm{X}$ & $\mathrm{X}$ & & \\
$\begin{array}{l}\text { Use of cost } \\
\text { of control }\end{array}$ & $\mathrm{X}$ & $\mathrm{X}$ & & & & \\
$\begin{array}{l}\text { Use of } \\
\text { qualitative } \\
\text { methods }\end{array}$ & & & $\mathrm{X}$ & & & \\
$\begin{array}{l}\text { R-Square } \\
b\end{array}$ & 0.4494 & 0.2018 & 0.2537 & 0.2412 & 0.0254 & 0.0977 \\
\hline
\end{tabular}

aSignificant relationships (i.e., p-value $=.05$ or less) are indicated with an $\mathrm{X}$.

${ }^{b}$ The R-Square value describes the proportion of the variance in the designated outcome measure explained by the significant independent variable(s). 
regression model estimated that - assuming that the use of all other available approaches was held constant-1992 DSM expenditures as a percent of retail revenues were approximately

1.7 percentage points greater in states that required the use of percentage adders, 2.3 percentage points greater in states that required weighting and ranking, and 0.8 percentage points greater in states that required the cost of control approach (a monetized method).

One or more approaches to treating externalities also were found to be significantly related to all the other measures of DSM usage, although the amount of variance explained was not nearly as great as for 1992 DSM expenditures. The use of adders was positively related to projected 1997 expenditures $(p=.04), 1997$ energy savings $(p=.02)$, and peak reduction in both $1992(p=.05)$ and $1997(p=.004)$. In addition, there was a positive relationship between the weighting and ranking approach and energy savings in $1992(p=.004)$ and $1997(p=.02)$. Finally, the qualitative approach was positively related to 1992 energy savings $(p=.04)$ and the cost of control method was positively related to projected 1997 expenditures $(p=.002)$. When the effects of the various significant independent variables were combined, we were able to explain about one-fourth of the variance in 1992 and 1997 energy savings (R-Square $=0.2537$ and 0.2412 respectively) and about one-fifth of the variance in 1997 DSM expenditures (R-Square=0.2018). The amounts of variance explained for 1992 and 1997 peak reduction were substantially smaller.

\section{TREATMENT OF DSM EXPENDITURES}

\section{Types of DSM Cost Recovery Mechanisms}

DSM program costs consist of capital and operating expenses. Utilities must account for and recover these costs from their customers in some manner. Until recently, PUCs would only allow their utilities to expense DSM outlays and recover them dollar-for-dollar on a current basis. In other words DSM expenditures were treated as annual operating expenses rather than as longer-term capital investments. However, many interested parties have argued that, to place DSM programs on an equal footing with supply-side resources, utilities should be able to amortize conservation and load control expenditures over a specific useful lifetime and earn a return at least equal to the utilities' approved return on equity (ROE).

State regulators currently utilize several different DSM cost recovery mechanisms (Nadel, Reid, and Wolcott 1992; Reid, Brown, and Deem 1993). A balancing account, or DSM rider, allows a utility to capitalize and amortize expenses and recover them through a surcharge to existing base rates. Deferred accounts allow the utility to set aside certain DSM charges for possible recovery in a future rate case. Ratebasing inserts specified DSM costs into the overall rate base of the utility and recovers them over time through rates. Each of the above methods can allow for the utility to earn a percentage return on the unamortized balance over the amortization period. Regulators can set the return at a specific index, at the approved rate of return on common equity, or at some premium to the ROE. A final form of cost recovery approved by some regulators is the use of energy service charges that allow a utility to recover costs from a surcharge imposed on customers who elect to participate in specific DSM programs. As with 
cost-effectiveness tests and externality evaluation, regulatory authorities can allow multiple methods for recovery of DSM program expenditures.

Nearly two-thirds of the states allowed utilities to expense their DSM costs, and just under half allowed utilities to include some DSM costs in the rate base. A number of states allowed both approaches, depending on the type of cost incurred. Thirty percent of the states allowed cost recovery through the use of a DSM rider, and the same number allowed utilities to defer expenses until the next rate case (Fig. 4.4). Finally, only three states approved energy service charges as a way to recover DSM costs. Over half the states allowed the use of more than one recovery mechanism, usually combining the expensing of operating costs with one of the other methods to recover capital costs.

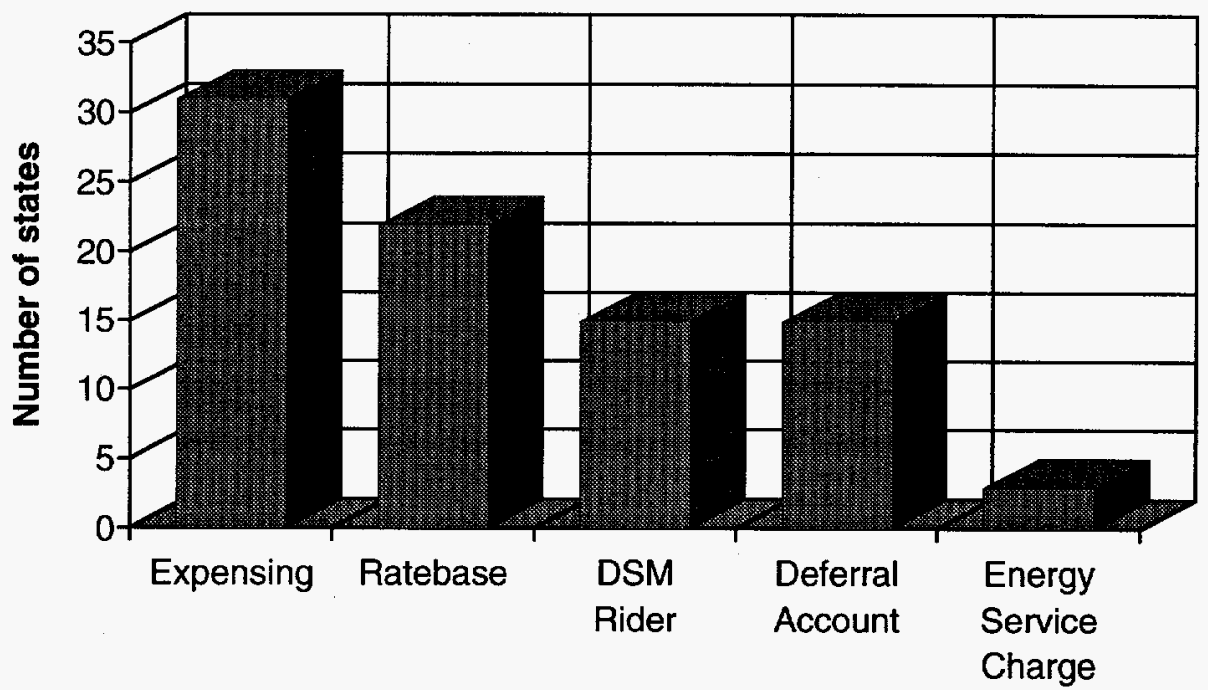

Type of DSM cost treatment

Fig. 4.4. Number of states allowing selected types of DSM cost recovery mechanisms.

Of the five methods for recovering DSM expenses that were examined, only one-the use of a rider mechanism-was found to be significantly related to DSM usage (Table 4.4). Positive relationships were found between the use of riders and 1992 DSM expenditures $(p=.04), 1992$ energy savings $(p=.02)$, and projected 1997 energy savings $(p=.02)$. The amount of variance in the dependent variables explained by the entire set of cost recovery mechanisms ranged from about $22 \%$ for 1997 energy savings to about $15 \%$ for 1992 DSM expenditures. The amount of variance explained by the use of riders alone was smaller than this-sometimes substantially-ranging from about $19 \%$ for 1997 energy savings $(R-S q u a r e=0.1869)$ to about $5 \%(R-S q u a r e=0.0483)$ for 1992 DSM expenditures.

\section{Allocation of DSM Costs}

An important consideration in recovering DSM expenditures is the manner in which these costs are allocated to the various classes of customers. A utility can either spread costs evenly to 
Table 4.4. Relationships between use of DSM rider to recover program costs and outcome measures ${ }^{a}$

\begin{tabular}{lccc}
\hline & \multicolumn{3}{c}{ Outcome measures } \\
\cline { 2 - 4 } & $\begin{array}{c}\text { 1992 DSM } \\
\text { expenditures }\end{array}$ & $\begin{array}{c}1992 \text { energy } \\
\text { savings }\end{array}$ & $\begin{array}{c}1997 \text { energy } \\
\text { savings }\end{array}$ \\
\hline Use of DSM rider & $\mathrm{X}$ & $\mathrm{X}$ & $\mathrm{X}$ \\
R-Square $^{b}$ & 0.0483 & 0.0740 & 0.1869 \\
\hline
\end{tabular}

aSignificant relationships (i.e., $\mathrm{p}$-value $=.05$ or less) are indicated with an $\mathrm{X}$.

${ }^{b}$ The R-Square value describes the proportion of the variance in the designated outcome measure explained by the significant independent variable.

all customer classes or the utility can charge the particular customer classes differently based on their program utilization. The latter measure is similar to energy service charges. More than twofifths of the states allowed their IOUs to allocate DSM program costs to specific customer classes.

\section{LOST REVENUE RECOVERY}

Once a utility is allowed a certain rate of return, profits are realized from each $\mathrm{kWh}$ of electricity that is sold. Thus, the more electricity a utility sells, the more profits it will accumulate. When a utility initiates a DSM program, any resulting reduction in electricity sales will cause revenues - and profits - to fall (Moskovitz, Harrington, and Austin 1992). To prevent this from occurring, several states allow for the recovery of lost revenues through various means. A revenue adjustment performed during a general rate case can recover revenues that had been lost as a result of DSM activities undertaken since the previous rate case. A DSM-specific adjustment mechanism allows utilities to recover lost revenues through surcharge or rider accounts that are periodically adjusted for under- (or over-) recovery; the same mechanism used to recover DSM program costs may be used to collect for lost revenues. Finally, there is the decoupling of profits from sales using either an $E R A M$-type mechanism ${ }^{26}$ or a revenue-per-customer $(R P C)$ arrangement ${ }^{27}$ (Nadel, Reid, and Wolcott 1992; Reid, Brown, and Deem 1993).

\footnotetext{
${ }^{26}$ The Electric Revenue Adjustment Mechanism (ERAM) was developed in California in 1982 as a means to eliminate the loss of base revenue caused by fluctuations in sales, specifically decreased sales as a result of conservation measures. A balancing account keeps track of actual and allowed revenues with annual adjustments made in attrition hearings. The balance in the account is collected (refunded) from ratepayers through a surcharge in the following year.

${ }^{27} \mathrm{RPC}$ decoupling sets fixed allowed revenues based on the average number of customers in a specified test-year. Any discrepancy between actual and allowed revenues is eliminated through a surcharge (refund) to rates in the following year.
} 
Approximately two-fifths of the states allowed IOUs to recover revenues lost as a result of their energy conservation programs. Of the PUCs allowing lost revenue recovery, over half claimed some sort of DSM-specific adjustment, such as a rider, while over a quarter reported the use of rate case adjustments (Fig 4.5). Only four states used decoupling. California and New York used the ERAM approach, while Maine and Washington used RPC as a means of decoupling sales from profits. Only New York allowed two methods to be used for lost revenue recovery: a DSMspecific adjustment mechanism and ERAM.

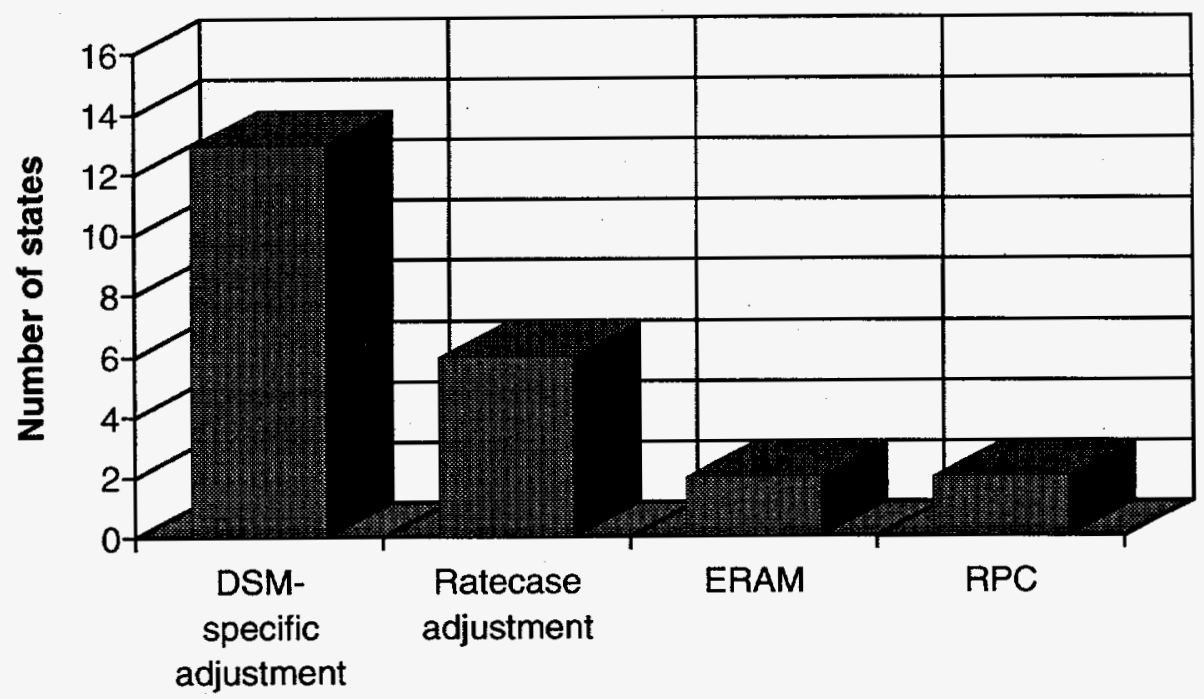

Type of lost revenue allowance

Fig. 4.5. Number of states using selected types of lost revenue recovery mechanisms.

A significant positive relationship was found between state regulations allowing utilities to recover lost revenues and three measures of DSM usage: 1992 expenditures $(p=.009), 1992$ energy savings $(p=.007)$, and projected 1997 energy savings $(p=.0005)$. The amount of variance explained by this factor ranged from $20 \%$ for projected savings (R-Square $=0.2032$ ) to $11 \%$ for 1992 DSM expenditures (R-Square $=0.1103$ ). When we ran a multiple regression analysis using the four possible lost revenue recovery mechanisms described above, we were able to explain more of the variance in the dependent variables (Table 4.5). One lost revenue recovery mechanism - the revenue per customer approach - was found to be positively related to 1992 expenditures $(p=.001)$ and to energy savings for $1992(p=.0001)$ and $1997(p=.007){ }^{28}$ By itself, the use of this form of decoupling explained $25 \%$ of the variance in 1992 energy savings (R-Square $=0.2509$ ) and $16 \%$ of the variance in 1992 expenditures (R-Square $=0.1603$ ). Together with the use of the DSM-specific adjustment mechanism, the revenue per customer approach accounted for over $20 \%$ of the variance in projected 1997 energy savings (R-Square $=0.2039$ ). In all cases, the amount of variance explained by the entire regression equation (including the lost

\footnotetext{
${ }^{28}$ This approach was used in two states: Maine and Washington.
} 
revenue recovery approaches that were not found to be significantly related to DSM usage) was four to seven percentage points greater.

Table 4.5. Relationships between use of key lost revenue recovery approaches and outcome measures ${ }^{a}$

\begin{tabular}{lccc}
\hline & \multicolumn{3}{c}{ Outcome measures } \\
\cline { 2 - 4 } & $\begin{array}{c}1992 \mathrm{DSM} \\
\text { expenditures }\end{array}$ & $\begin{array}{c}1992 \text { energy } \\
\text { savings }\end{array}$ & $\begin{array}{c}1997 \text { energy } \\
\text { savings }\end{array}$ \\
\hline $\begin{array}{l}\text { Use of revenue per customer } \\
\text { arrangement }\end{array}$ & $\mathrm{X}$ & $\mathrm{X}$ & $\mathrm{X}$ \\
$\begin{array}{l}\text { Use of DSM-specific adjustment } \\
\text { mechanism }\end{array}$ & & & $\mathrm{X}$ \\
R-Square $^{b}$ & 0.1603 & 0.2509 & 0.2039 \\
\hline
\end{tabular}

${ }^{a}$ Significant relationships (i.e., $\mathrm{p}$-value $=.05$ or less) are indicated with an $\mathrm{X}$.

${ }^{b}$ The R-Square value describes the proportion of the variance in the designated outcome measure explained by the significant independent variable(s).

\section{FINANCIAL INCENTIVES FOR DSM USE}

\section{Types and Magnitude of Financial Incentives}

In order to increase utility investment in DSM programs, some regulators have provided financial incentives that reward utilities for aggressive use of DSM resources. Such mechanisms have the potential to make DSM a profit center equal in return to supply-side resources. A shared savings incentive allows utilities a certain percentage of savings that are achieved due to DSM programs. A markup or performance adder rewards utilities with aggressive DSM programs with a certain percentage of their DSM program costs. Some regulators use a $R O E$ adjustment to increase utilities' overall rate of return for successful DSM performance. A rate-based bonus $R O E$ awards only DSM expenditures included in the rate base with a return higher than for supply-side investments. A bounty-per-unit allows utilities to earn a set amount per unit of energy (in kilowatts or kWh) saved through DSM (Reid, Brown, and Deem 1993).

Half the states reported awarding some type of incentive to their regulated utilities for DSM performance. Over three-quarters of these states employed the shared savings approach, while nearly a third used rate-based bonus ROE (Fig. 4.6). Bounty-per-unit incentives were used by a fifth of the states allowing DSM awards, while nearly as many adjusted overall ROE for aggressive DSM performance. Only two states used performance adders as a method of rewarding utilities for their DSM activities. Nearly half the states allowing incentives offered multiple incentive mechanisms, generally a combination of the shared savings approach and another mechanism. In 1992, approved incentives ranged from $\$ 150,000$ to $\$ 72,000,000$. 


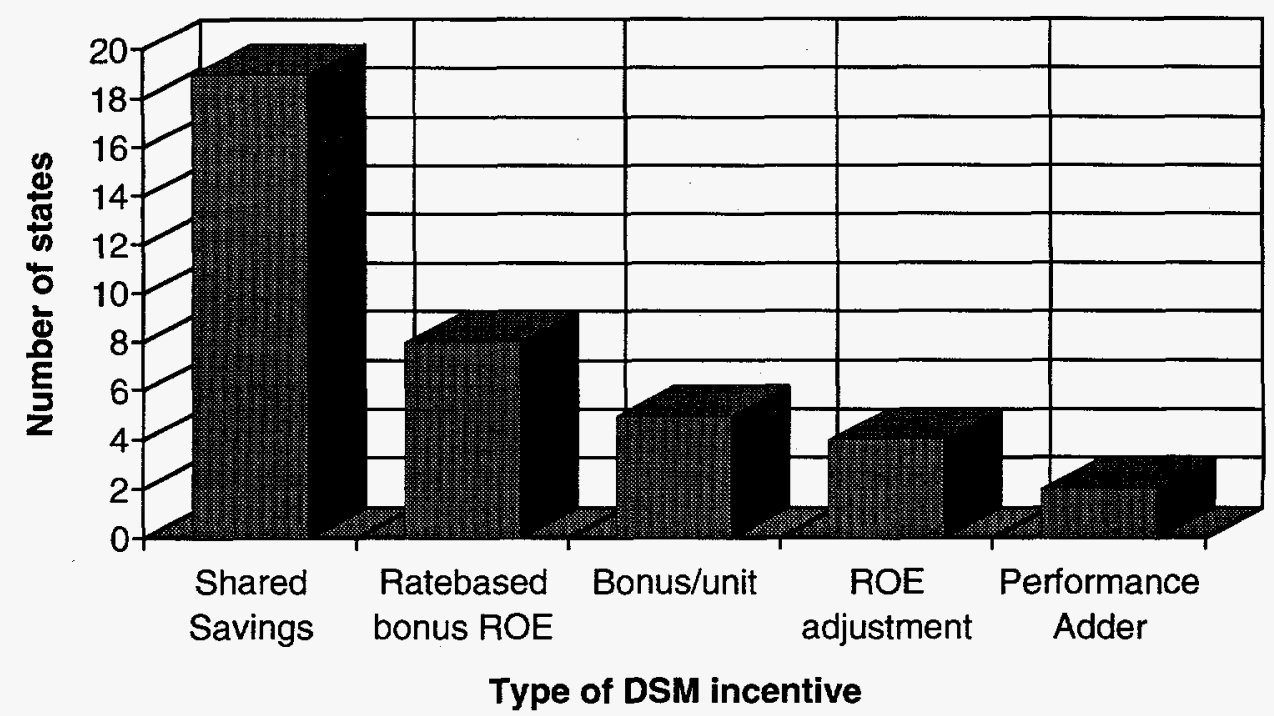

Fig. 4.6. Number of states using different types of DSM incentive mechanisms.

States that awarded financial incentives were found to have greater utility DSM usage than the other states in terms of 1992 DSM expenditures $(p=.0006)$, projected 1997 expenditures $(p=.01), 1992$ energy savings $(p=.01)$, and 1997 expenditures $(p=.0001)$. The simple fact of whether or not a state provided incentives accounted for over $27 \%$ of the variance in projected 1997 energy savings (R-Square $=0.2740$ ), nearly $20 \%$ of the variance in 1992 DSM expenditures (R-Square $=0.1976$ ), and about $10 \%$ of the variance in 1992 energy savings (R-Square $=0.1076$ ) and 1997 expenditures $(\mathrm{R}-\mathrm{Square}=0.0949)$.

Constructing a multiple regression equation containing the five different incentive mechanisms described above allowed us to account for substantially more of the variance in DSM usage (Table 4.6). Our complete model explained over $40 \%$ of the variance in 1992 DSM expenditures, with the use of two mechanisms-bounty-per-unit $(\mathrm{p}=.0004)$ and shared savings $(p=.02)$-accounting for nearly all $(R-S q u a r e=0.3740)$ of the observed variance. As with environmental externalities, this is a surprisingly large effect to be associated with a single category of regulatory requirement. Our regression coefficients were 0.0195 for the bounty and 0.0058 for shared savings, meaning that, all else being equal, 1992 DSM expenditures as a percent of retail revenues were estimated to be nearly 2 percentage points greater in states that allowed the use of a bounty and 0.6 percentage points greater in states with a shared savings mechanism.

Our complete model also explained over $38 \%$ of the variance in 1997 energy savings. In this case, shared savings $(p=.002)$, bounty-per-unit $(p=.01)$, and performance adders $(p=.02)$ accounted for the large majority $(R-S q u a r e=0.3095)$ of the variance among states. The regression coefficients were 0.0202 for shared savings, 0.0287 for the bounty, and 0.0508 for the performance adder. 
Table 4.6. Relationships between use of key financial incentive mechanisms and outcome measures ${ }^{a}$

\begin{tabular}{|c|c|c|c|c|}
\hline & \multicolumn{4}{|c|}{ Outcome measures } \\
\hline & $\begin{array}{c}1992 \text { DSM } \\
\text { expenditures }\end{array}$ & $\begin{array}{l}1992 \text { energy } \\
\text { savings }\end{array}$ & $\begin{array}{c}1997 \text { energy } \\
\text { savings }\end{array}$ & $\begin{array}{l}1997 \text { peak } \\
\text { reduction }\end{array}$ \\
\hline Use of bounty & $\mathbf{X}$ & $\mathbf{X}$ & $\mathbf{X}$ & \\
\hline $\begin{array}{l}\text { Use of shared } \\
\text { savings }\end{array}$ & $\mathbf{X}$ & & $\mathrm{X}$ & $\mathbf{X}$ \\
\hline $\begin{array}{l}\text { Use of } \\
\text { performance } \\
\text { adder }\end{array}$ & & $X$ & $\mathbf{X}$ & \\
\hline $\mathbf{R}$-Square ${ }^{b}$ & 0.3740 & 0.2159 & 0.3095 & 0.0677 \\
\hline
\end{tabular}

aSignificant relationships (i.e., p-value $=.05$ or less) are indicated with an $\mathrm{X}$.

${ }^{b}$ The R-Square value describes the proportion of the variance in the designated outcome measure explained by the significant independent variable(s).

Together, the performance adder $(\mathrm{p}=.008)$ and bounty mechanism $(\mathrm{p}=.01)$ accounted for almost $22 \%$ (R-Square $=0.2159$ ) of the variance in 1992 energy savings. And, by itself, the shared savings mechanism $(p=.03)$ accounted for almost 7\% (R-Square=0.0677) of the variance in 1997 peak reduction.

\section{Methods Used to Calculate Energy Savings and Load Reduction}

Nearly all the states that offer incentives expect their utilities to substantiate energy savings and load reduction in some manner. Self-regulated utilities also use various performance measures to evaluate their own DSM programs (Nadel, Reid, and Wolcott 1992). The use of engineering estimates is the easiest and least-costly method, in that it relies on estimated (rather than observed) figures of energy savings and load reductions due to the various DSM programs. Metering measures savings directly from a sample of actual participants (and perhaps a control group) and uses this to calculate overall DSM program effects. The analysis of billing data involves the examination of samples of customer bills before and after the installation of DSM programs to measure the resulting savings.

Of those states that offered DSM incentives, over four-fifths reported the method or methods that they allowed their utilities to use to verify program effects. All but one of the states that reported the use of performance measures allowed engineering estimates to be used. Nearly half of the states reporting the methods used by their utilities to calculate DSM program effects allowed the analysis of billing data, and nearly the same number allowed metering to be used. Two-thirds of the reporting states allowed the use of more than one method. In nearly all cases, these regulators specified the use of engineering estimates in conjunction with one of the other. 
verification methods. No significant relationship was found between DSM usage and any of the methods used to calculate program effects.

\section{Incentive Thresholds, Caps, and Penalties}

In order for a utility to begin earning incentives, many regulators require a certain performance threshold to be reached. There also are incentive caps to limit the financial gain that utilities can receive from their DSM efforts. In addition, penalties may accrue to utilities that do not meet their projected goals (EEI 1993b).

Nearly two-thirds of the states offering incentives required some performance threshold to be reached before utilities could earn incentives (Fig. 4.7). The threshold could be as simple as meeting $50 \%$ of the projected utility energy savings or as complex as a matrix taking into account both energy savings and cost efficiency. Two-fifths of the states allowing incentives placed a cap on how much a utility may earn. This cap can be a dollar figure, a maximum percentage of shared savings, or a maximum number of basis points added to ROE. Over half the states allowing incentives placed a penalty on utilities that failed to reach their specified savings threshold.

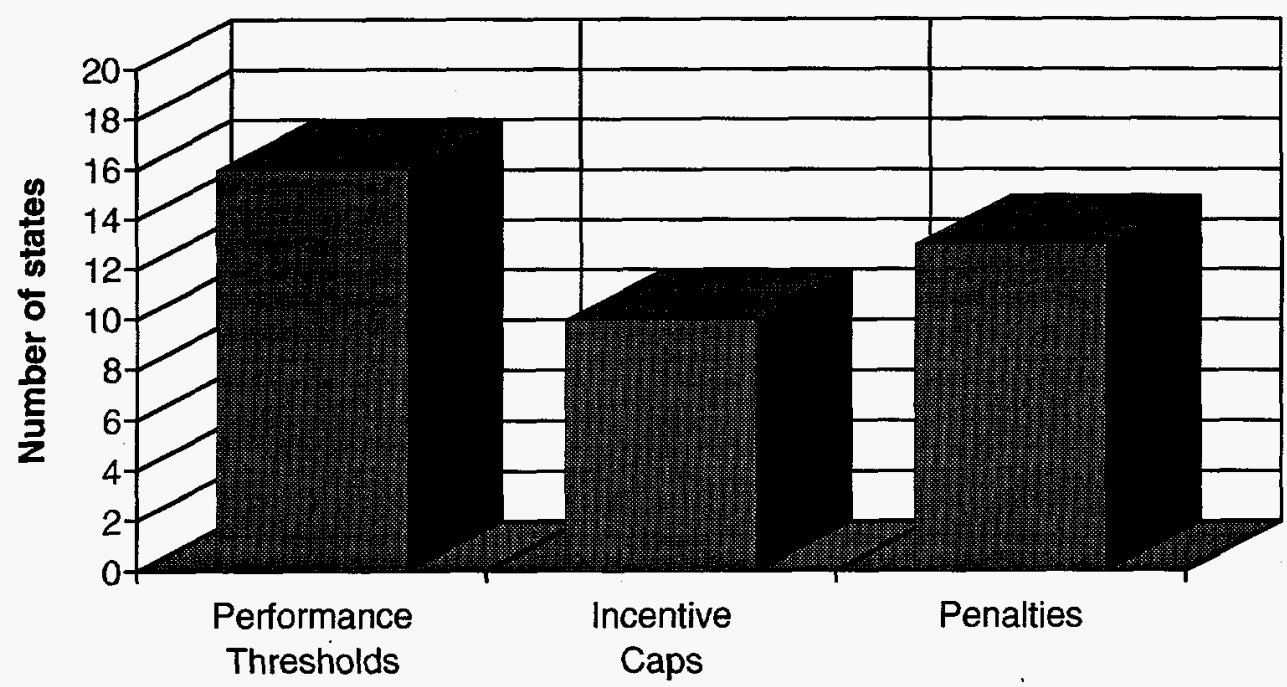

Mechanism in Use

Fig. 4.7. Number of states using incentive thresholds, caps, and penalties for poor performance.

The presence of a threshold requirement $(\mathrm{p}=.02)$, by itself, was found to account for slightly more than $20 \%$ of the variance in 1992 DSM expenditures (R-Square $=0.2043$ ) among states that granted incentives. The use of a penalty mechanism $(p=.05)$ and the use of incentive 
caps, when placed together in a multiple regression equation, explained over $18 \%$ of the variance in 1992 expenditures ( $R$-square $=0.1855) .{ }^{29}$

\section{ALL REGULATORY REQUIREMENTS}

We performed a stepwise regression analysis on the state data set using the significant regulatory factors identified above to see how much of the variance in our measures of DSM usage could be explained by all key regulatory variables combined. ${ }^{30}$ Eight regulatory variables were identified that together accounted for nearly $70 \%$ of the variance in 1992 DSM expenditures (R-Square $=0.6937)$ among the states. These variables were: the use of bounties $(p=.0001)$, shared savings $(p=.04)$, and performance adders $(p=.07)^{31}$ as financial incentive mechanisms; the use of adders $(p=.001)$, weighting/ranking $(p=.02)$, and cost of control $(p=.03)$ as techniques for addressing environmental externalities; the frequency with which IRPs were prepared $(p=.003)$; and the requirement that some specific cost-effectiveness test be used in the development of integrated plans $(p=.04)$. With the exception of the cost-effectiveness test requirement, the coefficients associated with all these variables were positive and ranged from 0.0187 for the use of weighting and ranking to 0.0050 for the cost of control approach to addressing environmental externalities. ${ }^{32}$ Four of the seven binomial variables used in this equation had coefficients greater than 0.01, meaning that - all else being equal-1992 DSM expenditures as a percent of retail revenues were estimated to be at least one percentage point greater in states using the specific approach or mechanism in question.

Our stepwise regression also explained substantial variance in other measures of DSM usage. This analysis explained almost $57 \%$ of the variance in 1992 energy savings (R-Square= 0.5671 ) and $52 \%$ of the variance in projected 1997 energy savings $(R-S q u a r e=0.5174)$. The amount of variance explained in the remaining measures of DSM usage was smaller, ranging from $29 \%$ for projected 1997 peak reduction $(\mathrm{R}-\mathrm{Square}=0.2885$ ) to $13 \%$ for 1992 peak reduction (RSquare $=0.1310$ ). The use of a revenue per customer approach to recovering lost revenues

\footnotetext{
${ }^{29}$ The use of an incentive cap was not significant at the .05 level when analyzed in a multiple regression equation with the use of penalties. By itself in a linear regression analysis, the use of a penalty mechanism explained less than $9 \%$ of the variance in 1992 expenditures $(R-S q u a r e=0.0869)$ and was not significant at the .05 level.

${ }^{30}$ As noted earlier, many of the variables studied are highly correlated with each other. Accordingly, it is likely that several different sets of regulatory variables could be created to account for nearly as much variance in DSM usage as the variables identified through our stepwise regression.

${ }^{31}$ While we normally use .05 as a threshold level for statistical significance, we have included this variable because its p-value is not substantially above .05 and, more importantly, because it was shown to be significantly related to DSM usage through our earlier hypothesis tests.

${ }^{32}$ The one variable that was negatively related to DSM expenditures was the cost-effectiveness test requirement, which explained less than $3 \%$ of the variance in DSM expenditures. The reader must remember that the relationship identified here applies only in the presence of all other independent variables in the multiple regression equation. The requirement for a cost-effectiveness test, by itself, does not have a negative effect on DSM usage. However, in the presence of numerous other factors that tend to encourage increased investment in DSM resources, a cost-effectiveness test requirement could act to lower DSM expenditures somewhat by encouraging more economical program choices.
} 
$(p=.0001)$ proved to be very significantly related to 1992 energy savings, while the simple fact of whether or not financial incentives were given $(p=.0002)$ was important in explaining 1997 energy savings. The use of a DSM rider for recovering DSM expenditures was significantly related to energy savings for both $1992(p=.005)$ and $1997(p=.003)$. 


\section{CONCLUSIONS}

This chapter summarizes and interprets the analytical findings presented in the preceding chapters, first for environmental factors and then for regulatory requirements. It concludes with a discussion of the role that regulators play in influencing utility DSM usage and with suggestions concerning what they can do to promote cost-effective DSM.

\section{KEY ENVIRONMENTAL CHARACTERISTICS}

The extent to which PUCs supported the use of collaboratives and workshops as mechanisms to obtain public involvement on important policy and program issues was more strongly related to DSM usage by the IOUs than was any other environmental factor. The relationship between the support for collaboratives and DSM usage was positive, while the opposite was true concerning regulator support for workshops and associated DSM usage. In combination, these two approaches to obtaining public involvement explained about two-fifths of the variance in both DSM expenditures and energy savings for 1992, and nearly as much of the variance in projected 1997 energy savings. It is likely that the use of collaboratives or other highly interactive public involvement mechanisms, which engage utilities in intense sharing of technical and policy-related ideas with energy efficiency advocacy groups and environmentalists (among others), did indeed exert some influence on utilities to more actively pursue the use of DSM resources. However, commission support for collaboratives frequently coexisted with other regulatory policies-such as support for DSM incentives-that themselves had a direct effect on utility DSM usage.

The next most powerful environmental factor influencing DSM usage was regulatory support for utility load building. Not surprisingly, the relationship between these variables was negative, indicating that utilities operating in states that most strongly favored load building responded by pursuing DSM resources less vigorously than did their cohorts in other states. Interestingly, this variable explained substantially more of the variance in projected 1997 energy savings than of any other measure of DSM usage. The implication of this is that utilities tended to interpret regulatory support for load building as a lack of support for programs to save future energy and designed their plans accordingly.

Finally, we found that DSM expenditures were lower in those states with less immediate need for new peaking and baseload resources. As with support for load building, the effect of this need for power was much more evident in projected future activities than in present actions. This indicates that, as it becomes more immediate, the need for power is likely to have an increasing effect on utility DSM spending patterns. Another interesting finding was that the need for baseload resources was much more strongly linked to utility DSM expenditures than was the need for peak resources, suggesting that reducing the need for more expensive baseload units might provide utilities with a better incentive to pursue DSM resources. 
As mentioned in Chapter 3, a combined analysis using all the above factors was able to account for over half of the variance in the states' 1992 DSM expenditures and for substantial (but smaller) amounts of the variance in most of the other measures of DSM usage. Clearly, the regulatory environment can have an important influence on utilities' decisions regarding their pursuit of DSM resources. Of course, these environmental factors are closely tied to the regulatory requirements that are established to guide utility actions, which is discussed next.

\section{KEY REGULATORY REQUIREMENTS}

Of all the regulatory requirements studied, the approaches used to treat environmental externalities and grant financial incentives to IOUs stood out from the others as having the greatest influence on utility DSM usage. Lost revenue recovery and IRP requirements were found to be moderately important in terms of their relationship to utility use of DSM resources. DSM cost recovery approaches and cost-effectiveness tests, while not unimportant, were least strongly linked to DSM use.

In combination, three possible approaches to treating environmental externalities-the use of adders, weighting and ranking, and cost of control—explained well over two-fifths of the observed variance in the states' 1992 DSM expenditures. Sizable amounts of the variance in future expenditures and in current and projected energy savings also were explained, but these relationships were not nearly as strong as for 1992 expenditures. The use of adders also was one of the few regulatory variables that was significantly related to peak reduction, although the amount of variance explained was small. Our findings clearly show that the use of externalities, which serves to improve the cost-effectiveness of DSM resources relative to supply-side alternatives, had a strong and immediate effect on utility investment in DSM programs. The motivating force here appears to be not as much the achievement of energy savings or peak reduction as the allocation of fiscal resources in the most cost-effective manner possible.

Two incentive mechanisms, the use of bounties and shared savings, together accounted for nearly two-fifths of the variance in 1992 DSM expenditures. These two approaches plus the use of performance adders explained almost one-third of the observed variance among states in terms of projected 1997 energy savings, and the use of performance adders and bounties explained slightly more than one-fifth of the variance in 1992 energy savings. In addition, we found a relatively weak connection between the shared savings approach and projected 1997 peak reduction. These findings tell us that the provision of financial incentives by state regulators had a more powerful effect on utilities' immediate expenditures and their intentions regarding future energy savings than on other measures of DSM usage. Clearly, the ability of regulators to affect the profitability associated with various utility resource portfolios is a powerful tool for influencing DSM investment.

Regulatory approval of a revenue per customer approach to recovering lost revenues (a form of decoupling) explained one-fourth of the observed variance in 1992 energy savings and also was significantly related (but not as strongly) to projected 1997 energy savings and 1992 DSM expenditures. Projected energy savings also were associated with the use of a DSM-specific 
adjustment mechanism, like a rider. By allowing utilities to recover lost revenues, and especially by approving the decoupling approach, PUCs apparently have encouraged utility DSM usage. It is no accident that regulatory approval of lost revenue recovery was most closely tied to energy savings measures, since the purpose of lost revenue recovery is to increase the attractiveness of energy conservation programs by keeping revenues from declining due to DSM-induced reductions in electricity sales.

Both the length of time that IRP has been required and the frequency with which integrated plans must be prepared were positively related to various measures of DSM usage. The length of time since planning was mandated explained nearly one-fifth of the variance in 1992 DSM expenditures and somewhat less than this for both measures of energy savings. The frequency of plan preparation accounted for one-sixth of the variance in 1992 expenditures and slightly less than that for projected expenditures and for energy savings (1992 and 1997). The frequency with which plans were prepared even explained a small amount of the variance in 1997 peak reduction. The message from these results is that states that pushed IRP and required their utilities to become experienced in plan preparation tended to experience greater DSM usage, as measured in a wide variety of ways.

The use of a rider mechanism to recover DSM program costs explained slightly less than one-fifth of the variance among states in projected 1997 energy savings and substantially less than that for 1992 energy savings and DSM expenditures. Apparently, the use of a rider to recover DSM outlays in a timely manner encouraged utilities to invest in DSM programs, but it is unclear why this factor was so much more strongly related to future energy savings than to any other measure of DSM usage.

States that required their regulated utilities to apply a specific cost-effectiveness test in the development of their integrated plans experienced greater DSM expenditures and projected future energy savings, but these relationships were relatively weak. No clear finding emerged about the effectiveness of any particular test in promoting utility DSM usage.

An analysis of all state regulatory requirements that were significantly related to utility DSM usage explained nearly $70 \%$ of the variance in 1992 DSM expenditures, more than half of the variance in energy savings for 1992 and 1997, and some fraction of the savings for the remaining measures of DSM usage. This, in conjunction with the individual relationships discussed above, clearly illustrates the power of state regulatory requirements to influence utility use of DSM resources. 


\section{IMPLICATIONS FOR REGULATORS}

The preceding sections of this chapter have shown the importance of key regulatory requirements and environmental characteristics in influencing utilities to use DSM resources. ${ }^{33}$ There is little doubt that regulators have played a vital role in encouraging more aggressive use of DSM resources by utilities through their regulations concerning environmental externalities, financial incentives, and other subjects as well as by their support for highly interactive approaches to obtaining public involvement on important policy and program issues. It should be noted that the key variables identified in this study did a poorer job of explaining utility efforts to reduce peak demand than they did for DSM expenditures and energy savings. This indicates that either peak reduction was driven by factors that were not included in our study or that the peak reduction numbers provided by the utilities were not consistently accurate.

The amount of variance in DSM expenditures and energy savings explained by each significant variable is illustrated in Figs. 5.1 and 5.2. A basic factor that appears to underlie many of the environmental and regulatory variables that were found to be strongly related to DSM expenditures and energy savings is a desire by the PUC to put DSM on an equal footing with supply-side resources and a support for aggressive utility use of those demand-side resources that prove to be beneficial. Our findings indicate that utility interest in vigorously providing DSM services to customers owes much to the efforts of regulators to encourage such activities. And it appears that, without continued strong PUC policies, utility DSM efforts could falter.

Regulatory policies that have encouraged IOUs to increase their DSM expenditures and energy savings have done so by getting utilities to examine potential DSM resources, by ensuring that a broad range of interests are actively represented in the process, by increasing the costeffectiveness of DSM relative to the alternatives, and by ensuring that the aggressive pursuit of demand-side resources will enhance - or at the very least will not diminish-utility revenues and profits. In this report, we have identified the specific mechanisms by which this has been accomplished. However, it is important to note that these findings reflect the situation that existed as of 1992, before the issues of competition and potential deregulation assumed the greater importance that they currently hold for utilities and their regulators. The fact that the regulatory environment appears to be on the brink of changing - perhaps dramatically-means that the specific factors that we have identified as influencing utility DSM usage may not be as potent in the coming years. For example, financial incentives for the aggressive use of DSM would not be as attractive in the future if the resources chosen necessitate an increase in utility rates that drive large industrial customers off the system, ultimately resulting in an overall drop in revenues. But while the effects of specific policies will undoubtedly change as the regulatory climate is transformed, utilities' desire to operate profitably will remain constant. For regulators with an interest in promoting the continued use of cost-effective DSM resources, the challenge is to

\footnotetext{
${ }^{33} \mathrm{~A}$ stepwise regression analysis combining all significant regulatory and environmental factors enabled us to explain more of the variance in nearly all our measures of DSM usage than we were able to explain with either the regulatory or environmental factors by themselves. For 1992 DSM expenditures, our combined set of variables explained over $73 \%$ of the observed variance.
} 


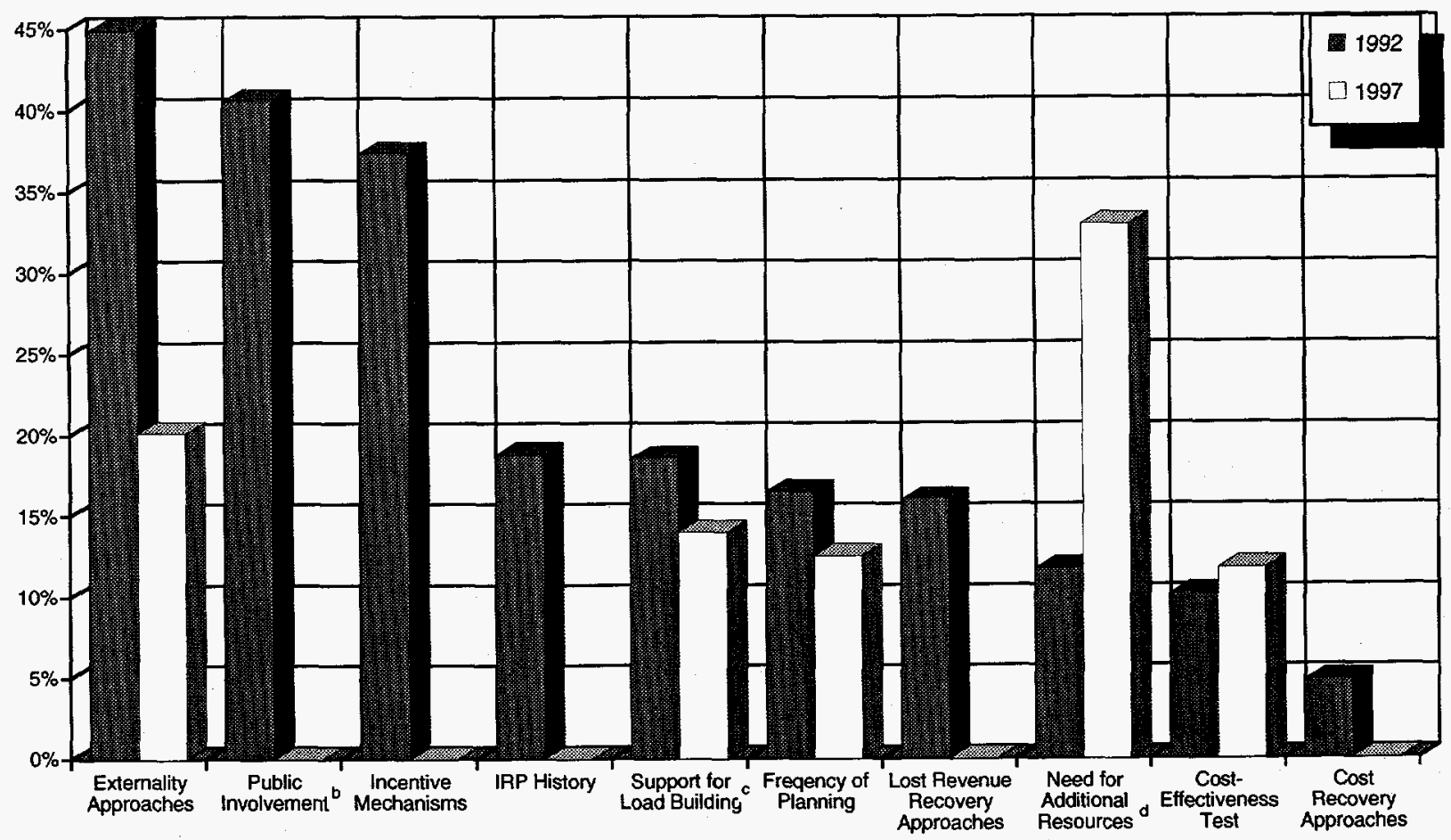

Fig. 5.1. Amount of variance in DSM expenditures explained by key independent variables. ${ }^{\mathrm{a}}$

${ }^{2}$ Each bar represents the amount of variance explained by the independent variable (or variables) found to be significant at least at the .05 level. These findings come from the individual tests of each related set of variables and not from the combined analysis of all significant variables. Due to multicollinearity, the bars cannot be summed to get total variance explained by all factors combined.

${ }^{b}$ Regulator support for collaboratives was positively related to DSM expenditures while support for workshops was negatively related to this measure.

${ }^{\circ}$ Regulator support for load building programs was negatively related to DSM expenditures

dThe number of years until new baseload resources will be needed was negatively related to 1992 DSM expenditures, while the number of years until both new baseload and new peaking resources will be needed was negatively related to projected 1997 expenditures.

understand the changing dynamics of the new world we are living in and to adopt policies that continue to make DSM a desirable option.

We recommend that state regulators begin their search for workable approaches to encouraging utility DSM usage by examining the factors identified in this report as having had important effects on utility decisions to use DSM resources. For each policy (e.g., the support for collaboratives) and regulatory requirement (e.g., the requirement that environmental externalities be addressed), regulators must ask themselves whether the relationships identified in this study are likely to hold now and in the foreseeable future. For instance, will changing conditions in a given 


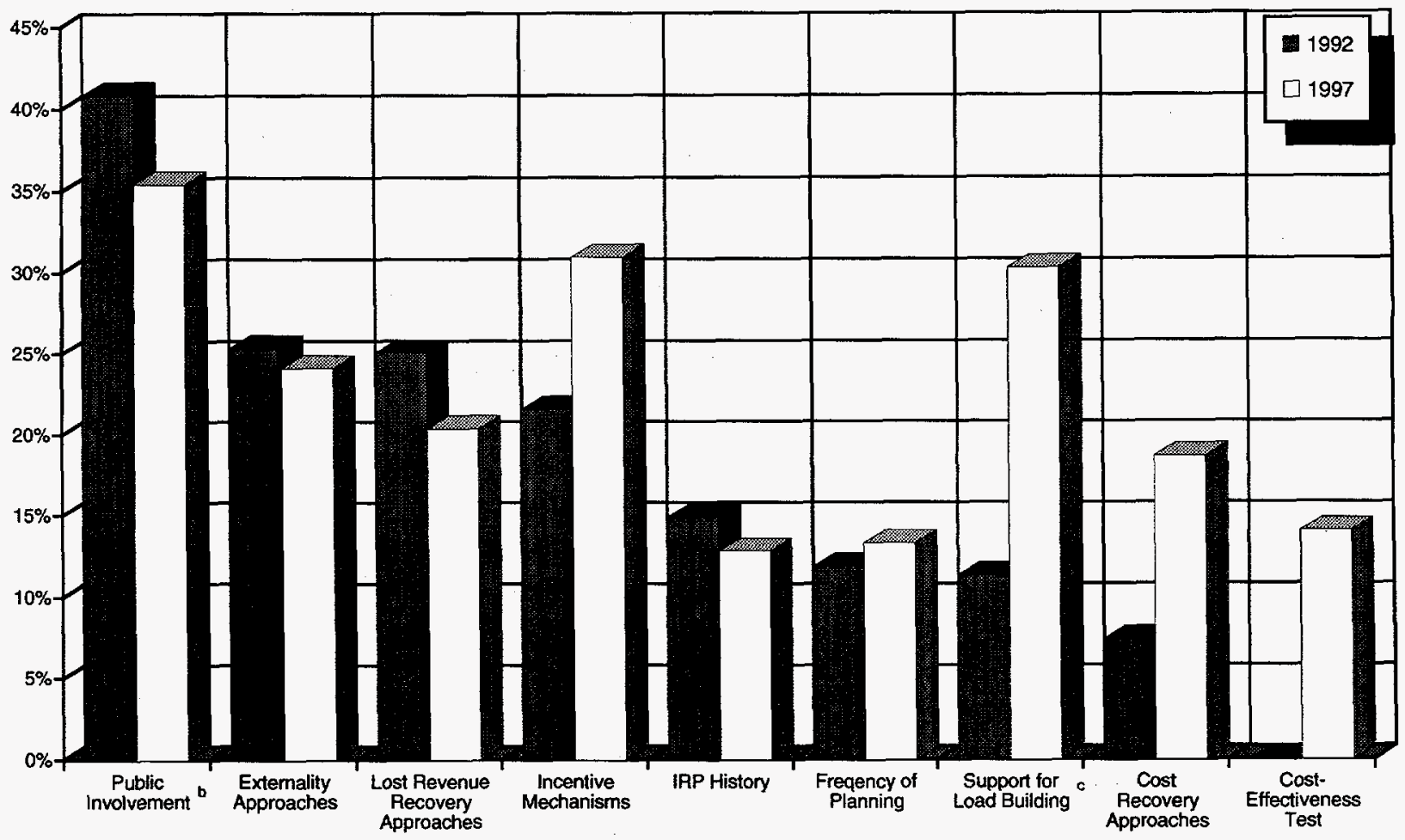

Fig. 5.2. Amount of variance in energy savings explained by key independent variables. ${ }^{a}$

a Each bar represents the amount of variance explained by the independent variable (or variables) found to be significant at least at the .05 level. These findings come from the individual tests of each related set of variables and not from the combined analysis of all significant variables. Due to multicollinearity, the bars cannot be summed to get total variance explained by all factors combined.

begulator support for collaboratives was positively related to energy savings while support for workshops was negatively related to these measures.

'Regulator support for load building programs was negatively related to energy savings.

state keep a revenue per customer approach to lost revenue recovery from encouraging greater DSM usage like it did in 1992 ? Will the selection of DSM resources whose cost-effectiveness is enhanced by the use of environmental externality adders continue to be attractive to utilities in light of their heightened concern with competitiveness? And will any actions taken by state regulators themselves to promote competition have negative effects on utility DSM usage? Our guess is that a number of the relationships identified in this report will continue to hold in many states, at least in the near-term future, but it would be wise for each regulatory agency to consider the relevance of our findings to their own jurisdiction and to be cognizant of how their own actions might change things. 
Once the approaches suggested in this report have all been considered, the next step is to consider potential new policies and regulations to encourage the beneficial use of DSM resources. First, within the topical areas covered in this study, might any of the specific approaches that were found to be unimportant assume greater importance in the coming years? For example, could energy service charges become a more important type of DSM cost recovery mechanism than this study showed it to be? Then, it would be worthwhile for regulators to search for new types of actions that they can take to encourage utilities to continue their use of cost-effective DSM. Such actions, which go beyond the scope of this report, could include steps to discourage large customers from leaving the system as a result of DSM-related price increases or to compensate utilities with active DSM programs for revenue losses incurred as a result of such defections. By combining new regulatory approaches with those that have proven effective in the past and promise to be useful in the future, regulatory agencies can continue the progress they have made in encouraging utility use of cost-effective demand-side resources. 


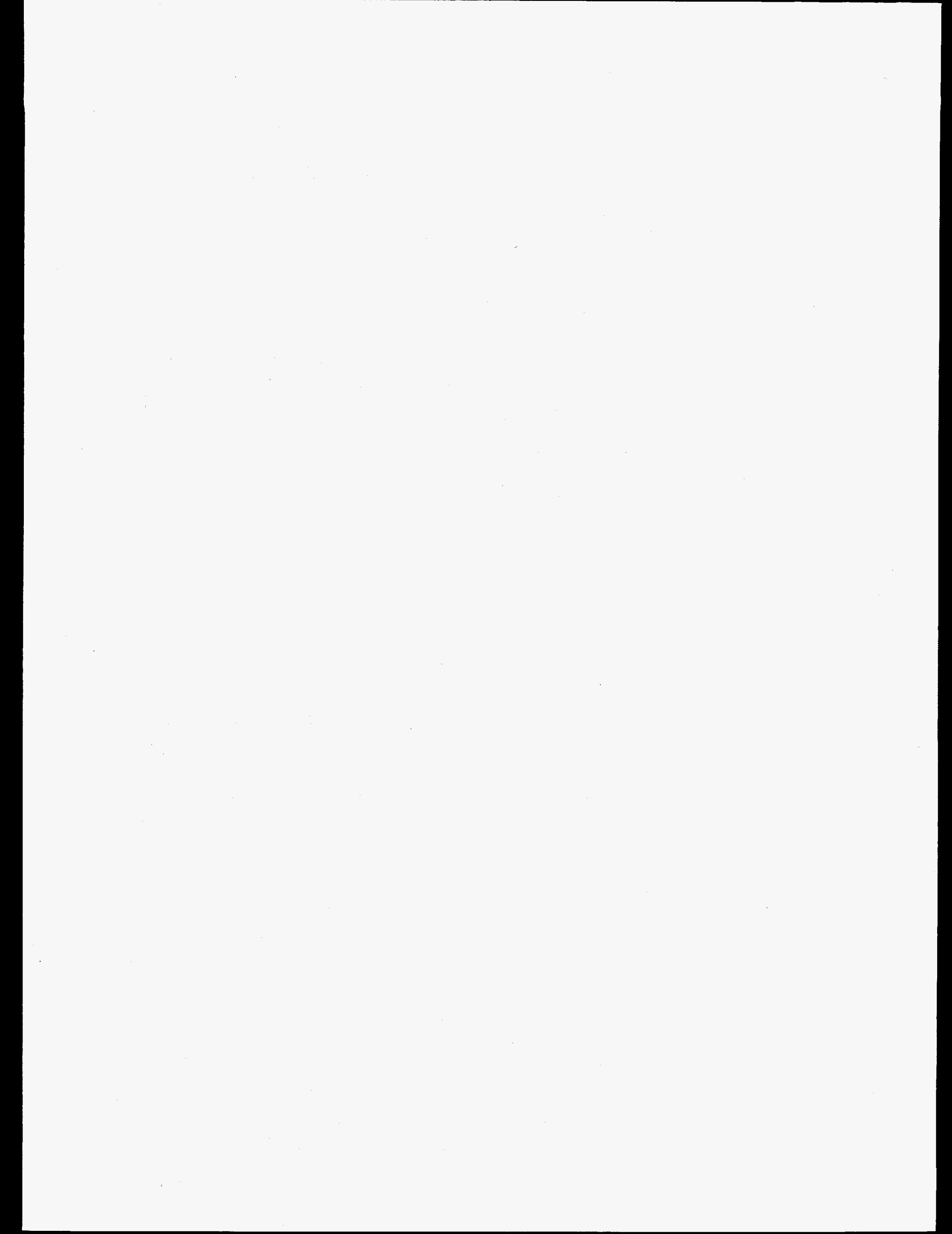




\section{ACKNOWLEDGMENTS}

We thank all those staff members of state regulatory agencies and consumer-owned utilities who took the time to provide us with information concerning the environment in which utilities operate and to describe specific regulatory requirements. This report would not have been possible without their help. Special thanks go to Mary Kilmarx, Ken Rose, and Steve Weil, who provided us with valuable feedback on our proposed research design. We likewise are grateful to Linda Bromley, Julia Brown, Scott Brown, Mike Foley, Gary Garnant, and Bill Wilson, whose input was especially helpful during the course of our study. We wish to acknowledge the contributions of Les Baxter, Tom Devlin, Joe Eto, Diane Pirkey, and Steve Puican, who reviewed and commented on a draft of this document. Eric Hirst provided important guidance and feedback throughout this project, from its inception through report preparation. Finally, we wish to thank Mariann Huskey and Ethel Schorn for preparing this document. 


\section{REFERENCES}

Edison Electric Institute 1992a, Environmental Externalities: An Issue Under Critical Review, Washington, D.C., May.

Edison Electric Institute 1992b, Environmental Externality: Testimony Summaries, Pub. No. 0792-37, Washington, D.C., July.

Edison Electric Institute 1993a, EEI Statistical Yearbook of the Electric Utility Industry/1992, Pub. No. 01-93-06, Washington, D.C.

Edison Electric Institute 1993b, Types of Incentive Regulation: A Primer for the Electric Utility Industry, Pub. No. 04-93-01, Washington, D.C., April.

Energy Information Administration 1992, Annual Electric Utility Report for the Reporting Period 1992, Form EIA-861, 1992, OMB No. 1905-0129.

Energy Information Administration 1993a, Natural Gas Anmual 1992 Volume 1, DOE/EIA-0131(92)/1, Washington, D.C., November.

Energy Information Administration 1993b, Supplement to the Annual Energy Outlook 1993, DOE/EIA-0554(93), Washington, D.C., February.

Hirst, E. 1994, Costs and Effects of Electric-Utility DSM Programs: 1989 through 1997, ORNL/CON-392, Oak Ridge National Laboratory, Oak Ridge, Tennessee, June.

Hohmeyer, O., and R. L. Ottinger (Eds.) 1990, External Environmental Costs of Electric Power, Springer-Verlag: Berlin.

Moskovitz, D., C. Harrington, and T. Austin 1992, "Weighing Decoupling vs. Lost Revenues: Regulatory Considerations," The Electricity Journal, Vol. 6, No. 2, pp. 58-63, November.

Nadel, S. M., M. W. Reid, and D. R. Wolcott (Eds.) 1992, Regulatory Incentives for DemandSide Management, American Council for and Energy-Efficient Economy, Washington, D.C.

National Association of Regulatory Utility Commissioners 1992, Profiles of Regulatory Agencies of the United States and Canada, Yearbook 1991-1992, Washington, D.C.

National Association of Regulatory Utility Commissioners 1993, Environmental Externalities and Electric Regulation, ORNL/Sub/95X-SH985C, Washington, D.C., September. 
Reid, M. W., J. B. Brown, and J. C. Deem 1993, Incentives for Demand-Side Management, Second Edition, ORNL/Sub/95X-SH985C, National Association of Regulatory Utility Commissioners, Washington, D.C., March.

Schweitzer, M., M. English, and J. Altman 1994, "DSM/IRP Collaboratives: What Have They Accomplished," Energy Sources: Journal of Extraction, Conversion, and the Environment, Vol. 16, No. 1, pp. 161-176, January-March.

Schweitzer, M., E. Hirst, and L. J. Hill 1991, Demand-Side Management and Integrated Resource Planning: Findings from a Survey of 24 Electric Utilities, ORNL/CON-314, Oak Ridge National Laboratory, Oak Ridge, Tennessee, February.

U. S. Department of Commerce, Economics and Statistics Administration 1993, Survey of Current Business, Vol. 73, No. 4, Washington, D.C., April.

U.S. General Accounting Office 1991, Electricity Supply: Utility Demand-Side Management Programs Can Reduce Electricity Use, GAO/RCED-92-13, Washington, D.C., October. 
APPENDIX A. DESCRIPTION OF LARGEST CONSUMER-OWNED ELECTRIC UTILITIES 


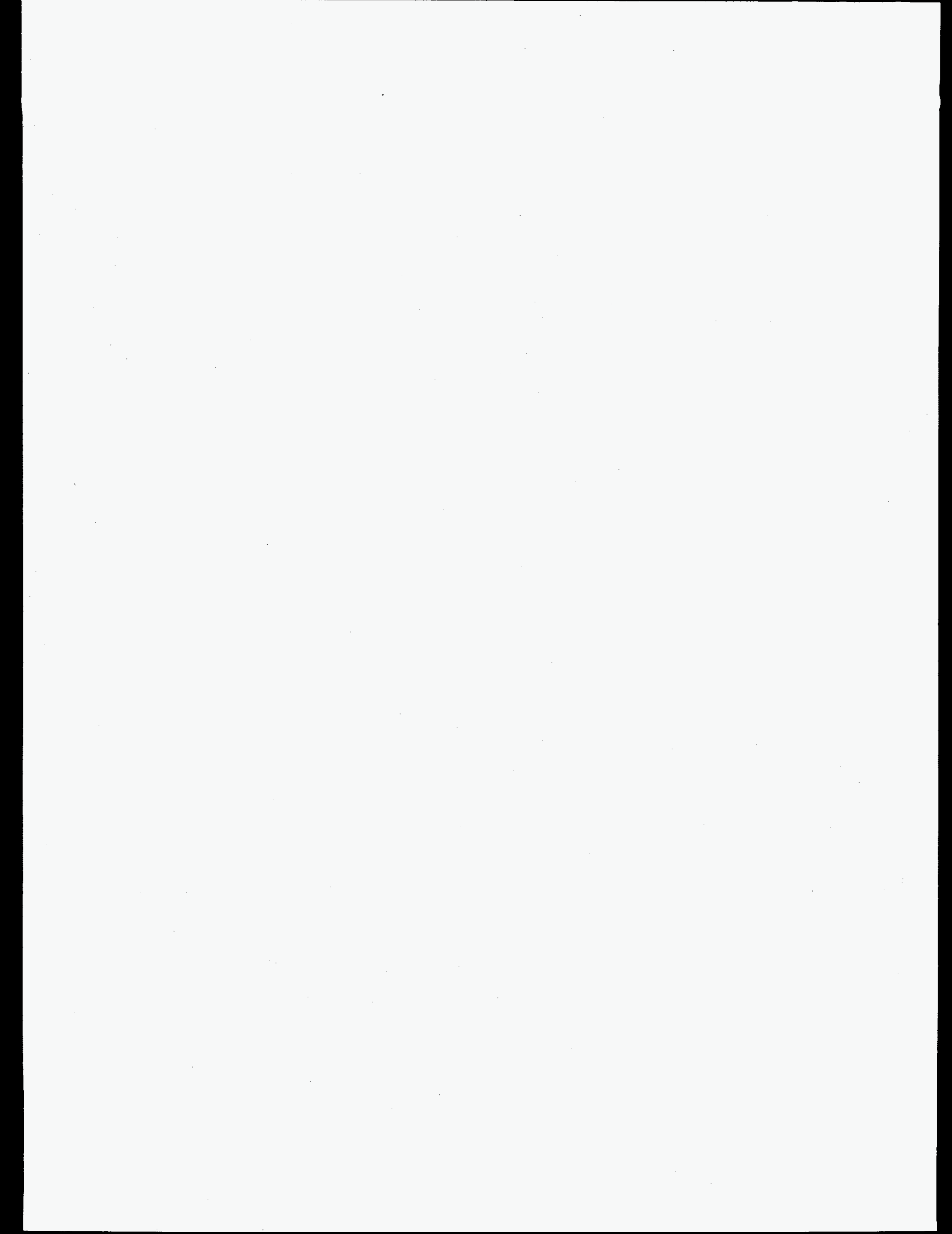




\section{INTRODUCTION}

We attempted to collect the same types of data for the 20 largest $^{34}$ state- and locally-owned $^{-}$ utilities in the U.S. and for the 3 largest federal power systems that we gathered for the PUCs and their regulated utilities. The 23 COUs that we targeted are listed in Table A.1. All of these utilities provided detailed information on their 1992 and projected 1997 demand-side activities on Form EIA861. However, only 14 of the 23 responded to our direct questions about their operating environment and the procedures (analogous to the regulatory requirements of the state regulators) established by their policy-making boards.

Table A.1. Consumer-owned utilities included in study

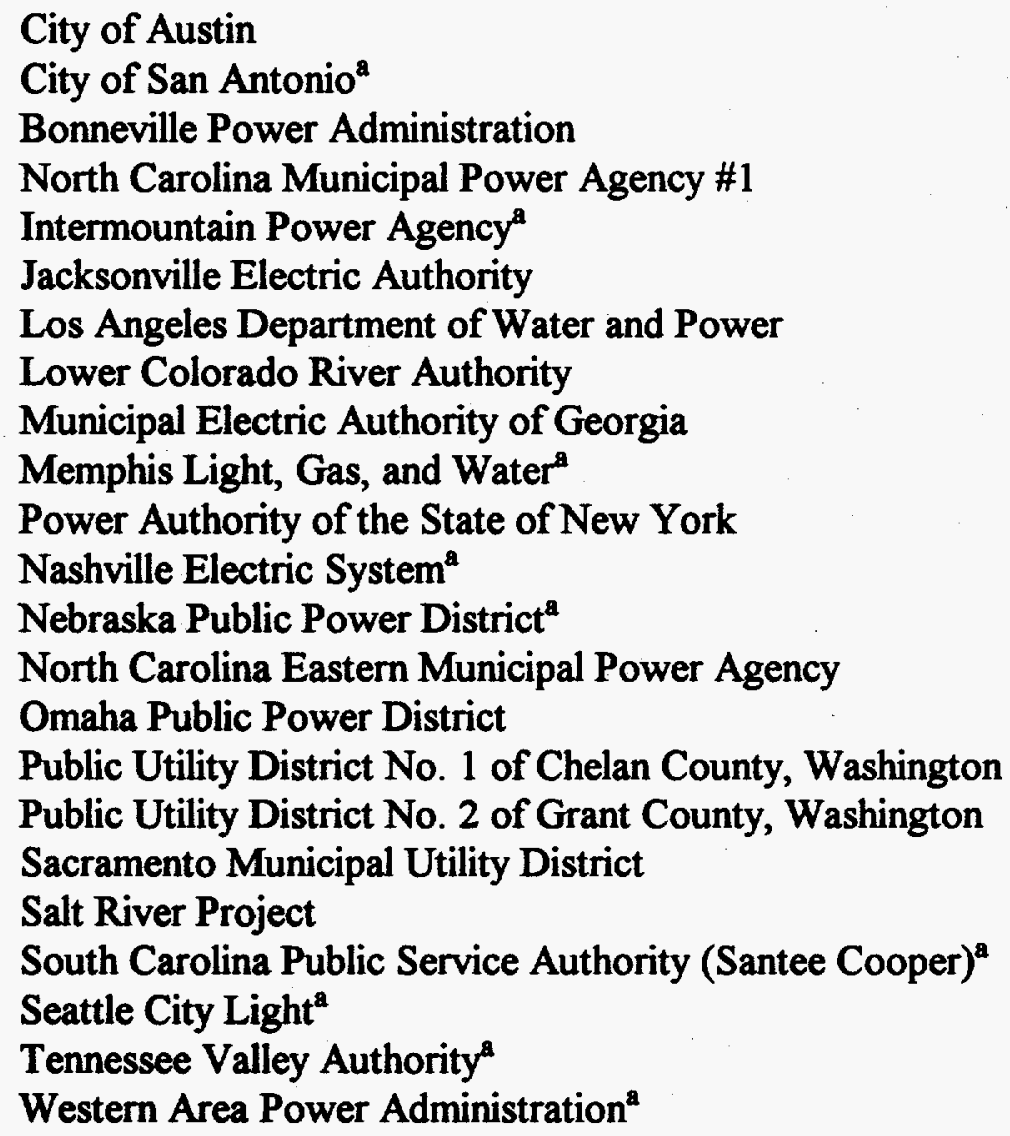

City of Austin

City of San Antonio ${ }^{a}$

Bonneville Power Administration

North Carolina Municipal Power Agency \#1

Intermountain Power Agency ${ }^{\mathrm{a}}$

Jacksonville Electric Authority

Los Angeles Department of Water and Power

Lower Colorado River Authority

Municipal Electric Authority of Georgia

Memphis Light, Gas, and Water"

Power Authority of the State of New York

Nashville Electric System ${ }^{a}$

Nebraska Public Power District

North Carolina Eastern Municipal Power Agency

Omaha Public Power District

Public Utility District No. 1 of Chelan County, Washington

Public Utility District No. 2 of Grant County, Washington

Sacramento Municipal Utility District

Salt River Project

South Carolina Public Service Authority (Santee Cooper) ${ }^{\mathbf{a}}$

Seattle City Light ${ }^{\mathbf{a}}$

Tennessee Valley Authority

Western Area Power Administration ${ }^{\mathrm{a}}$

2Information was collected on DSM usage, but utility did not respond to questions about operating environment and key policies.

\footnotetext{
${ }^{34}$ Utility size was determined by total electricity sales.
} 
Normalized 1992 and 1997 DSM expenditures ${ }^{35}$ were calculated by dividing each utility's reported DSM expenditures by its own revenues for the same year. ${ }^{36}$ We calculated normalized energy savings by dividing each utility's energy savings by its own sales for the same year. And normalized peak reduction was computed by dividing each utility's peak reduction by its own peak demand. 37

The same basic protocol that was used on the PUCs also was used to gather information from the COUs, with a few minor modifications to reflect the fact that these entities set their own policies rather than establish them for others like the PUCs do. Staff members associated with each of the large COUs ${ }^{38}$ were interviewed by telephone or-if such interviews were inconvenient for the individual contacted-were sent a copy of the protocol to fill out on their own. ${ }^{39}$ As with the PUCs and IOUs, all of the information collected is current as of 1992.

We did not test our hypotheses (Appendix B) for the COUs because the number of observations for most hypotheses was too small and because our respondents do not represent a random sample of all COUs.

\section{UTILITY DSM USAGE}

\section{DSM Expenditures}

As shown in Figure A.1, approximately two-thirds of the largest COUs reported spending less than $1 \%$ of retail revenues on DSM in 1992. Five of these utilities reported no expenditures at all for DSM programs. At the other end of the scale, one utility (Seattle City Light) reported spending over $6.2 \%$ of its revenues on DSM. This range is nearly one-third greater than for the state-aggregated IOUs. The mean expenditure for DSM programs by the COUs was $1.1 \%$ of retail revenues, but the median expenditure was only $0.4 \%$. The large discrepancy between mean and median for the COUs indicates a highly-skewed distribution, with a few high-spending utilities inflating the mean. For 1997, the range is expected to increase by about two-fifths due to growing

\footnotetext{
${ }^{35}$ The 1997 DSM expenditures reported by the publicly-owned utilities on EIA-861 were adjusted to 1992 dollars the same way they were adjusted for the IOUs, as explained in Chapter 1 .

${ }^{36} 1997$ revenues (as well as electricity sales and peak demand) were projected for the publicly-owned utilities the same way they were projected for the IOUs (see Chapter 1).

${ }^{37}$ For those publicly-owned utilities that do more than half of their business in the wholesale market, DSM expenditures, energy savings, and peak reduction were normalized by dividing by total (as opposed to retail) revemes, sales, and peak demand, respectively.

${ }^{38}$ Key staff members with a good understanding of the workings of the publicly-owned utility were our respondents in all cases. Individual members of utility policy-making boards were not interviewed.

${ }^{39}$ For those publicly-owned utilities that did not supply us with primary data, we typically ended up with missing values on all items except DSM usage because the secondary sources that provided selected information on the PUCs did not contain information on the publicly-owned utilities.
} 


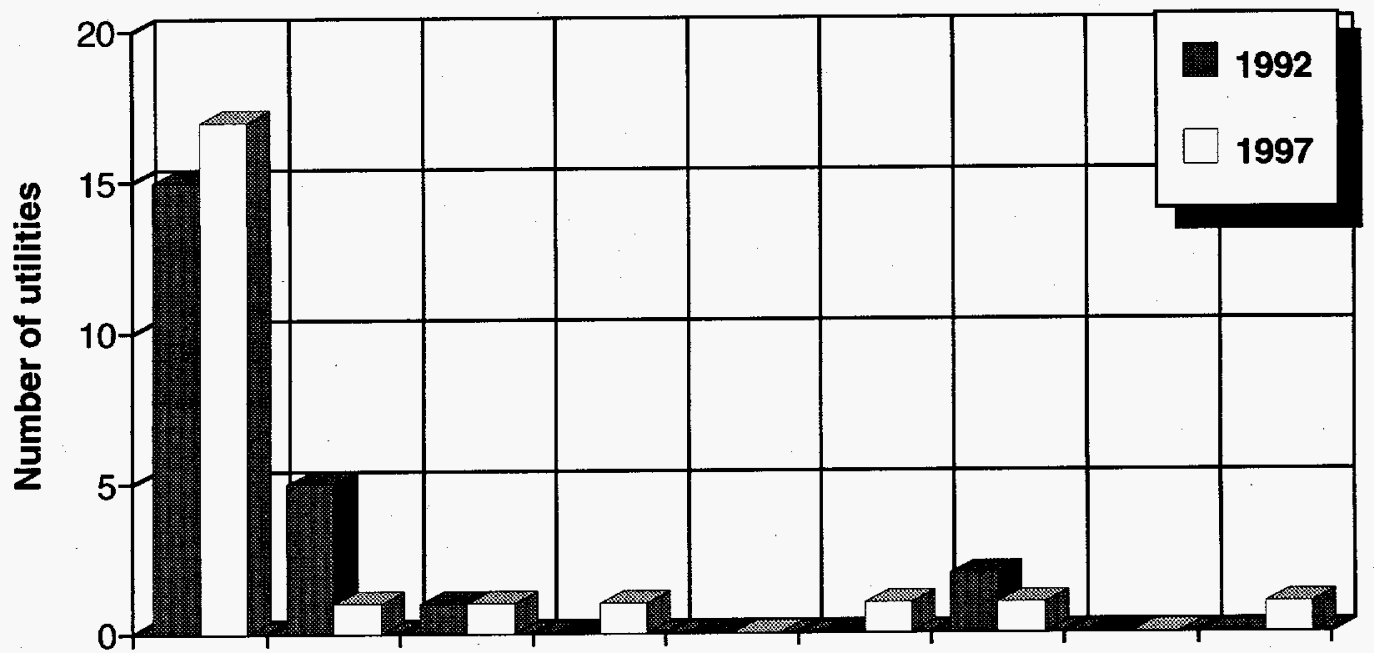

0\%-1\% $\quad 1 \%-2 \% \quad 2 \%-3 \% \quad 3 \%-4 \% \quad 4 \%-5 \% \quad 5 \%-6 \% \quad 6 \%-7 \% \quad 7 \%-8 \% \quad 8 \%-9 \%$ DSM expenditures as a percentage of retail revenues

Fig. A.1. DSM expenditures by consumer-owned utilities, 1992 and 1997.

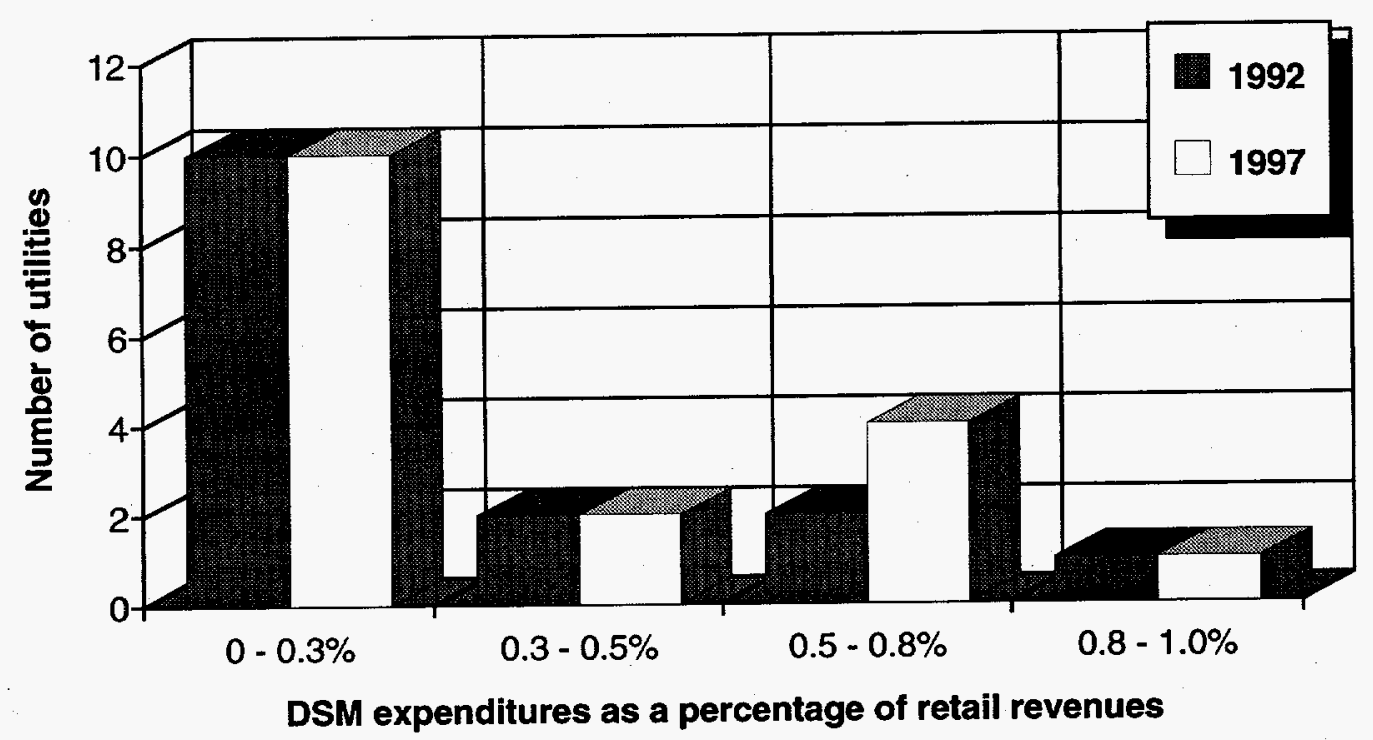

Fig. A.2. Breakdown of expenditures for consumer-owned utilities spending less than 1\% of retail revenues on DSM programs, 1992 and 1997. 
expenditures by a few utilities. However, the number of utilities spending less than $1 \%$ of their revenues on DSM will actually increase slightly during this same period. Mean and median expenditures are projected to rise a little, to approximately $1.4 \%$ and $0.5 \%$ of revenues, respectively. This represents an increase of only about $15 \%$ in median expenditures from 1992 to 1997. As these numbers and Fig. A.1 illustrate, the distribution of expenditures by the COUs will continue to be substantially skewed. DSM expenditures projected for the various COUs in 1997 are very highly correlated $(\mathrm{r}=0.87)$ with the expenditures made by the same utilities in 1992 .

A comparison of the different utility types shows that the median DSM expenditure by the COUs was a little less than two-fifths of the median expenditure by the state-aggregated IOUs in 1992. This disparity will increase in the future, with the median expenditure by the COUs expected to be less than one-fourth of the median expenditure by the IOUs in 1997. The rate at which the median expenditure for the IOUs is expected to increase from 1992 to 1997 is six times the projected growth rate for the COUs.

Figure A. 2 provides a closer look at those utilities spending less than $1 \%$ of their retail revenues on DSM. The majority of these utilities spent less than $0.3 \%$ of revenues on DSM in 1992 and will continue to do so in 1997 . However, the number of utilities spending $0.5 \%$ or more on DSM will increase by 1997.

\section{Energy Savings}

For 1992, the distribution of energy savings for the COUs (Fig. A.3) appears similar to that for the state-aggregated IOUs except that the COUs exhibit a greater range. As with the IOUs, about two-thirds of the COUs show a DSM-induced energy saving of less than $1 \%$ of retail sales. The mean energy saving was just under $1 \%$, but the median was only $0.2 \%$, in line with the highly skewed distribution shown in Fig. A.3. For 1997, the range of energy savings will increase slightly and the mean is projected to double, to $2 \%$ of sales. The projected 1997 median savings of $0.9 \%$ is four and a half times the size of the 1992 median. While a substantial increase is projected in the number of utilities saving $4 \%$ or more of their retail sales as a result of DSM programs, over half of the utilities will still experience savings of less than $1 \%$ and the overall distribution will remain skewed. DSM-induced savings expected in 1997 are highly correlated $(r=0.81)$ with the savings achieved in 1992.

In 1992, the median DSM-induced energy saving achieved by the COUs was a little over half of the median saving experienced by the state-aggregated IOUs. The gap between these two types of utilities will grow in the near-term future, with the median saving achieved by the COUs projected to amount to just over two-fifths of the IOUs' median saving in 1997.

The breakdown of utilities saving less than $1 \%$ of retail electric sales through DSM programs in 1992 (Fig. A.4) shows that all of them achieved savings of less than $0.3 \%$. In fact, just over half of these utilities reported no energy savings at all in 1992. By 1997, there will be two fewer utilities saving less than $1 \%$ of sales as a result of their DSM efforts, and the number of 


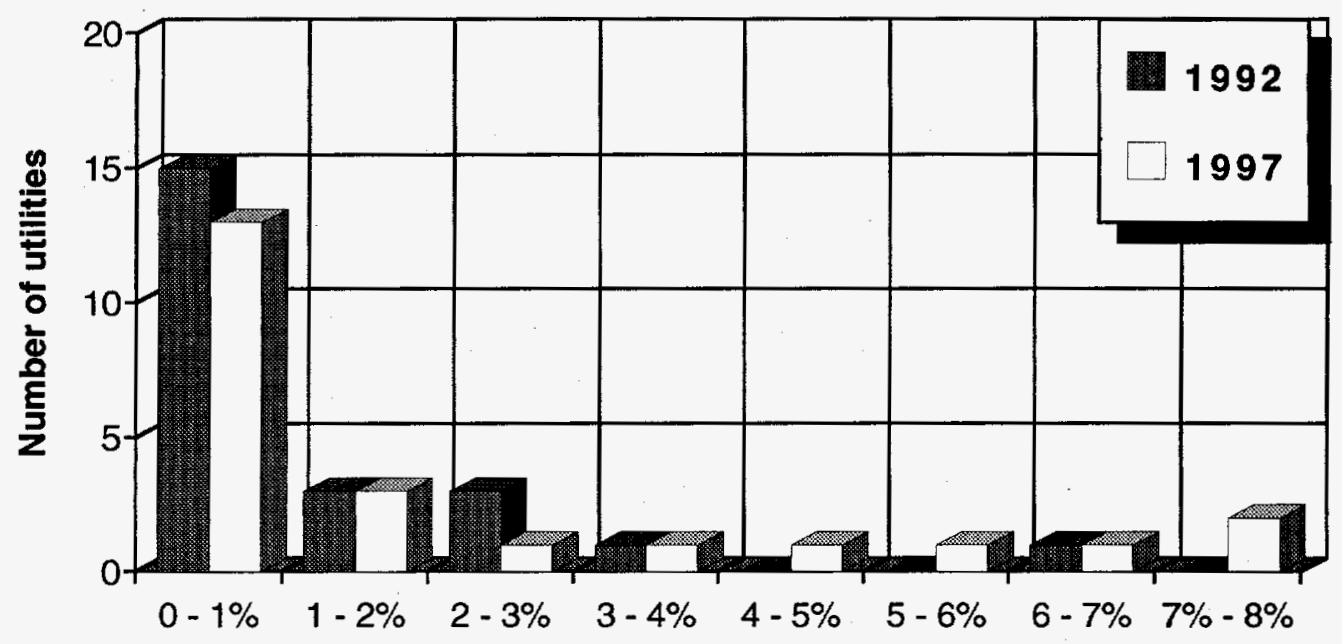

Energy savings as a percentage of retail electric sales

Fig. A.3. DSM-induced energy savings by consumer-owned utilities, 1992 and 1997.

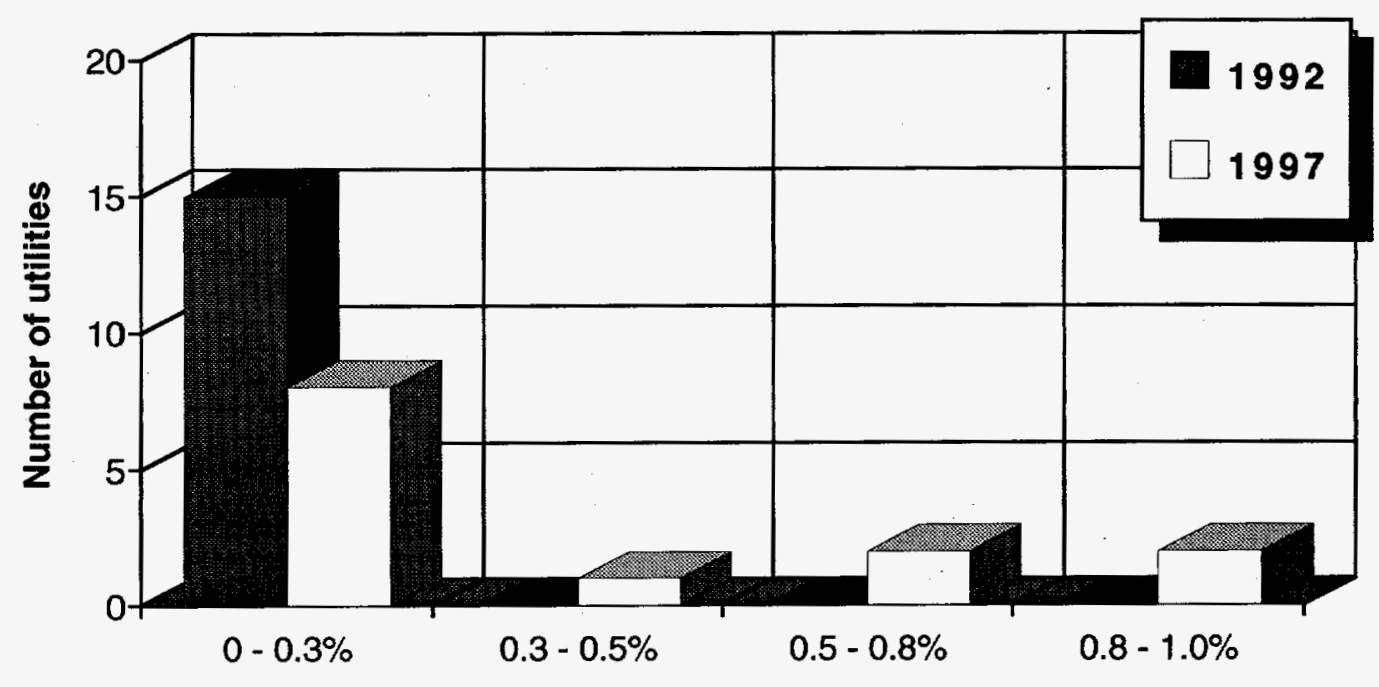

Energy savings as a percentage of retail electric sales

Fig. A.4. Breakdown of energy savings for consumer-owned utilities saving less than $1 \%$ of retail sales due to DSM programs, 1992 and 1997.

utilities saving less than $0.3 \%$ will decline almost by half. However, there will be no change in the number of utilities reporting zero energy savings. 
Peak Reduction

For the COUs, the range of retail peak reductions is less than for the IOUs and the proportion of respondents reporting reductions of less than $5 \%$ is substantially higher (Fig. A.5). For 1992, five utilities reported zero savings while one (the City of Austin) reported a $17.9 \%$ reduction in peak demand. The mean peak reduction was $4 \%$ and the median was $1.2 \%$. By 1997 , the distribution is expected to change somewhat, although over four-fifths of the utilities will continue to have peak reductions of less than $10 \%$. Five utilities will continue to experience no peak reductions, but the range will be increased by the Sacramento Municipal Utility District's anticipated $24.7 \%$ reduction in retail electric peak demand. Also, the number of utilities achieving savings of 5\% or more will grow. Accordingly, the mean peak reduction is expected to increase by about two-fifths, to 5.6\%. And the projected 1997 median peak reduction of $4.1 \%$ is three and a half times the 1992 median. DSM-induced peak reductions expected in 1997 are highly correlated $(r=0.86)$ with the peak reductions achieved in 1992.

In 1992, the median peak reduction achieved by the COUs was less than one-fifth that of the state-aggregated IOUs. By 1997, however, it is projected that this gap will have closed substantially, with the COUs' median peak reduction approaching half that of the IOUs. The rate at which the COUs' median peak reduction is projected to increase from 1992 to 1997 is over five times that at which the IOUs' peak reduction will increase.

Fig. A.6 presents a more detailed picture of those utilities reporting peak reductions of less than $10 \%$. Between 1992 and 1997, the number of utilities achieving peak reductions of less than $2 \%$ is expected to decrease while the number reducing their retail peaks by 5 to $10 \%$ will grow.

\section{Comparison of Outcomes}

An overview of the accomplishments of the COUs in terms of the various outcome measures examined in this study is presented in Fig. A.7. In 1992, the median annual DSM expenditure was $0.4 \%$ of retail revenues, the median cumulative energy saving was $0.2 \%$ of retail sales, and the median cumulative peak reduction was $1.2 \%$ of retail peak. For 1997 , the median annual expenditure is projected to be slightly less than $0.5 \%$ of retail revenues, the median cumulative energy saving will be $0.9 \%$ of retail sales, and the median cumulative peak reduction will be $4.1 \%$ of retail peak.

Energy savings for 1992 were significantly correlated with peak reduction $(r=0.62)$ and, to a lesser extent, with DSM expenditures $(r=0.44)$. DSM expenditures and peak reduction were not significantly correlated with each other, however. For 1997, energy savings were once again correlated with peak reduction and DSM expenditures, but this time the relationship was stronger with expenditures $(r=0.59)$ than with peak reduction $(r=0.49)$.

The median annual DSM expenditure is expected to grow by only $15 \%$ in the five-year period from 1992 to 1997 . During that same period, the median cumulative energy saving will grow by nearly $350 \%$ and the median cumulative peak reduction is expected to increase by just over $250 \%$. Clearly, the COUs are planning substantial growth in both their peak reduction and 


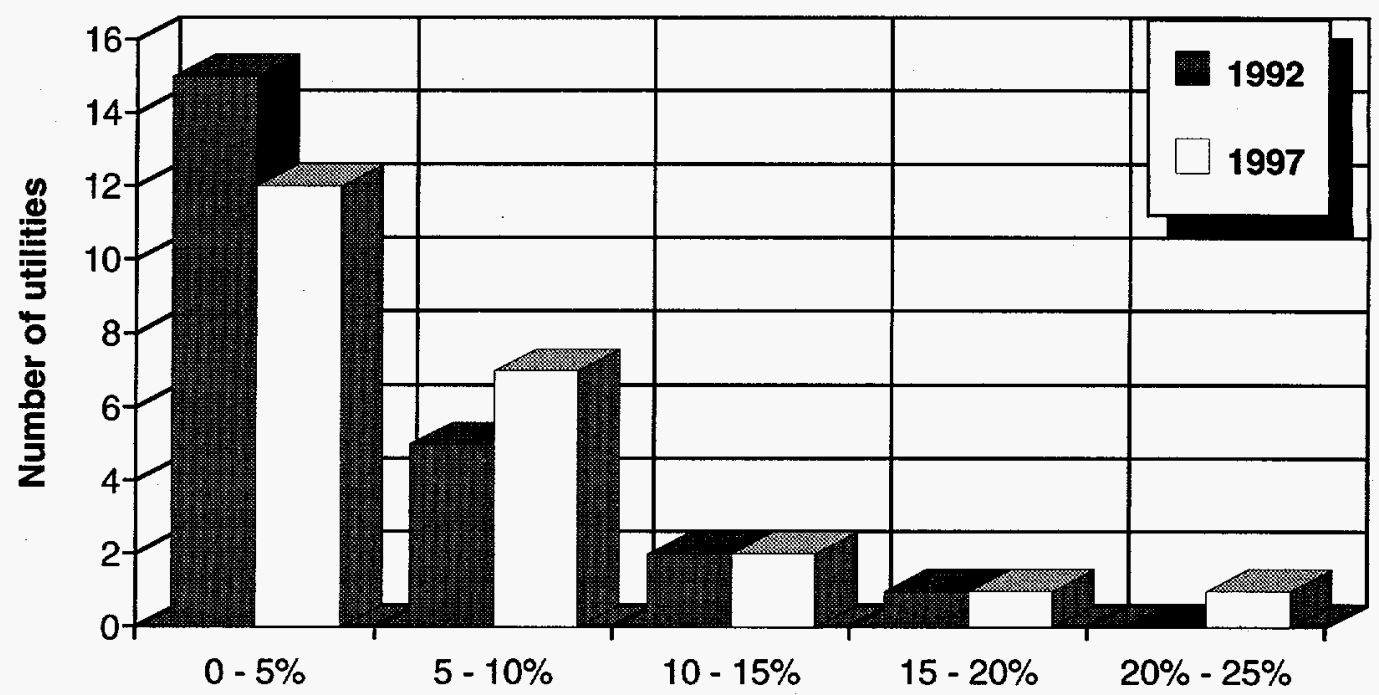

Peak reduction as a percentage of retail peak

Fig. A.5. DSM-induced peak demand reduction by consumer-owned utilities, 1992 and 1997.

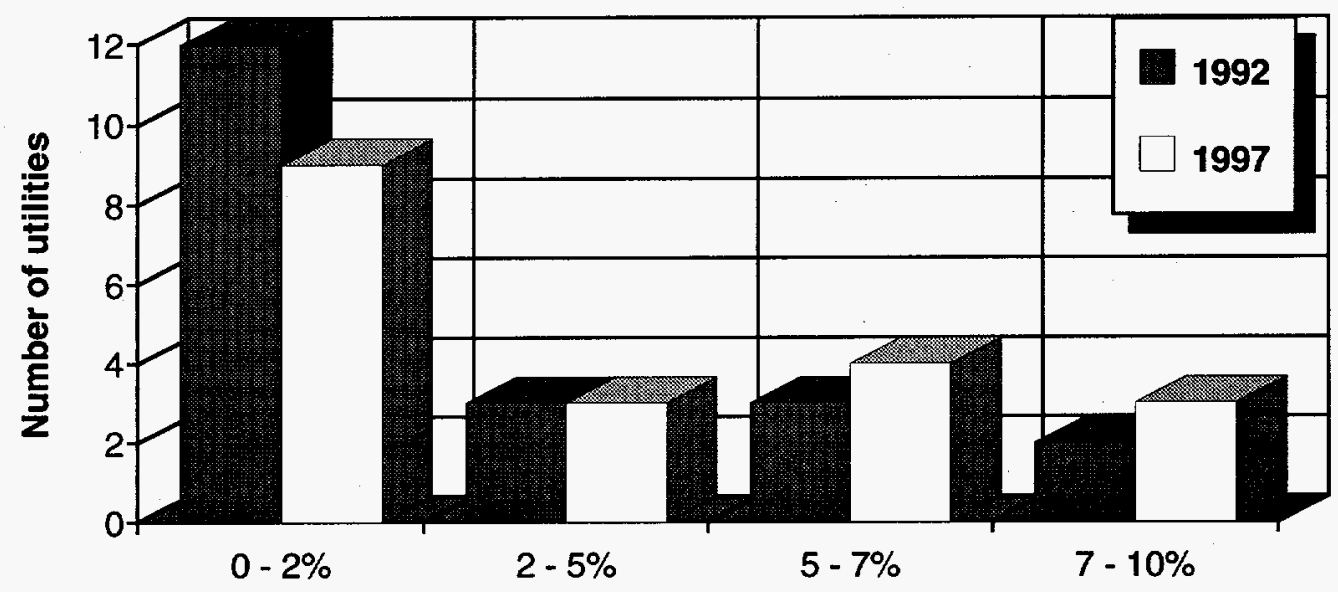

Peak reduction as a percentage of retail peak

Fig. A.6. Breakdown of peak reduction for consumer-owned utilities reducing retail peak demand by less than 10\% through the use of DSM programs, 1992 and 1997.

energy savings efforts. While cumulative energy savings are expected to grow somewhat faster than peak reduction, the difference in growth rates between the two is not nearly as dramatic as for the IOUs. 


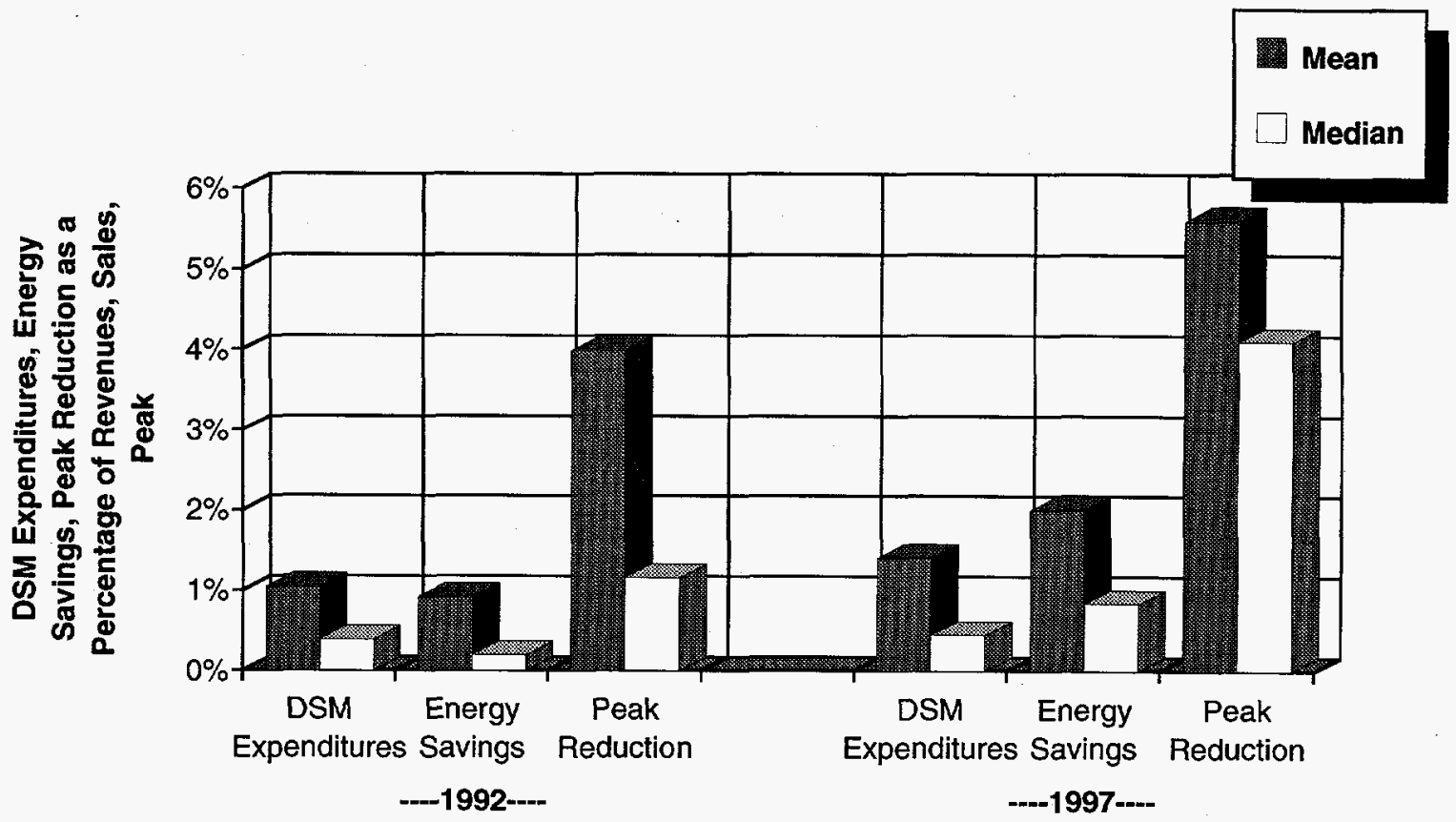

Fig. A.7. Comparison of outcome measures for consumer-owned utilities, 1992 and 1997.

\section{REGULATORY ENVIRONMENT}

\section{Key Characteristics of Service Area}

Need for Additional Peaking and Baseload Units. Eleven COUs reported when they expect to need additional peak period resources. Just over one-third of the responding utilities expected that they would need new peak period resources in five years or less, and the same number anticipated such a need in the next six to nine years (Fig. A.8). Slightly more than onefourth of the utilities providing.information on this item expected to go more than 10 years before experiencing the need for new peak period resources. The reported length of time until new peaking resources would be required ranged from one to 38 years; the mean length of time for this was almost ten years but the median was only seven years. Both these numbers were substantially higher than the corresponding figures for the states, indicating that the COUs' need for new peaking resources was generally not as immediate as was the IOUs'.

Nine COUs reported when they anticipate that their state would need additional baseload resources. Slightly more than one-fifth of those said that they would require new baseload resources within five years, and the same number anticipated the need for such resources in six to ten years (Fig. A.8). On the other end of the scale, just over one-fifth of the COUs expected to go 20 years or longer before they need new baseload resources. As with the IOUs, the reported length of time until new baseload resources would be required ranged from one to 23 years. The 


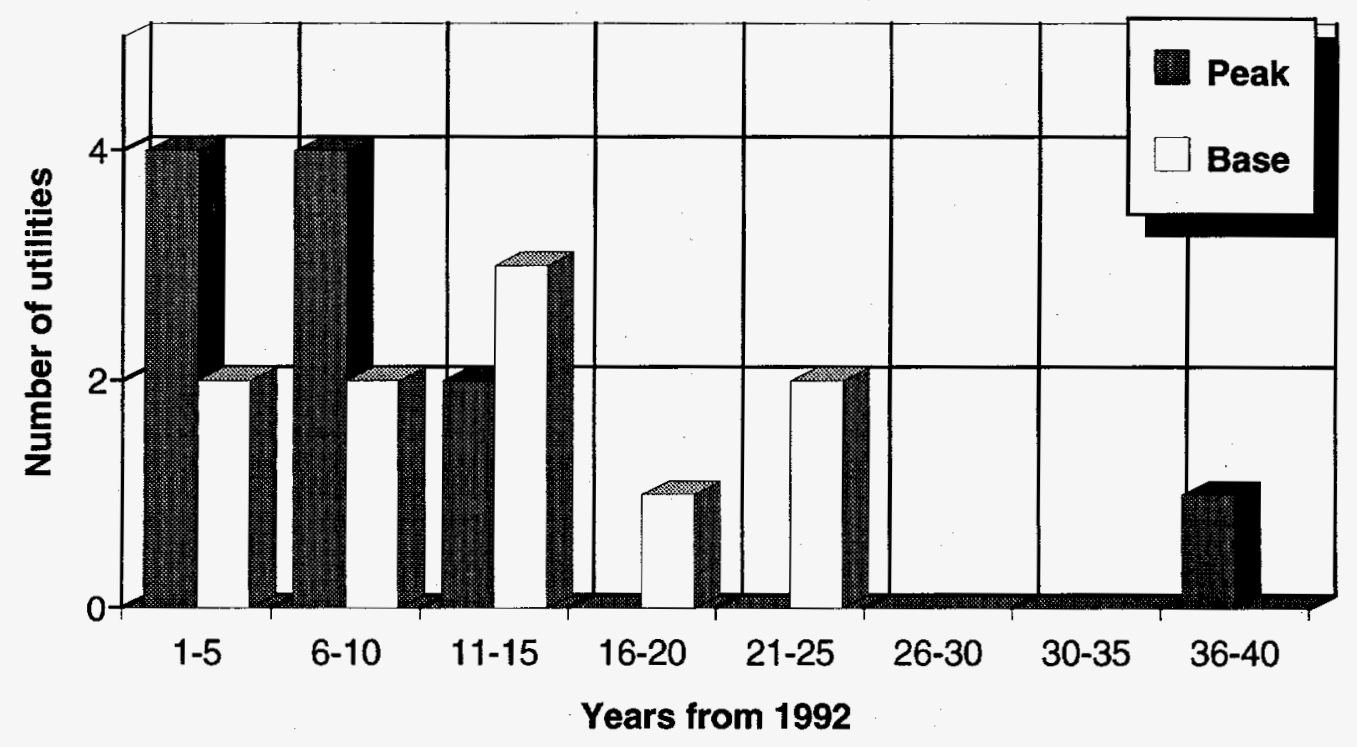

Fig. A.8. Number of years until new peaking and baseload units will be needed by consumer-owned utilities.

mean of almost 12 years and the median of 11 years were only slightly higher than the corresponding numbers for the states.

\section{Personnel of Policy-Making Body}

Size of Electric Policy Staff. To oversee their electric operating policy, the COUs used only about half the staff that the state PUCs did. For the 11 respondents to this question, the number of staff members ranged from 0 to 38, with a mean of just under 10 and a median of 5 . Over nine-tenths of the responding utilities reported having 15 staff members or less involved in electric policy issues.

Background of Policy-Makers. On average, almost 30\% of the members of COUs' policy-making boards came from business backgrounds (Fig. A.9). And, as with state regulatory commissions, a substantial portion of board members had prior experience as elected officials. In marked contrast to state regulatory commissions, almost one-fourth of the members of COUs' policy-making boards came from the utility industry. Such boards also typically had much greater representation from environmental and public interest groups than did state regulatory commissions and many fewer members from government staff agencies and private law practice.

Turnover of Policy-Makers. Two-thirds of the 12 COUs responding to this question lost no members of their policy-making board during 1992 and only 2 experienced a turnover of onefifth or more of their members. 


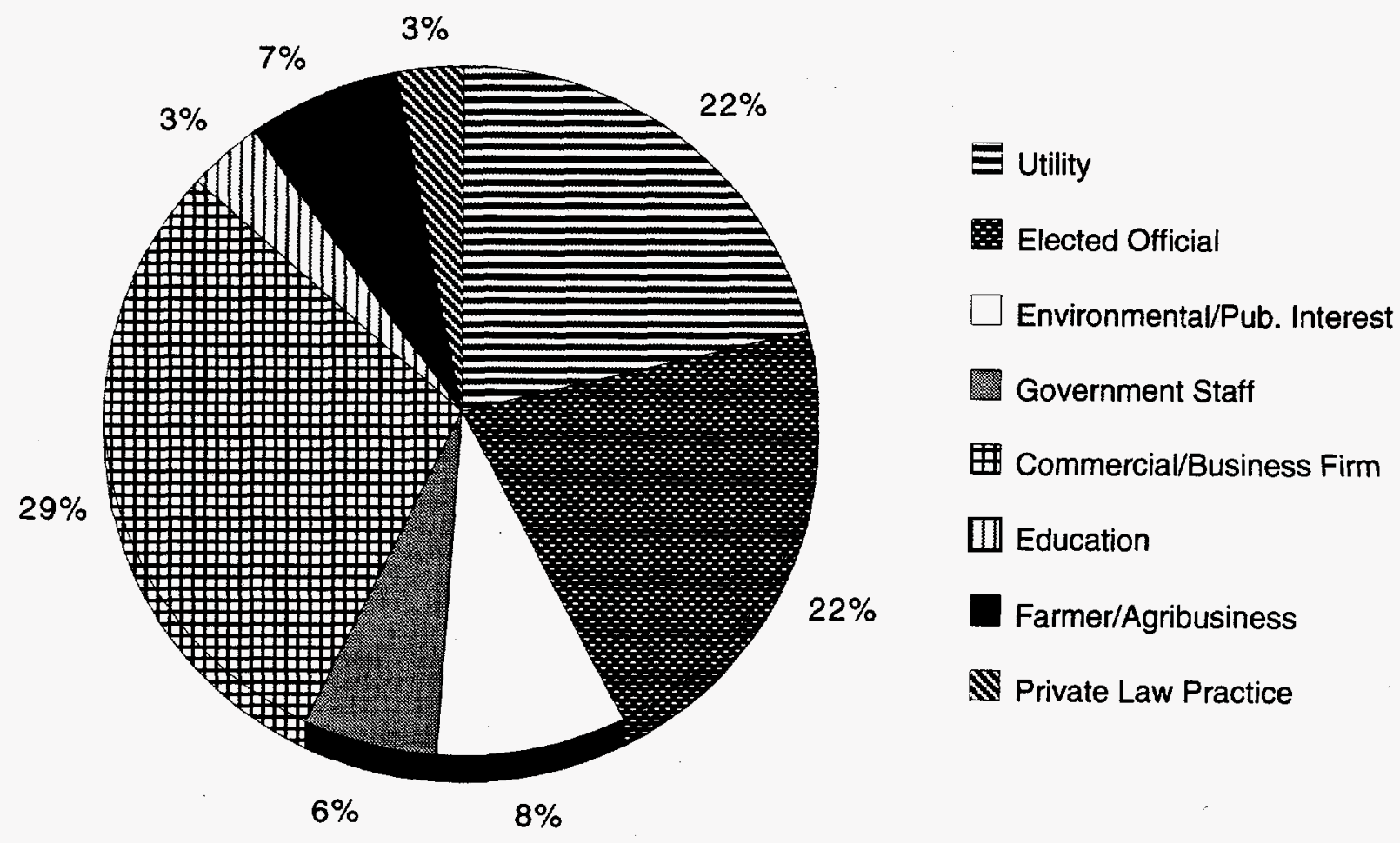

Fig. A.9. Principal work experience of board members for consumer-owned utilities: mean percentages for each major category.

\section{Attitudes and Actions of Policy-Makers}

Load Building, Energy Efficiency, and Load Reduction. Load building programs tended to be favored more highly by COUs, which gave them a mean score of 3.5 , than by the state regulatory commissions. The COUs also displayed a smaller range of responses on this item, with no board expressing strong opposition to load building efforts (Fig. A.10). As did state regulators, the boards of COUs showed considerable support for both energy efficiency and load reduction programs, with energy efficiency (mean of 4.2 ) being favored slightly more than load reduction (mean of 3.9). On both of these items, the extent of support by the COUs was slightly less than that expressed by the PUCs.

Public Involvement. The use of public meetings, workshops, and task forces/advisory groups were all highly valued by the policy-making boards of COUs as methods for obtaining public involvement on important policy and program issues, while collaboratives and focus groups were less strongly supported (Fig. A.11). The only major difference between the responses given by the COUs and those provided by the state regulatory agencies concerned their support for collaboratives. The policy-making boards were lukewarm in their support for this approach (mean of 3.5 and median of 3 ), while the PUCs (mean of 4.1 and median of 4 ) were considerably more supportive of this type of public involvement. 


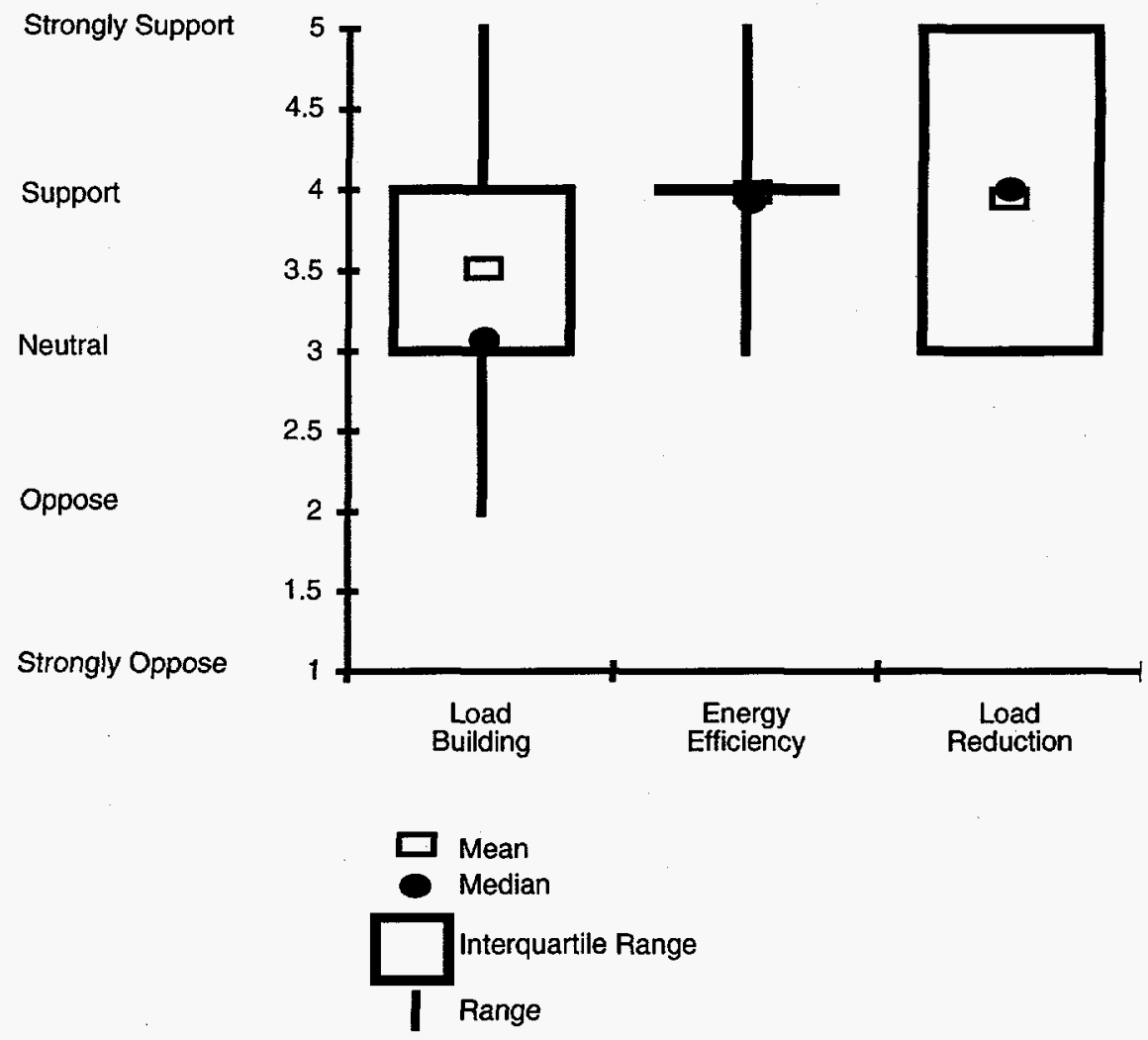

Fig. A.10. Distribution of support for load building, energy efficiency, and load reduction programs by board members of consumer-owned utilities.

Information Sources for Policy Decisions. The source of information considered most important by the policy-making boards of COUs was advice from staff, with a mean of 4.3 and a median of 4 (Fig. A.12). These scores were almost identical to those provided by the state regulatory commissions. Here, however, is where the similarity ends. The next most important source of information for the COU boards was advice from paid consultants (mean of 3.7 and median of 4), which was considerably less important to the PUCs. In contrast, testimony at regulatory hearings was substantially more important to the state regulatory agencies than to the COUs. All the remaining sources of information were rated as being of slight importance to the COUs' policy-makers. When disregarding those utilities that did not consider a particular type of information, the mean scores for the remaining utilities increased but only one item (testimony at hearings) rose much above the level of moderate importance. ${ }^{40}$

\footnotetext{
${ }^{40}$ Even when examining only those utilities that consider testimony from regulatory hearings, publicly-owned utilities still attribute considerably less importance to this item (mean of 3.8) than do state regulatory commissions (mean of 4.6).
} 


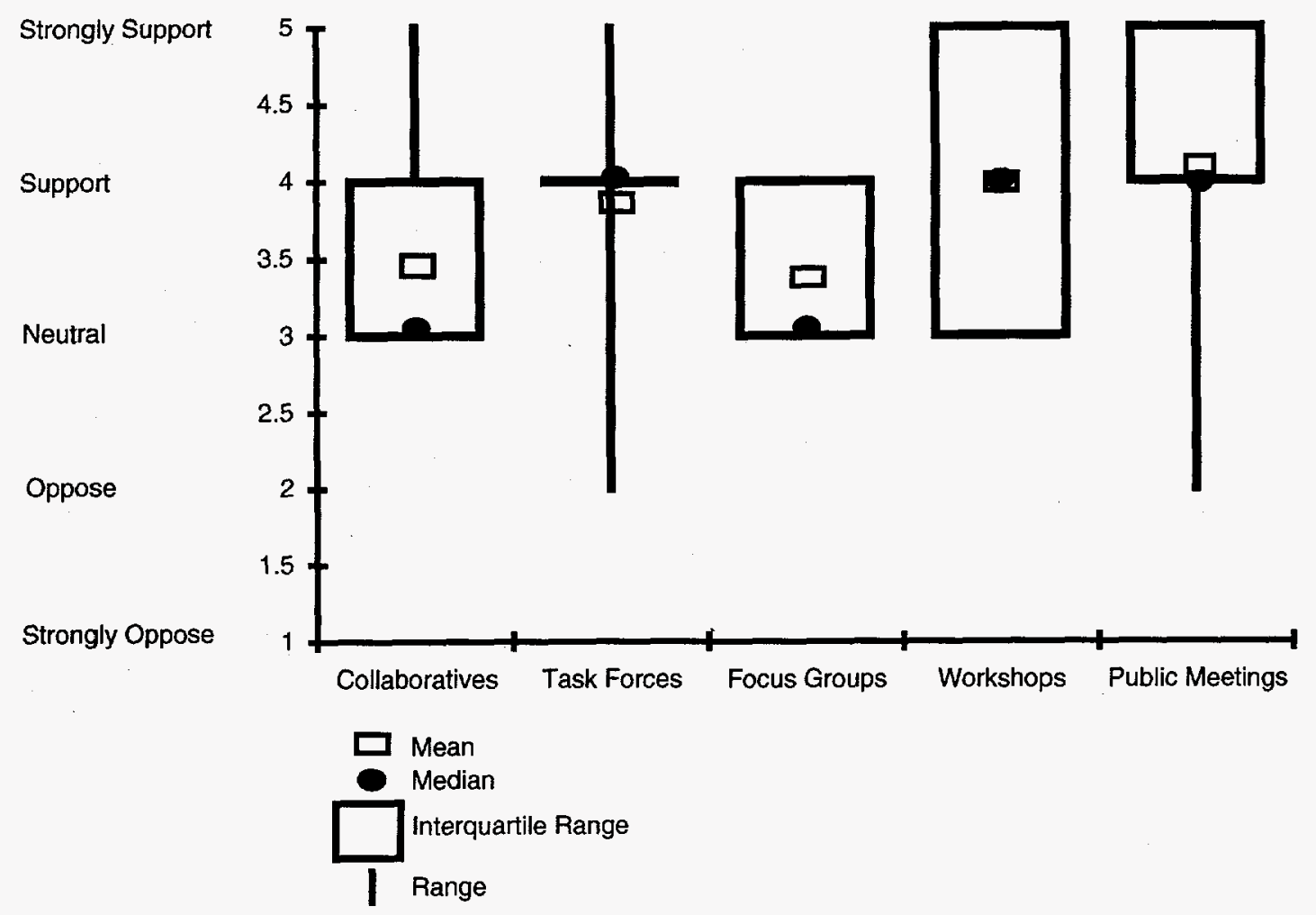

Fig. A.11. Distribution of support for various forms of public involvement by board members of consumer-owned utilities.

Provision of Assistance Programs for Utilities and NUPs. The municipal, state, and federal power agencies seem to have done somewhat more toward educating utility staff and/or NUPs on IRP and DSM issues than have the PUCs. However, this could be due, at least in part, to the fact that some of the largest COUs are affiliated with smaller public utilities to whom they normally provide information and assistance. Over half of the nine utilities responding to this question reported holding seminars or workshops during the past year, with nearly all of these holding only one or two. Nearly half of the respondents held conferences during 1992, with half of these putting on 6 to 10 such events, and a third of the respondents provided educational materials to utility staff and/or NUPs.

\section{REGULATORY REQUIREMENTS}

\section{IRP Requirements}

Nature and History of IRP Requirements. Of the responding COUs, nearly two-thirds prepared IRPs. Of these, half began in 1990 or more recently. Figure A.13 shows the distribution of the years in which responding utilities began developing their IRPs. Of those utilities doing 


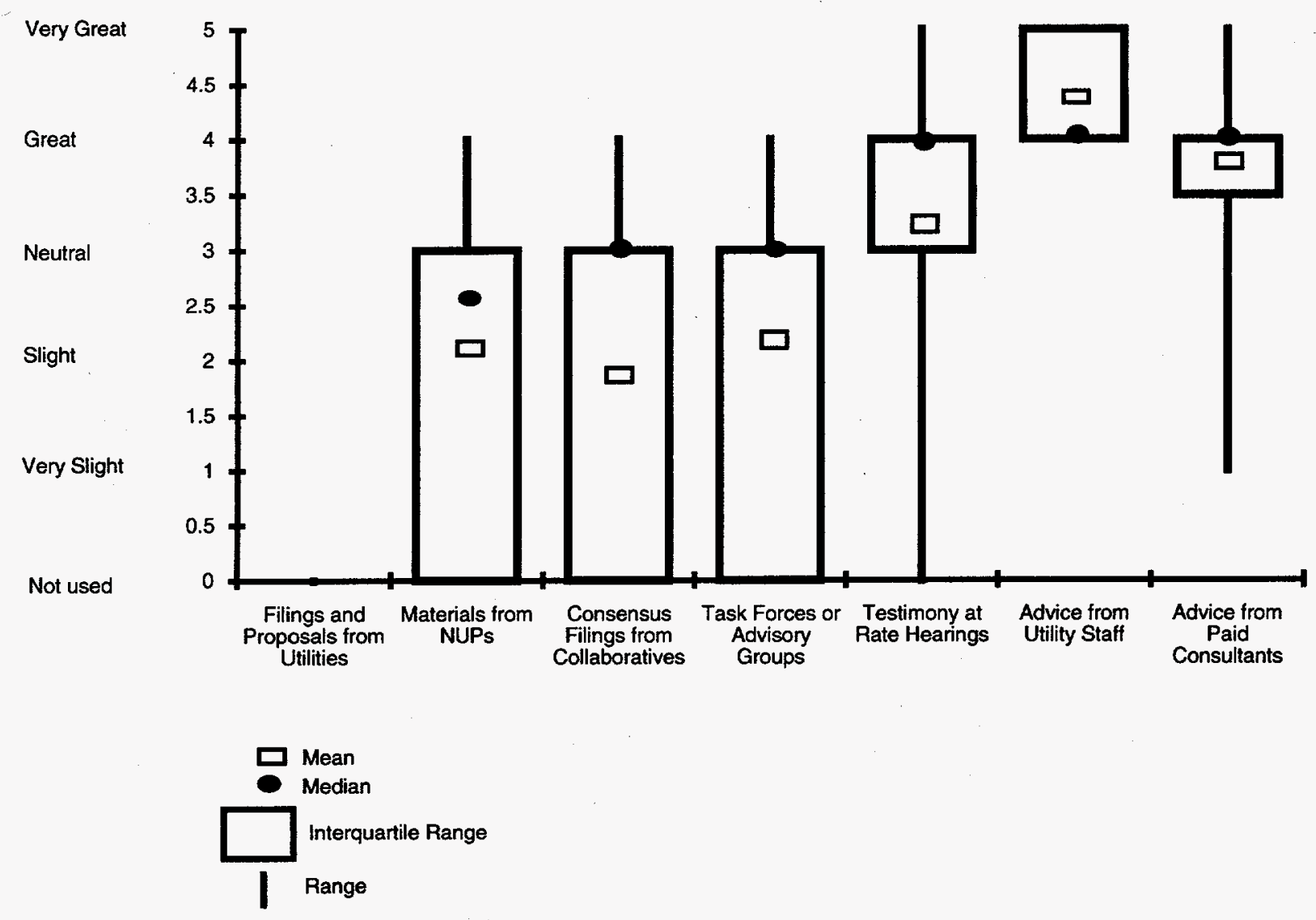

Fig. A.12. Distribution of responses on importance of various types of information to board members of consumer-owned utilities when making policy decisions.

IRPs, nearly two-thirds updated their plan annually, with the rest revising their plan every two years.

IRP Review and Approval Procedures. Slightly less than two-thirds of the COUs that prepared IRPs required public review of the plan. The same number of utilities reported that approval of subsequent utility actions depended on their inclusion in the plan. Because these utilities are not regulated by state PUCs, the questions on formal approval of the plan by a regulatory body are not applicable.

\section{Cost-Efiectiveness Tests}

Over half of the COUs responding to this question performed various cost-effectiveness tests, and nearly $90 \%$ of those preparing IRPs did so. As with the states, the TRC Test led, with over half the COUs requiring this test, and the Participant Test was last, with just a seventh of the utilities using this measure. Figure A.14 shows the distribution of responses for the various types 


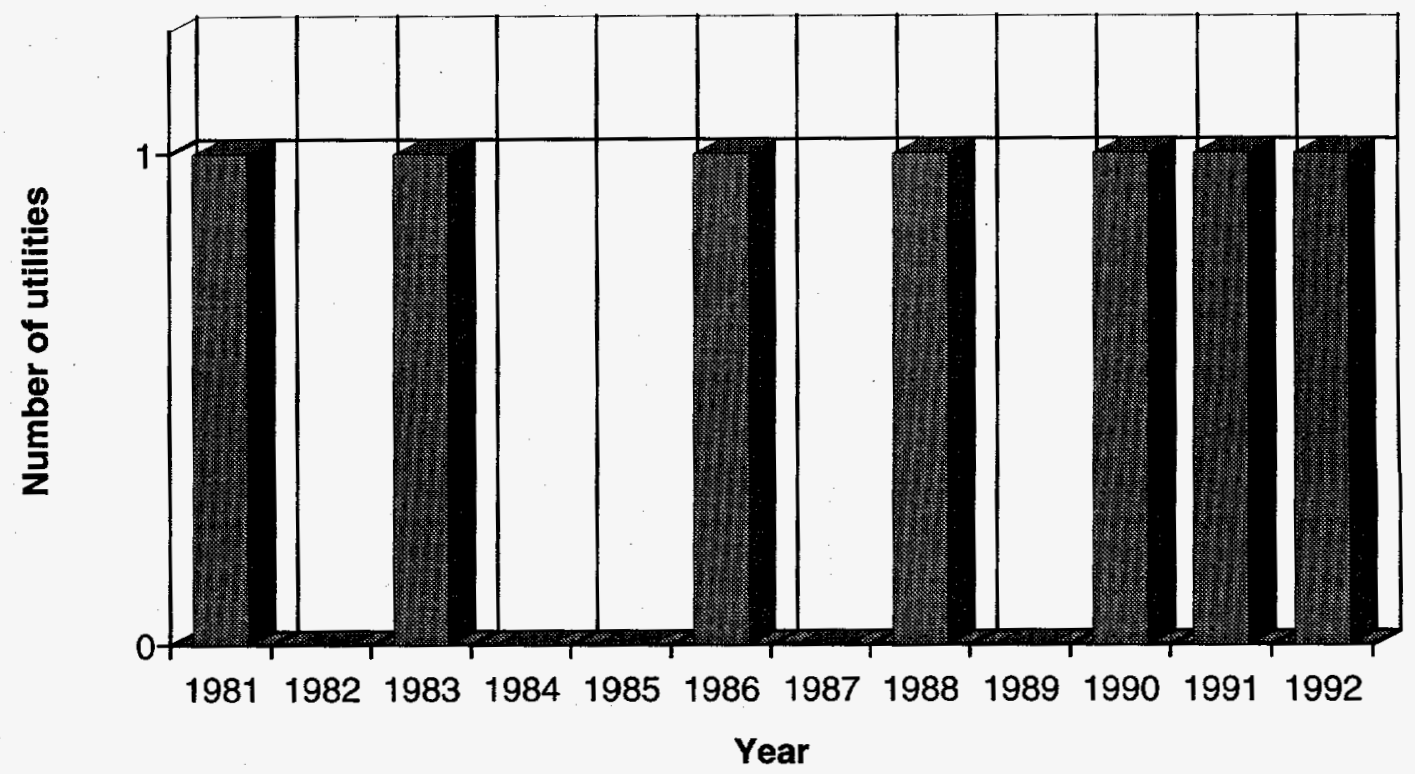

Fig. A.13. Year in which IRP requirements were established by consumer-owned utilities.

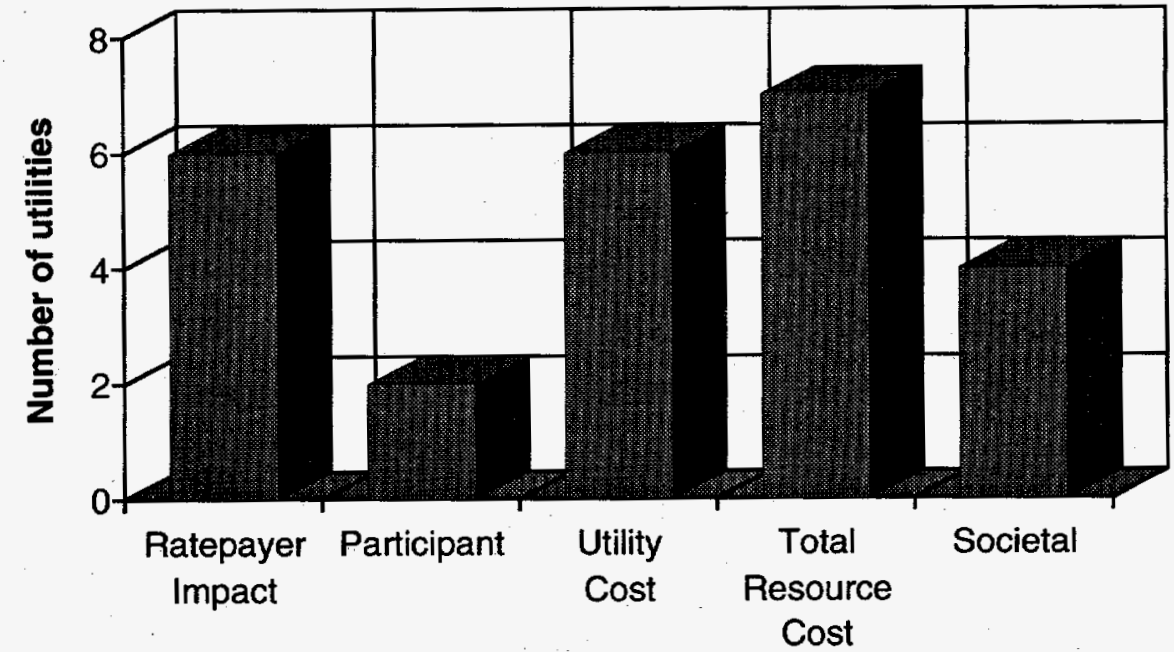

Type of cost-effectiveness test

Fig. A.14. Number of consumer-owned utilities using various cost-effectiveness tests.

of cost-effectiveness tests for the COUs. All of the COUs that performed cost-effectiveness tests in the development of an integrated resource plan used multiple tests. 


\section{Environmental Externalities}

Seven of the eight COUs that developed IRPs considered environmental externalities in selecting resource options (Fig. A.15). Five utilities used quantitative approaches, and two employed qualitative methods to address externalities, indicating that the use of qualitative approaches was considerably less common among the COUs than among the IOUs. Only one COU reported using more than one method in establishing externality values.

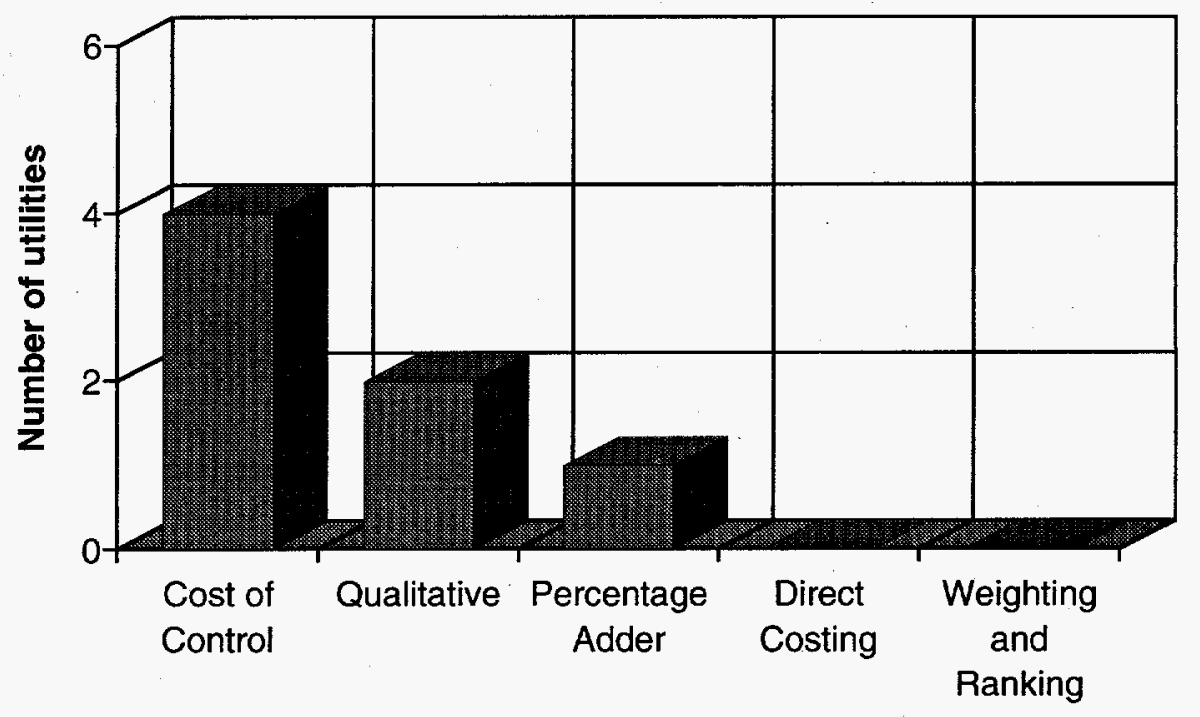

Type of externality cost method

Fig. A.15. Number of consumer-owned utilities using various methods for treating environmental externalities.

\section{Cost Treatment of DSM Expenditures}

Types of DSM Cost Recovery Mechanisms. Expensing DSM program costs was favored by nearly three-fourths of the responding COUs, while a third of these utilities chose to include conservation costs in the rate base (Fig. A.16). The COUs used DSM riders and deferral accounting substantially less than did the states, and no COU employed energy service charges. The COUs were much less likely than the states to use a combination of cost recovery methods, with only one-fifth electing multiple means of DSM cost recovery.

Allocation of DSM Costs. While more than two-fifths of the states allowed their IOUs to allocate DSM program costs to specific customer classes, none of the responding COUs allocated DSM costs in this manner. 


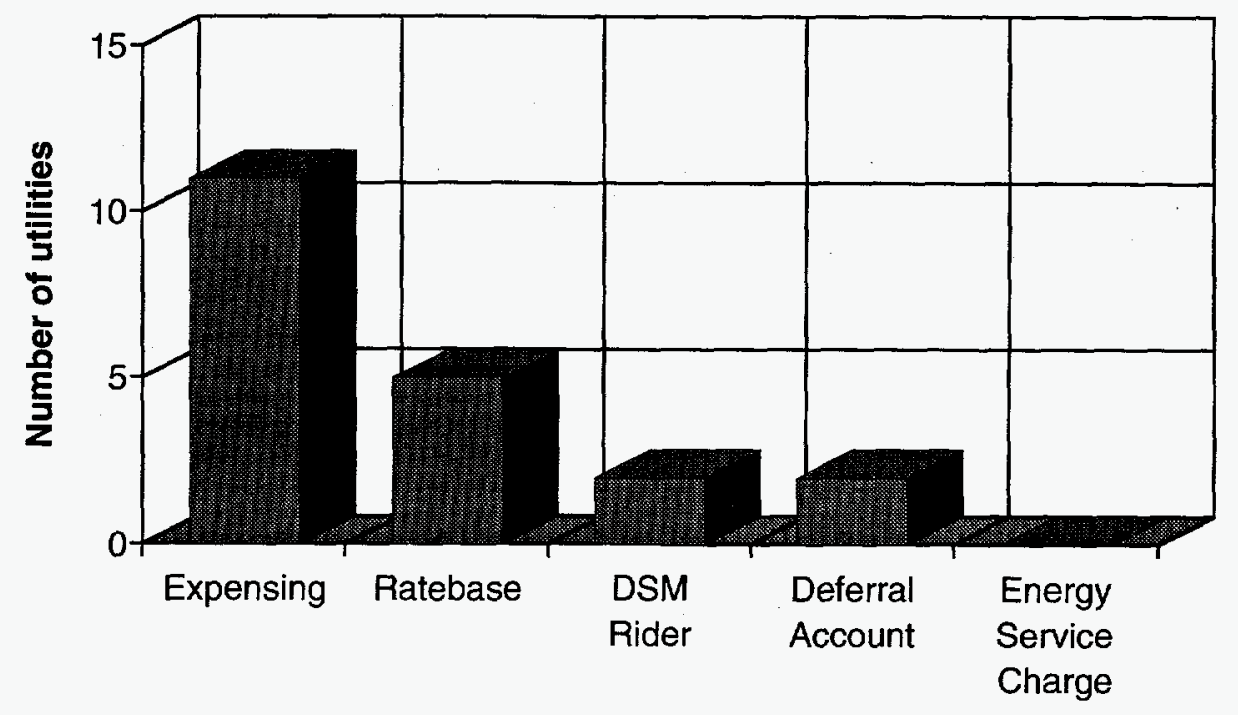

Type of DSM cost treatment

Fig. A.16. Number of consumer-owned utilities using selected types of DSM cost recovery mechanisms.

\section{Lost Revenue Recovery}

Over three-fourths of the responding COUs did not have mechanisms in place for the recovery of lost revenues. The three utilities that did recover lost revenues accomplished this by adjusting their revenue during the rate-setting process.

\section{Financial Incentives}

Types and Magnitude of Financial Incentives. The Bonneville Power Administration, which used a shared savings mechanism, was the only COU that allowed any type of DSM incentive. Obviously, the use of financial incentives is not a relevant issue for nearly all the largest COUs, presumably because of their not-for-profit nature.

Methods Used to Calculate Energy Savings and Load Reduction. Only two of the COUs reported the methods they used to calculate energy savings and load reduction. Both employed metering and engineering estimates, and one also analyzed billing data.

Incentive Thresholds, Caps, and Penalties. Only one COU required a performance threshold and capped incentives. No utility imposed a penalty for failing to reach its threshold level of energy savings or load reduction. As pointed out earlier, the use of financial incentives is not generally a salient issue for the largest COUs. 


\section{APPENDIX B. HYPOTHESIZED RELATIONSHIPS}





\section{HYPOTHESIZED RELATIONSHIPS}

\section{Regulatory Environment}

1. The size of the regulatory staff is related to DSM expenditures, energy savings, and peak reduction.

2. The previous work experience of regulatory commissioners (or board members of selfregulated utilities) is related to utility DSM expenditures, energy savings, and peak reduction (positively for advocacy or public interest group experience; negatively for business/industrial background).

3. The rate of commissioner (or board member) turnover is related to utility DSM expenditures, energy savings and peak reduction.

4. Current peak and baseload capacity (i.e., number of years until new resources are needed) is inversely related to DSM expenditures, energy savings, and peak reduction.

5. Support by regulatory commissioners (or board members of self-regulated utilities) for load building is inversely related to DSM expenditures, energy savings, and peak reduction.

6. Support by regulatory commissioners (or board members of self-regulated utilities) for energy-efficiency programs is positively related to DSM expenditures, energy savings, and peak reduction.

7. Support by regulatory commissioners (or board members of self-regulated utilities) for load reduction programs is positively related to DSM expenditures, energy savings, and peak reduction.

8. Support by regulatory commissioners (or board members of self-regulated utilities) for various mechanisms used by utilities to get public involvement on key policy and program issues is related to DSM expenditures, energy savings, and peak reduction.

9. The importance given by regulators to different types of information when making regulatory decisions is related to utility DSM expenditures, energy savings, and peak reduction (positively for collaborative filings and task force/advisory group input).

10. The nature and frequency of regulator-sponsored assistance programs on IRP/DSM for utilities and/or NUPs is related to DSM expenditures, energy savings, and peak reduction. (Effects vary positively with frequency for each type of program.)

11. The statewide price of electricity is positively related to DSM expenditures, energy savings, and peak reduction. 
12. The statewide price of natural gas is related to DSM expenditures, energy savings, and peak reduction.

13. Statewide personal income is related to DSM expenditures, energy savings and peak reduction.

\section{Regulatory Requirements Regarding DSM/RRP 41}

14. Requirements for integrated resource plan submittal are related to utility DSM expenditures, energy savings, and peak reduction (positively for the length of time a planning requirement has been in effect and the frequency with which plans must be submitted).

15. Where submittal of IRPs is required, review and approval procedures are related to utility DSM expenditures, energy savings, and peak reduction (positively for requirements for public review and formal plan approval and the length of time for which plan approval has been required).

16. Cost-effectiveness test requirements are related to utility DSM expenditures, energy savings, and peak reduction (positively for requirements for TRC and Societal Tests).

17. Methods required by regulators for including the costs of environmental externalities in the integrated plan are related to DSM expenditures, energy savings, and peak reduction (positively for quantitative approaches).

18. Regulations concerning cost-treatment of DSM programs are related to DSM expenditures, energy savings, and peak reduction (positively for DSM riders).

19. Regulations concerning lost revenue recovery are related to DSM expenditures, energy savings, and peak reduction (positively for decoupling and DSM-specific adjustment mechanisms).

20. Financial incentives are related to DSM expenditures, energy savings, and peak reduction (positively for all financial incentive mechanisms and magnitude of incentives).

21. Where incentives are provided, the methods used to measure energy savings and load reduction are related to DSM expenditures, energy savings, and peak reduction.

22. Where incentives are provided, the use of incentive thresholds, caps, and penalties for poor performance is positively related to DSM expenditures, energy savings, and peak reduction.

\footnotetext{
${ }^{41}$ For consumer-owned utilities that are not subject to external regulations, we are interested in utility policies regarding these issues rather than regulatory requirements.
} 
23. The number of $\mathrm{SO}_{2}$ bonus allowances is positively related to DSM expenditures, energy savings, and peak reduction. 

APPENDIX C. INTERVIEW PROTOCOL 



\section{Interview Protocol for Regulators}

[Please frame all responses for 1992]

\section{Regulatory Environment}

1) How many full-time equivalent staff members do you have that are involved in electric utility regulation?

2) How many of your commission members have previous work experience in each of the following categories?

Utilities

Environmental or energy conservation advocacy group or law firm

Other public interest group or law firm

Elected government official

Commercial / Industrial organization or law firm Other

3) What was the percentage of commission members who left the organization in 1992 ?

4) Current generating capacity:

a) Year in which peak period resources will be needed?

b) Year in which baseload resources will be needed?

Questions 5 - 8 use the following scale:

\section{1=strongly oppose $2=0$ ppose $3=$ neutral $4=$ support $5=$ strongly support}

Question: To what extent does your commission as a whole support each of the following for utilities in your region?

5) load building

6) energy-efficiency programs

7) load reduction programs

8) To what extent does your commission as a whole support utility use of the following mechanisms to obtain public involvement on important policy and program issues:

Collaboratives

Task forces or advisory groups

Focus groups

Workshops

Public meetings

Other 
Question 9 uses the following scale:

\section{$1=$ =ry slight $2=$ slight $3=$ moderate $4=$ great $5=$ =very great $[0=$ not used]}

9) How important does your commission as a whole consider the following types of information when making regulatory decisions on policy and program issues:

Filings of proposals and supporting documents by utilities

Filings of materials by Non-Utility Parties [NUPs\}

Consensus filings by utility-NUP collaboratives

Input from utility-NUP task forces or advisory groups

Testimony at regulatory hearings

Advice from regulatory staff

Advice from paid consultants

Other

10) In the past year, how many times did your commission provide the following types of assistance on IRP/DSM for utility staff and/or NUPs?

Seminars / workshops

Educational materials

Conferences

Other 


\section{Regulatory Requirements}

\section{1) IRP Requirements}

1.1) Do you require your regulated utilities to submit integrated resource plans?

If Yes: [otherwise, skip to question 4]

1.2) In what year was the requirement established?

1.3) How frequently must utilities submit the plans?

$$
\begin{aligned}
& \text { monthly } \\
& \text { quarterly } \\
& \text { semiannually } \\
& \text { annually } \\
& \text { biennial } \\
& \text { every } 3 \text { years } \\
& \text { other }
\end{aligned}
$$

1.4) Is there public review of the plan?

1.5) Do you formally approve the submitted plan?

1.6) If Yes, when was approval established?

1.7) Does approval of subsequent utility actions depend on their inclusion in the approved plan?

1.8) Does approval of the plan guarantee subsequent approval of specific actions it contains?

\section{2) Cost-effectiveness tests}

2.1) Do you require your regulated utilities to apply any specific cost-effectiveness test in the development of their integrated resource plans?

If Yes:

2.2) What tests [s] do you require?

Ratepayer Impact Measure Test

Participant Test

Utility Cost Test [Rev. Req.]

Total Resource Cost Test

Societal Test

Other

2.3) Do you allow utilities to submit results from tests other than those required? 


\section{3) Environmental Externalities}

3.1) Do you require your regulated utilities to consider environmental externalities when selecting resource options?

If Yes:

3.2) What methods do you require?

$$
\begin{aligned}
& \text { Quantitative Methods } \\
& \text { Cost of Control } \\
& \text { Percentage Adder } \\
& \text { Direct Costing } \\
& \text { Weighting\&Ranking } \\
& \text { Qualitative Methods } \\
& \text { Other }
\end{aligned}
$$

4) Cost treatment of DSM programs

4.1) How do you allow your regulated utilities to recover DSM expenditures?

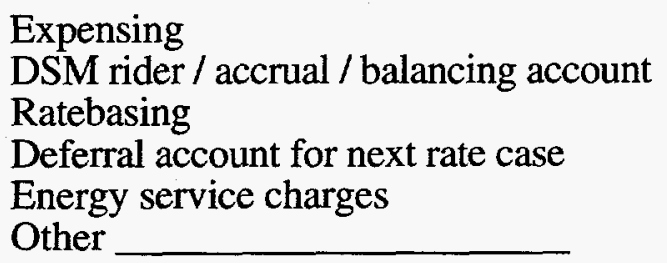

Charging costs to user classes only?

\section{5) Lost revenues}

5.1) Do you allow for utility recovery of revenues lost due to DSM programs?

If Yes:

5.2) How do your regulated utilities recover lost revenues?

Revenue adjustment as part of rate case

DSM-specific adjustment

Decoupling:

ERAM-type mechanism

Other

\section{6) Incentive regulation}

6.1) Do you grant incentives for utilities using DSM programs to conserve energy? 
If Yes:

6.2) What incentives do you allow?
Shared savings
Markup / Performance adder
ROE adjustment
Ratebased bonus ROE
Bounty/unit of energy saved
Customer service incentives
Other

6.3) What method do you allow your regulated utilities to use for the calculation of energy savings and load reduction?

\section{Engineering estimates \\ Metering \\ Analysis of billing data \\ Other}

6.4) Is there a threshold requirement that needs to be reached before incentives are earned?

At what level?

6.5) Are incentives capped?

At what level?

6.6) Are there penalties for poor performance?

6.7) What was the total amount of incentives approved in 1992?

\section{7) $\mathrm{SO}_{2}$ Bonus Allowances}

7.1) What was the total number of $\mathrm{SO}_{2}$ bonus allowances approved by your regulatory agency in the past year? 